NBSIR 77-1247 (R)

\title{
Proposed Technical Data Requirements for the National Solar Heating and Cooling Demonstration Program
}

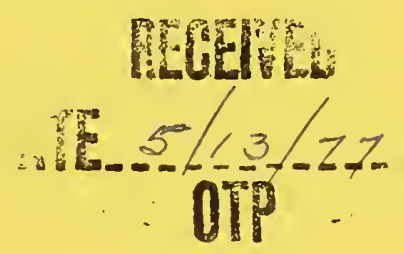

Solar Energy Program

Office of Housing and Building Technology

Center for Building Technology, IAT

National Bureau of Standards

Washington, D.C. 20234

April 1977

Prepared for

Energy Research and Development Administration Division of Solar Energy

Washington, D.C. 20545

and

Department of Housing and Urban Development Division of Energy, Building Technology and Standards Washington, D.C. 20410

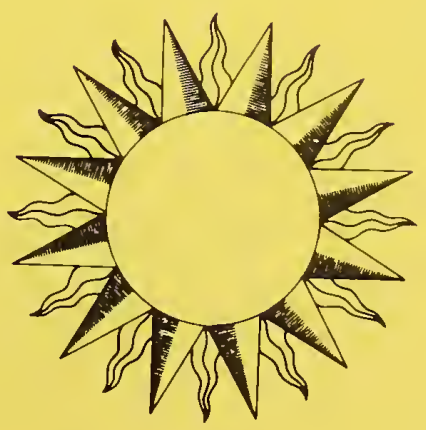


PROPOSED TECHNICAL DATA

REQUIREMENTS FOR THE NATIONAL

SOLAR HEATING AND COOLING

DEMONSTRATION PROGRAM

Solar Energy Program

Office of Housing and Building Technology

Center for Building Technology, IAT

National Bureau of Standards

Washington, D.C. 20234

April 1977

Prepared for

Energy Research and Development Administration

Division of Solar Energy

Washington, D.C. 20545

and

Department of Housing and Urban Development

Division of Energy, Building Technology and Standards

Washington, D.C. 20410

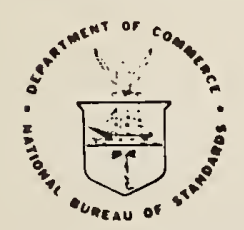

U.S. DEPARTMENT OF COMMERCE, Juanita M. Kreps, Secretary

Dr. Betsy Ancker-Johnson, Assistant Secretary for Science and Technology

NATIONAL BUREAU OF STANDARDS, Ernest Ambler, Acting Director 
$+$ 
The preparation of this plan has been a joint effort of members of the Solar Energy Program Team at the National Bureau of Standards.

The principal authors were:

$$
\begin{array}{ll}
\text { David Waksman } & \text { William E. Greene } \\
\text { Elmer R. Streed } & \text { Thomas W. Reichard } \\
\multicolumn{2}{c}{\text { Walter D. Urban }}
\end{array}
$$

Other team members who contributed to its preparation included:
John. K. Holton
James R. Shaver
Patricia M. McGuire
Larry W. Masters
Robert D. Dikkers
Leopold F. Skoda

The assistance of the Department of Housing and Urban Development, the Energy Research and Development Administration and the AIA Research Corporation are gratefully acknowledged. 
In view of the present accepted practice in this country for building technology, common U.S. units of measurement have been used throughout this document. In recognition of the position of the United States as a signatory to the General Conference of Weights and Measures, which gave official status to the metric SI system of units in 1960, assistance is given to the reader interested in making use of the coherent system of SI units by giving conversion factors applicable to U.S. units used in this document.

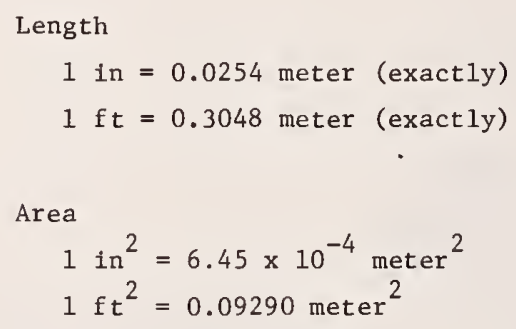

1 inch of mercury $\left(60^{\circ} \mathrm{F}\right)=3.377 \times 10^{3}$ pascal

1 pound-force/inch ${ }^{2}$ (psi) $=6.895 \times 10^{3}$ pascal

\section{Energy}

1 foot-pound-force $(\mathrm{ft}-\mathrm{lbf})=1.356$ joule

$1 \mathrm{Btu}$ (International Table) $=1.005 \times 10^{3}$ joule

1 Kilowatt-hour $=3.600 \times 10^{6}$ joule $-3.412 \times 10^{3}$ Btu

Power

1 watt $=1 \times 10^{7} \mathrm{erg} /$ second

$1 \mathrm{Btu} / \mathrm{hr}=0.2929$ watt

Temperature

$$
t_{0_{C}}=5 / 9\left(t_{0_{F}}-32\right)
$$

Heat

$$
\begin{aligned}
& 1 \text { Btu-in/h-ft }{ }^{2}-{ }^{\circ} \mathrm{F}=1.442 \times 10^{-1} \mathrm{~W} / \mathrm{m}-\mathrm{K} \text { (thermal conductivity) } \\
& 1 \text { Btu/1bm }-{ }^{\circ} \mathrm{F}=4.184 \times 10^{3} \mathrm{~J} / \mathrm{kg}-\mathrm{K} \text { (heat capacity) } \\
& 1 \text { langley }=4.184 \times 10^{4} \mathrm{~J} / \mathrm{m}^{2}=1 \mathrm{cal} / \mathrm{cm}^{2}=3.69 \mathrm{Btu} / \mathrm{ft}^{2}
\end{aligned}
$$


Public Law 93-409, the "Solar Heating and Cooling Demonstration Act of 1974" calls for the development of interim performance criteria for solar heating and cooling systems and the buildings in which they will be used. Section 8 of the law provides for the use of data from the demonstration program to develop definitive performance criteria, as well as testing procedures whereby manufacturers can certify that their products conform to definitive performance criteria. Responsibility for the development of these definitive performance criteria has been assigned by the Energy Research and Development Administration and the Department of Housing and Urban Development to the National Bureau of Standards (NBS).

The plan presented in this document was prepared in order to define the technical non-instrumentation (TNI) data required by NBS in order to effectively monitor the residential and commercial demonstration programs, mandated by P. L. 93-409, for feedback.

The TNI data consist of those data which either cannot be collected electronically or can be gathered more effectively by other means. These data will be manually collected, subsequently coded and stored in a central computer, and made available to various users in reduced form for evaluation studies.

This plan is a companion document to a similar plan published by NBS in August 1976* which identified the instrumentation data required by NBS to monitor and evaluate the "thermal effectiveness" and reliability of solar heating, cooling, and hot water systems.

*Streed, E. R., et al, "Thermal Data Requirements and Performance Evaluation Procedures for the National Solar Heating and Cooling Demonstration Program," NBS Report NBSIR 76-1137, August 1976. Available from NTIS, Order No. PB 257770 , price $\$ 5.00$. 
PART ONE - INTRODUCTION AND OVERVIEW

1.0 INTRODUCTION. . . . . . . . . . . . . . . . . . . . . . . . . . 1

1.1 Background. . . . . . . . . . . . . . . . . . . . . . . . . . . 1

1.2 Purpose . . . . . . . . . . . . . . . . . . . . . . . . . . 2

2.0 ORgAnizAtion. . . . . . . . . . . . . . . . . . . . . . . . . . 4

3.0 APPROACH. . . . . . . . . . . . . . . . . . . . . . . . . 5

3.1 Introduction. . . . . . . . . . . . . . . . . . . . . . . . 5

3.2 Sources and Types of Data . . . . . . . . . . . . . . . . . . . . . . . 5

4.0 DATA ACQUisition AND ANALYSIS . . . . . . . . . . . . . . . . . . . . . 15

4.1 General . . . . . . . . . . . . . . . . . . . . . . . . . 15

4.2 Collection of TNI Data. . . . . . . . . . . . . . . . . . . . . . . 15

4.3 Data Analysis . . . . . . . . . . . . . . . . . . . . . . . 16

5.0 TASK RESPONSIBILITIES . . . . . . . . . . . . . . . . . . . . . 18

PART TWO - BUILDING/SITE/SOLAR ENERGY SYSTEM IDENTIFICATION, MATERIALS AND PERFORMANCE

1.0 Introduction. . . . . . . . . . . . . . . . . . . . . . . . . 19

2.0 BULLDING/SITE . . . . . . . . . . . . . . . . . . . . . . . . 20

3.0 SOLAR ENERGY SYSTEM OR SYSTEMS IN THE BUILDING . . . . . . . . . . . . . . . . . . 26

APPENDIX A - Detailed Building Data Requirements for Room Thermal Load Ca1culation . • . • 60

APPENDIX B - Detailed Solar System Requirements for System Thermal Performance Calculations. 64

PART THREE - SOLAR ENERGY SYSTEM OPERATIONAL DATA REQUIREMENTS

1.0 IntRodUCtion. . . . . . . . . . . . . . . . . . . . . . . . 69

2.0 DESCRIPTION OF DICTIONARIES . . . . . . . . . . . . . . . . . . . . . . . 70

2.1 Purpose of Dictionaries . . . . . . . . . . . . . . . . . . . . 70

2.2 Event Dictionary . . . . . . . . . . . . . . . . . . . . . 70

2.3 Maintenance Actions Dictionary . . . . . . . . . . . . . . . . . . . . 70

2.4 Site/Building Element Dictionary. . . . . . . . . . . . . . . . . . . . . . . . . 70

2.5 Solar Hardware System Dictionary . . . . . . . . . . . . . . . . . . . 70 
3.0 TRANSCRIPTION OF MAINTENANCE DATA . . . . . . . . . . . . . . . . . . . . 71

3.1 Introduction to the Transcription Process . . . . . . . . . . . . . . . . 71

3.2 Identification and Translation of the Maintenance Items . . . . . . . . . . . 75

3.3 Organization of the Maintenance Items . . . . . . . . . . . . . . . . . . . 75

3.4 Entering of Maintenance Data to a Transcription Form . . . . . . . . . . . . . 76

3.5 Example of Transcription Process. . . . . . . . . . . . . . . . . . . 77

PART FOUR - TECHNICAL NON-INSTRUMENTED DATA ANALYSIS

1.0 INTRODUCTION. . . . . . . . . . . . . . . . . . . . . . . 114

2.0 AUTOMATIC DATA PROCESSING (ADP) . . . . . . . . . . . . . . . . . 114

2.1 Sample Printout of Identification, Materials and Performance Data (Part Two) . . 114

2.2 Sample Printouts of Annual Sumary Data (Part Three). . . . . . . . . . . . 115

2.3 Correlation/Investigative Tables (Printed). . . . . . . . . . . . . . . 118

PART FIVE - SUPPLEMENTARY DATA

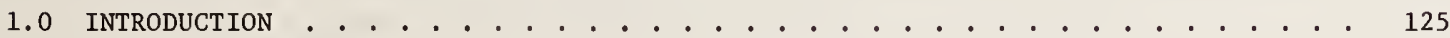

2.0 DATA REQUIREMENTS . . . . . . . . . . . . . . . . . . . . . . . . 125

2.1 Design and Construction Data Requirements . . . . . . . . . . . . . . . 125

2.2 Fallure Analysis Data . . . . . . . . . . . . . . . . . . . . 127

2.3 Operational Deterioration Studies . . . . . . . . . . . . . . . . . . . 127

2.4 Environmental Exposure Conditions . . . . . . . . . . . . . . . . . . . 130

REFERENCES . . . . . . . . . . . . . . . . . . . . . . . . . . 131 



\section{INTRODUCTION AND OVERVIEW}

\subsection{INTRODUCTION}

\section{$1.1 \quad$ Background}

Sections 5 and 6 of Public Law 93-409, the "Solar Heating and Cooling Demonstration Act of 1974" provide for the development of

1. interim performance criteria for solar heating and combined solar heating and cooling components and systems to be used in residential dwellings, and

2. interim performance criteria (relating to suitability for solar heating and combined solar heating and cooling) for such dwellings themselves.

Section 8 of the Act provides for the development, "as soon as feasible, and utilizing data available from the demonstration programs under Sections 5 and $6^{\prime \prime}$ of

1. definitive performance criteria for solar heating and combined heating and cooling components and systems to be used in residential dwellings, taking into account climatic variations existing between different geographic areas;

2. definitive performance criteria (relating to suitability for solar heating and combined solar heating and cooling) for such dwellings, taking into account climatic variations existing between different geographic areas; and

3. procedures whereby manufacturers of solar heating and combined solar heating and cooling components and systems shall have their products tested in order to provide certification that such products conform to the performance criteria established under paragraph 1.

As required by PL 93-409, "Interim Performance Criteria for Solar Heating and Cooling Systems and Dwellings" [1]* were prepared by the National Bureau of Standards for use by the Department of Housing and Urban Development (HUD) in the residential demonstration program. Similarly, the National Aeronautics and Space Administration (NASA) has developed interim performance criteria for commercial solar heating and cooling systems and facilities [2] for use by the Energy Research and Development Administration (ERDA) in the commercial demonstration program. Responsibility for the further development of commercial criteria has been assigned to NBS and a first revision to the NASA document was published by NBS [3] in November 1976 .

* Numbers in brackets indicate references listed on page 131. 
The further development and refinement of both the residential and the commercial performance criteria documents by NBS is dependent upon the feedback of experience gained from the solar demonstration program provided for by PL 93-409. The necessity for such feedback was recognized in Section 8 of PL 93-409 and was given further impetus by ERDA 76-6, the "National Program for the Solar Heating and Cooling of Buildings"[4]. In compliance with the intent of PL 93-409, ERDA 76-6 contains tasks that provide for monitoring the commercial and residential demonstrations for feedback leading to the development of improved performance criteria and standards.

\subsection{Purpose}

The plan presented in this document was prepared in order to define the technical non-instrumentation (TNI) data required by NBS in order to effectively monitor the residential and commercial demonstration programs for feedback. It is a companion document to a similar plan published by NBS in August 1976 [5] which identified the instrumentation data required by NBS to monitor and evaluate the "thermal effectiveness" and reliability of solar heating, cooling, and hot water systems.

The instrumentation data will be collected by means of electronic site data acquisition systems which will store the readouts from sensors installed in selected demonstration solar heating and cooling systems. The data will be subsequently transmitted to a central computer processing unit where they are to be reduced in accordance with procedures agreed upon by an interagency panel, and then provided to various users including NBS.

The TNI data consist of those data which either cannot be collected electronically or can be gathered more effectively by other means. These data will be manually collected, subsequently coded and stored in a central computer, and made avallable to various users in reduced form for evaluation studies.

The combined data defined in these two plans will serve as the basis for further studies that will be conducted by NBS in order to evaluate system and subsystem performance, to develop definitive performance criteria and standards and to formulate analytical models and other guidelines for the design of solar heating and cooling systems. Thermal performance data obtained by means of instrumentation will be combined with building/site/solar energy characteristics in order to evaluate system and subsystem thermal performance. Similarly, deterioration in system and subsystem thermal performance measured by means of instrumentation will be correlated with the TNI data identified in this plan in order to characterize the causes of such deterioration and relate them to material, component, subsyster and system characteristics. Other studies concerned with maintainability, safety, building and site problems and structural and mechanical performance, will be primarily dependent upon TNI data.

The analysis and subsequent evaluation of the TNI data will pinpoint the major problem areas, the causes of the problems, and the remedial actions taken. Subsystems, components, and parts which provided acceptable performance will be identified as well as those which performed poorly. With this information, relevant sections of the residential and commercial performance criteria will be studied and appropriate modifications made. 
- Warranties

- Repair and Maintenance Costs

- Systems Operating Costs

- Life Cycle Costs

- Operating Manuals

- Maintenance Manuals

- Design Manuals

- Intermediate Minimum Property Standards for Solar Heating and Domestic Hot Water Systems

- Optimum System/Energy Conservation Techniques

- Additional Systems Development 
This plan is structured into five parts.

Part One contains an overview of the entire TNI data requirements plan. In addition to summarizing the data requirements contained in the other four parts of the plan, Part One identifies the various potential sources of data and presents an overview of the entire TNI data collection and analysis process.

Part Two identifies those data required to describe demonstration program building/site/solar hardware system characteristics in a systematic manner.

Part Three provides a system for characterizing solar hardware related failures and problems that occur during the operational phase of the solar demonstration program. It contains: (1) detailed dictionaries that provide standard terms identifying solar hardware system elements, operational problems and the actions taken to alleviate these problems; (2) a description of how these dictionaries can be used to correlate these various factors; and (3) a specification for the forms that should be used to transcribe these data. At the present time, Part Three is solely concerned with problems that occur during the operational phase of the program. However, if the need arises, additional dictionaries can be added to permit the automated storage of design and construction events. The coding schemes identified in this part are preliminary in nature and are presented primarily for illustrative purposes.

Part Four contains detailed descriptions of the manner in which data from Parts Two and Three will be correlated and utilized as a basis for the engineering analysis of operational problems. Examples of typical computer printouts that will be used to identify and characterize these problems are presented.

Part Five is concerned with the identification and collection of additional data intended to: (1) characterize design and construction problems; (2) determine the cause of significant failures when such causes cannot be determined from maintenance reports; (3) monitor the deterioration of key system components prior to their actual failure; and (4) quantify the environmental conditions to which collectors are exposed at various demonstration program sites.

Data related to the areas listed below are not considered to lie within the scope of technical non-instrumentation performance data.

- Costs (equipment cost, operating costs, etc.) except where costs are used as indicators of system performance and/or the degree of severity of repairs.

- Institutional Constraints (financing, labor, etc.).

- Market Development and Acceptance.

- Environmental Impact.

It is recommended that Part one be read completely before proceeding to read the other parts. The first section of each part presents its objectives and scope, which may suffice for the reader not interested in additional detailed information. 
The approach to formulating the TNI data requirements plan is structured around the following factors: (1) the availability of the data; (2) considerations of kinds of data needed to identify critical sections of the interim performance criteria; and (3) the hardware in the systems.

Because of the large quantity of data anticipated from the ERDA and HUD demonstration projects, it is apparent that computer techniques must be used. Therefore, the majority of the data identified in this document have been defined in such a manner that they can be codified for computer processing. Figure 1.1, which was taken from ERDA 76-6, presents an overview of the entire demonstration program data collection, evaluation and dissemination process.

\subsection{Sources and Types of Data}

The various sources and types of demonstration program data are identified in the matrix shown in Figure 1.2. It is expected that these data will be collected by data collection contractors or subcontractors delegated with this responsibility by HUD and ERDA.

\subsubsection{Manufacturer Data}

These data include product description, failure analysis and quality control data.

Product description data include (1) identification of the materials and components that are used to make up the product (e.g., a collector), (2) descriptions of the performance of the product (e.g., collector thermal performance data), (3) descriptions of the key properties of materials that are used to make up the product (e.g., cover plate transmittance data, absorptive coating emittance and insulation material thermal conductivity). These types of data must be known by the manufacturer, or the product designer employed by the manufacturer in order to design the product. These data are identified in Part Two of this plan. Since it is recognized that the same products (e.g., solar collectors) will be used on several demonstration projects, it would be desirable to collect all of the pertinent data once and store it in a computer data file that can be referred to. This will avoid the repeated collection of a large amount of data. However, if this process is used, care must be exercised to make sure that the product actually used is the one described in the data file. Product changes instituted by the manufacturer must be taken into account.

Product testing and analysis reports, used by the manufacturer to obtain the product description data discussed above, should be collected and stored, when available; however, such data do not necessarily have to be computerized. This information will be compared with actual performance measured during the demonstration program and will serve as a basis for evaluating the adequacy of the analytical and testing procedures used. The testing and analytical documentation should adequately address the following:
a. Scope of test or analysis.
b. Apparatus and instrumentation.
c. Description of testing and/or analytical procedures used. 


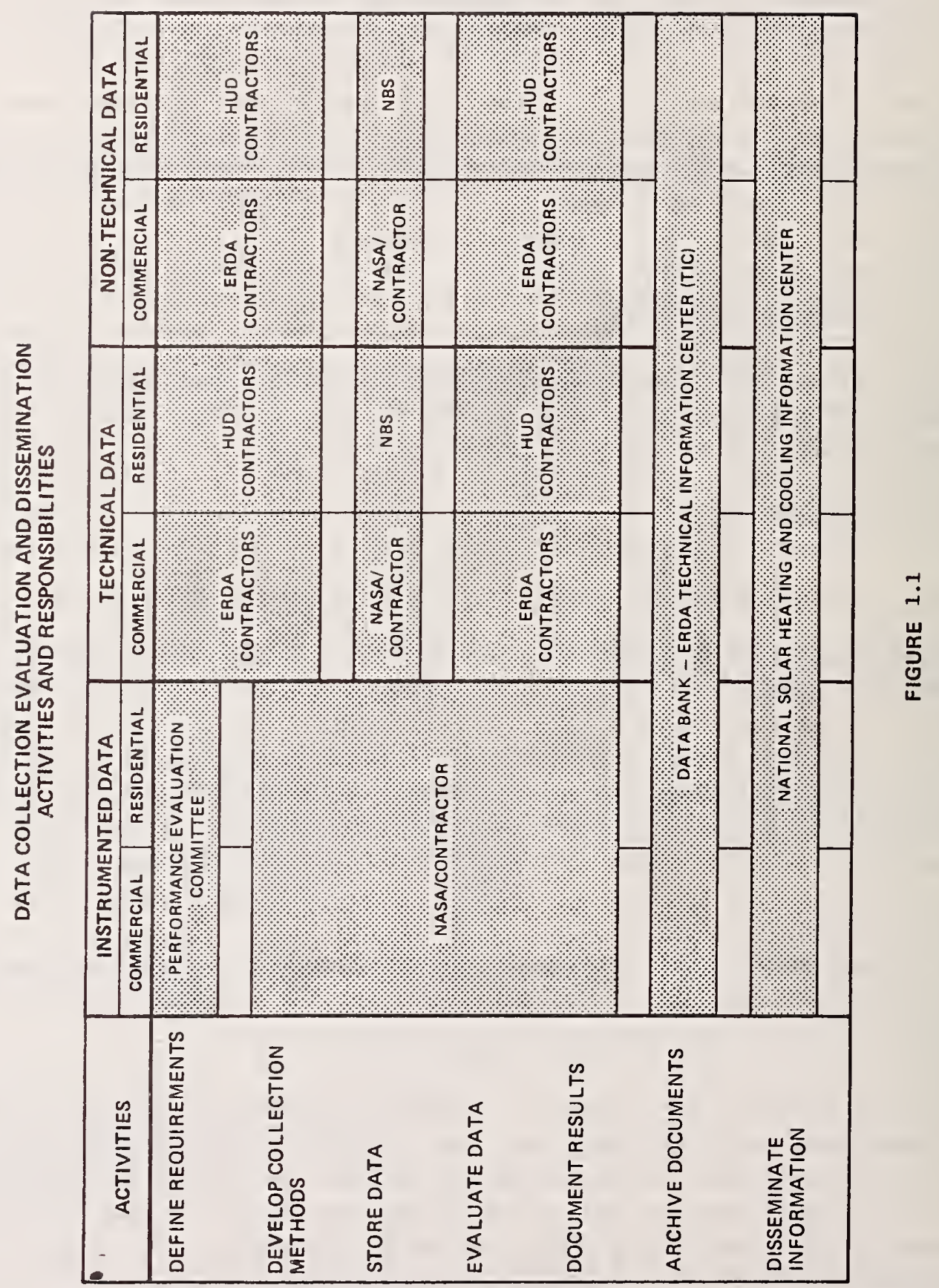




\begin{tabular}{|c|c|c|c|c|c|c|}
\hline $\begin{array}{c}\text { Sources } \\
\text { of }\end{array}$ & Manuf acturer & $\begin{array}{l}\text { Architect/ } \\
\text { Engineer }\end{array}$ & Builder & $\begin{array}{l}\text { Building } \\
\text { Official }\end{array}$ & $\begin{array}{l}\text { Maintenance } \\
\text { Contractor }\end{array}$ & Occupant \\
\hline $\begin{array}{l}\text { Product (system) } \\
\text { Description }\end{array}$ & * & * & * & & & \\
\hline $\begin{array}{l}\text { Product Testing } \\
\text { \& Analysis }\end{array}$ & * & & & & & \\
\hline Failure Analysis & * & & & & & \\
\hline Quality Control & * & & & & & \\
\hline $\begin{array}{l}\text { Building/Site } \\
\text { Description }\end{array}$ & & * & * & & & \\
\hline $\begin{array}{l}\text { Building/Site/Systen } \\
\text { Thermal Performance } \\
\text { Prediction }\end{array}$ & * & * & & & & \\
\hline Design Problems & & * & * & & & \\
\hline $\begin{array}{l}\text { Construction } \\
\text { Problems }\end{array}$ & & * & * & & & \\
\hline $\begin{array}{l}\text { Operational (and } \\
\text { Maintenance) } \\
\text { Problems }\end{array}$ & & * & * & & * & * \\
\hline $\begin{array}{l}\text { Building } \\
\text { Regulatory } \\
\text { Problems }\end{array}$ & & * & * & * & & \\
\hline $\begin{array}{l}\text { Safety and } \\
\text { Habitability }\end{array}$ & & & & & * & * \\
\hline
\end{tabular}

Figure 1.2 Major Sources and Types of Data 
d. Description of system/component/material tested or analyzed.

e. Test conditions.

f. Test results.

g. Conclusions.

Failure analysis data obtained by the manufacturer in order to determine the causes of product failures and other problems that occur during product production and system construction and operation should be collected. The data concerned with construction and operation failures and other problems can be fed directly into the data base defined in Part Three of this plan, and will serve as a means of determining the actual source of problems whose causes cannot be assessed without a significant amount of laboratory testing and engineering analysis. It is expected that data of this type will be obtained in cases where a significant number of problems occur.

Product quality control data will accrue from records of fabrication problems and of routine quality control testing, performed by the manufacturer to ensure that the product is being manufactured within design tolerances. It is desirable that these data be readily available from the manufacturer for use when problems occur in the field. (However, they do not need to be routinely collected by the data collection contractors). The purpose of these data is to have records of product manufacturing problems available for use on an as-needed basis when problems occur with systems and components during the demonstration programs. This will permit correlations to be made between quality control problems and events that occur in actual field operations. The manufacturer, in the majority of cases, would furnish these data. Specific types of information required include:

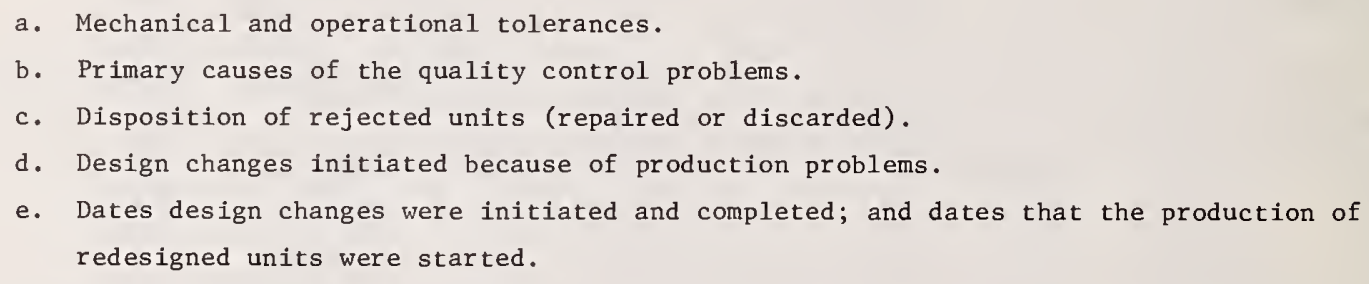

Building/site/system thermal performance data may be generated by the system manufacturer to a limited extent in the form of design guidelines and manuals.

\subsubsection{Architect/Engineer Data}

Several different types of data related to the design of the solar energy system and the building and site in which it will be installed can be obtained from the architect/engineer (A/E) responsible for the design of the system and its integration with the building and site.*

Building, site, and system data, primarily provided by the A/E, are needed to: (1) locate and characterize the building and site; (2) provide a description of major subsystems and components of solar energy system; and (3) provide data required for system thermal design and calculation of building thermal heating and cooling loads. These data would include product description data such as those identified in Section 3.2.1. In cases where packaged components (e.g., solar collectors) are factory manufactured units, it is expected that the A/E firm would be a secondary source in that it would provide data that was generated by the product manufacturers. However, many components of solar

*Note: It is recognized that the design of residential demonstration systems may not involve an A/E firm. In such cases, the individuals carrying out a similar function would be expected to provide 
energy systems will be designed and built to the A/E's specifications rather than factory assembled (e.g., thermal storage units). In such cases, the A/E would be the primary source of product description data of the types identified in Section 3.2.1. These data will be fed directly into the data base defined in Part Two of this plan.

Building/site/system thermal performance prediction data generated by the A/E in the course of designing the solar energy system should also be collected. These data, together with a description of the type of analytical model used, are identified in Part Two of this plan. They will be utilized by NBS to make comparisons both with actual measured thermal performance data and with the results of thermal modeling techniques. These comparisons will make it possible to determine the adequacy of existent analytical procedures and will lead to the development of improved modeling procedures where necessary.

Design problem data such as those identifying design problems caused by having to comply with the interim performance criteria or by institutional constraints should be documented. These data will be discussed in more detail in Part Five of this plan. It is expected that these data will be collected in a narrative form and stored in files that can be periodically reviewed by NBS technical personnel. To a limited extent, design changes that were made to avoid system hardware operational problems could be computerized by means of the system described in Part Three of this plan. However, the types of design problems that could occur are not clearly defined at this stage of the solar demonstration program.

Construction and operational problem data including descriptions of regulatory problems could be provided by the A/E firm to the extent that it is involved with such problems. However, it is expected that the $A / E$ would not be the primary source of such data.

\subsubsection{Builder Data}

It is expected that the builder/developer will be the primary source of construction problem data.

Construction problem data related to problems caused by compliance with the interim performance criteria should be recorded in narrative form and stored in files that can be periodically reviewed by NBS technical personnel. These data will be discussed in Part Five of this plan. System and component failures resulting from the construction process could be computerized by means of the system described in Part Three of this plan. However, at this time, insufficient information is available upon which a list of anticipated events could be generated.

Data related to building regulatory problems should also be collected. These data will be utilized by NBS in regulatory problem studies. Examples of the types of data that should be collected include:

\footnotetext{
- Problems involved in obtaining building permits

- Zoning problems

- Lack of clarity in code provisions

- Design modifications required.
}

Building/site/system description data and design and operational problem data should also be collected from the builder to the extent that he is able to provide them. 
Code compliance problems, as viewed by building officials responsible for solar energy system design reviews and the issuance of building permits, should be documented. This information, together with the code compliance data obtained from the builder (section 3.2.3), will serve as the basis for regulatory studies to be conducted by NBS. Examples of the types of data that it is expected will be collected include:

- Alternate methods approved by building officials

- Reasons for design rejections

- Problems in determining compliance such as lack of staff having the necessary technical expertise

- Deficiencies in solar related code provisions.

\subsubsection{Maintenance Contractor Data}

It is expected that maintenance contractors will be the primary sources of data related to problems that occur during the operational phase of the solar demonstration program.

Maintenance data reports containing the information identified on Form 1 , the Maintenance Service Call Report shown on the following pages, should be collected from the various demonstration program maintenance contractors. It is expected that the information on these forms will be reviewed by qualified technical personnel employed by the HUD and ERDA demonstration program management contractors and transcribed by them onto computer compatible data transcription forms designed in accordance with the data requirements specified in Parts Three and Four of this plan. These data address operational problems as well as those concerned with safety and habitability.

\subsubsection{Occupant Data}

Safety and habitability data related to factors such as personal injuries and discomfort (e.g., excessive glare, humidity and temperature swings) should be collected by means of interviews with the building occupants. These data will be correlated by NBS with the various types of systems used, and associated with relevant performance criteria. Documentation of occupant complaints that lead to maintenance contractor calls should be collected as a backup to the occupant survey data. 
1. System Identification:
a. Project identification number
b. Solar hardware system (SHS) identification number
c. Building location:
Street address
City or county \& state
d. Date SHS was originally placed in service

2. Maintenance Order Information:
a. Date of order
b. Reason for maintenance: Routine Complaint

3. Description of Service (Maintenance Actions) Performed

Describe each individual action performed: Include details related to the following:

1. Reason for performing action

2. Cause of any failure

3. Hardware element serviced

4. Problems encountered in performing the action (access for repair, availability of parts, etc.)

5. Outside air temperature if related to failure

6. Results of action

Use tables 1,2 , and 3 to describe hardware elements serviced and/or replaced and materials replaced. 
Maintenance Service Call Report

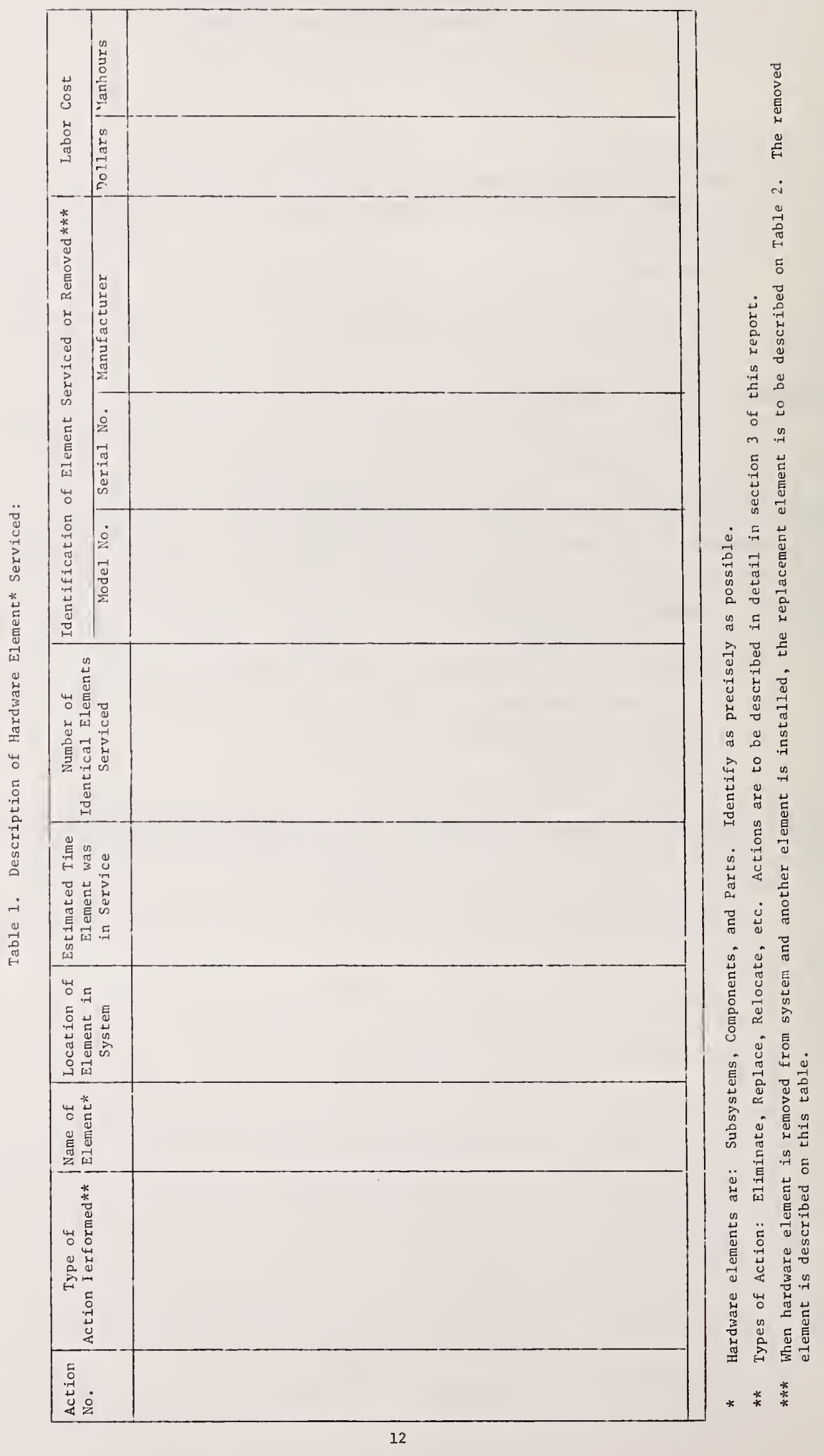


Solar Hardware System

Table 2. Description of Replacement Hardware Element

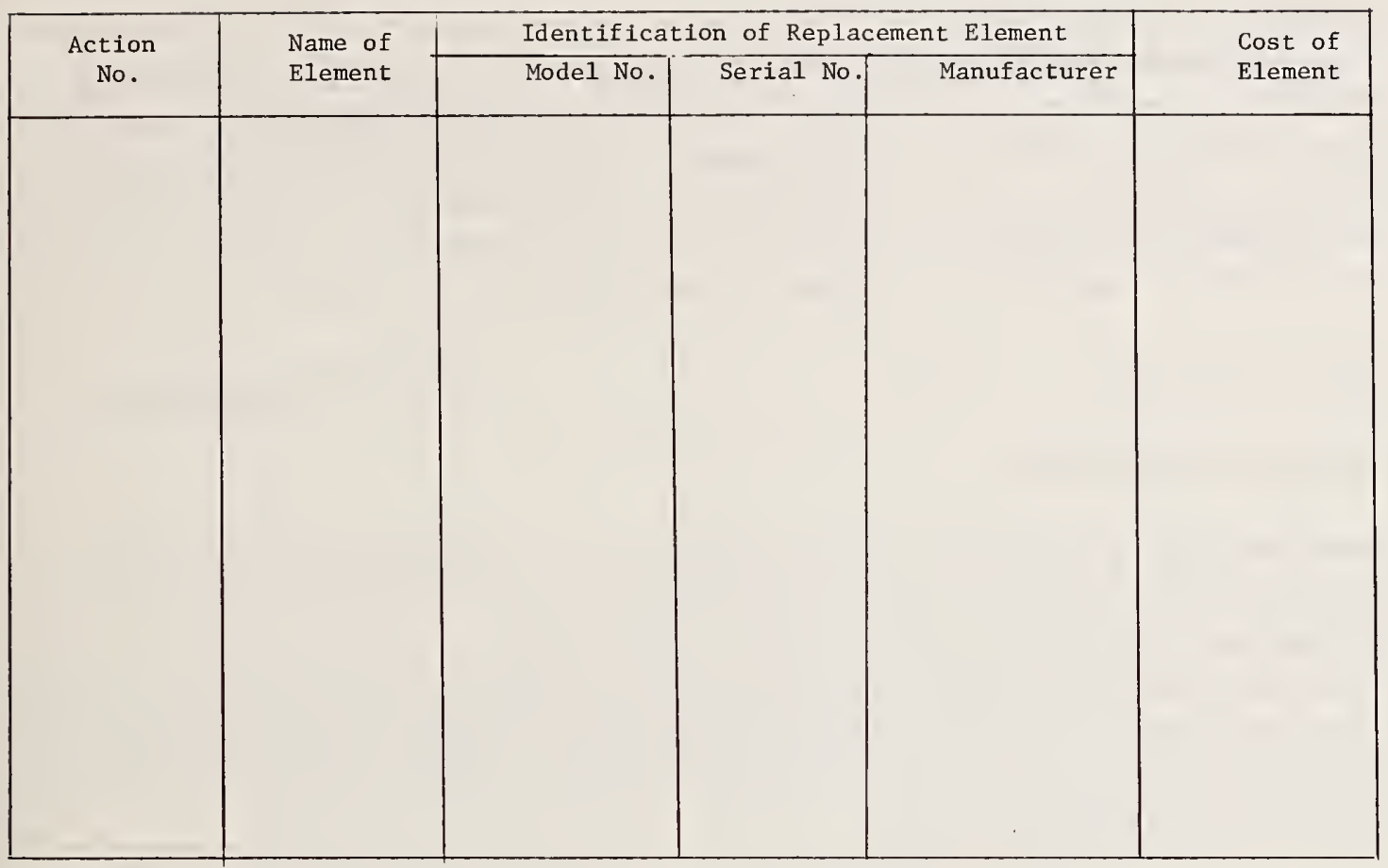

Table 3. Description of Replacement Material*

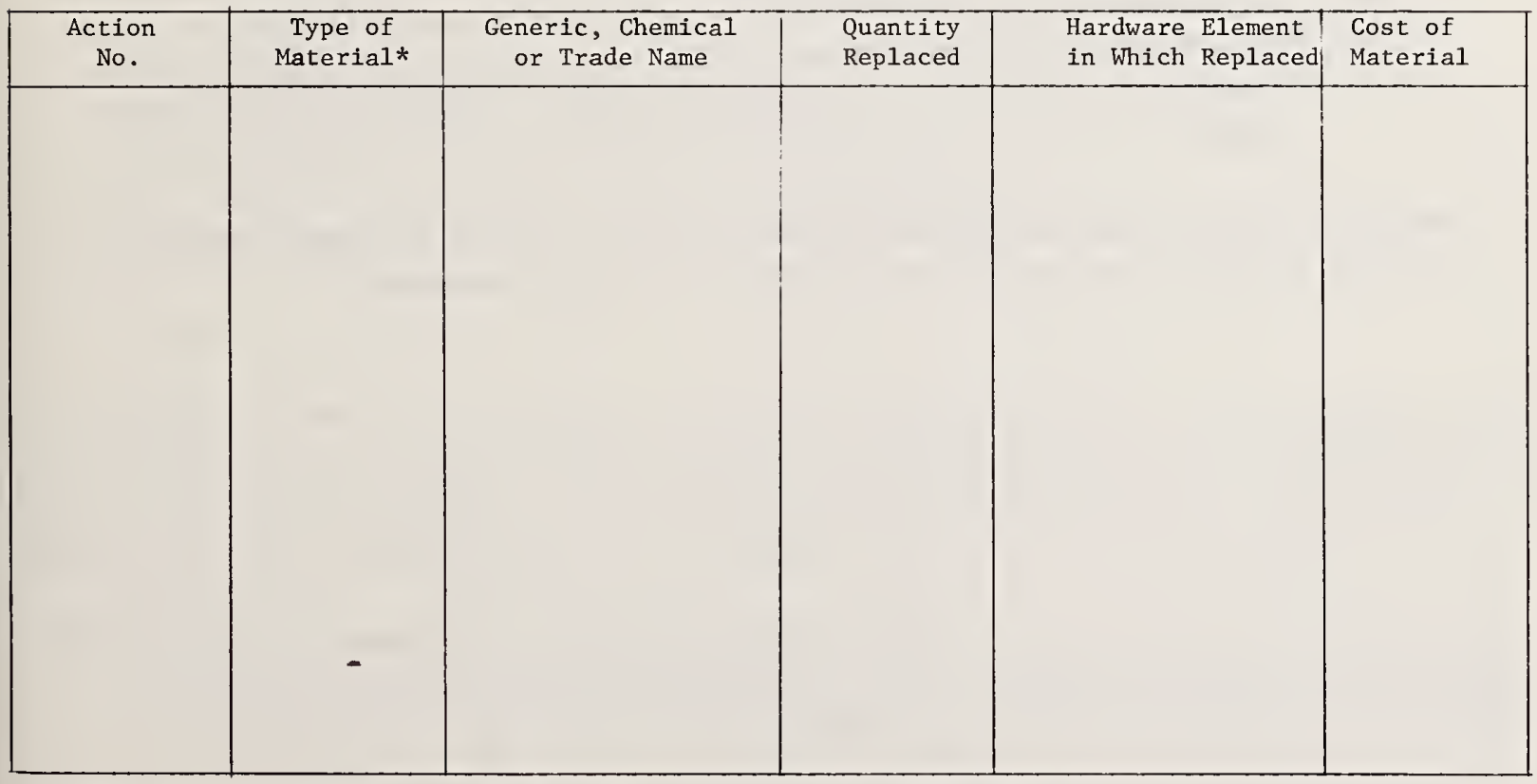

* Materials are expendable items such as: Bolts, Fluid, Gas, Gaskets, Insulation, Piping, Sealants, Screws, Wire, etc. 
Maintenance Service Call Report

Solar Hardware System

4. System Downtime:

a. Date and time the system became inoperative

b. Date and time the maintenance action(s) was initiated

c. Date and time the system was returned to operation

5. Cost of Maintenance Action(s):

a. Direct labor for each action (list labor in time and money for each action):

Totals from Table 1 hrs.

$\$$

b. Hardware elements replaced

Total from Table 2 .

$\$$

c. Materials replaced

Total from Table 3

$\$$

d. Total cost of maintenance actions

$\$$

6. Personne1 Identification:

a. Person completing this report

b Person responsible for performing maintenance

c. Firm responsible for performing maintenance

Address

Phone No.

7. Additional Remarks Regarding System or Maintenance: Include details of personal injuries and building damages if connected with either system operation or maintenance. 


\subsection{General}

Detailed catalogs of the TNI data required are contained in Parts Two and Three of this plan. The data defined in Part Two, which will be obtained from A/E firms integrating solar systems into dwellings, the system designer/manufacturer and the various component manufacturers, will be collected during the design and construction phases. The data requirements of Part Three relate to events which occur during the operational phase and to a limited extent the design and construction phase of the demonstration program. Recommendations for the collection and analysis of the data will be addressed in this section.

\subsection{Collection of TNI Data}

\subsubsection{Introduction}

The collection of TNI data presents a far different problem than does the collection of instrumentation data. The latter, by means of an automatic site data acquisition system, and the appropriate software, can be collected, processed and disseminated by microprocessors. But, the TNI data must be collected manually, and most probably transcribed manually for computer processing. Hand manipulation of data inherently breeds errors. Hence methods must be devised to minimize such errors. It is the purpose of this section to present a base-line data collection procedure to efficiently collect data.

\subsubsection{Base-Line Data Collection Tasks}

This procedure encompases the following tasks:

(1) Design of the forms on which to record the data that has been identified in the Parts Two and Three.

(2) Dissemination of forms to appropriate data sources for the recording of data.

(3) The manual recording of data on the forms.

(4) Review of the filled out forms for completeness by professional personnel.

(5) Collection and organization of the completed forms.

(6) Transcription of the data onto computer compatible forms.

\subsubsection{Design of Data Collection Forms}

In designing the forms for data collection it must be clearly understood that the data requirements listed in this document are not exhaustive. Therefore, the forms must allow for the recording of data which has not been anticipated. The forms should be concise and act as a check list, if possible. Moreover, instructions must be prepared for recording the data.

The following three Eypes of data collection forms are needed:

(1) Forms to record the problems encountered by A/E's, building officials, building occupants and contractors in integrating and installing solar systems into buildings. Since these 
records will be in a narrative report mode, the forms should be designed to insure comprehensiveness.

(2) Forms to collect the identification, materials and performance data listed is Part Two are needed. In addition, forms to transcribe these data into formats that are computer compatible are required.

(3) Forms to record the operational events data cataloged in Part Three. Most of the data are expected to emanate from the maintenance and repair of solar systems, once they are operating. Repair and maintenance forms must be designed to insure that data contained in Part Three are recorded accurately and that they can be readily transcribed for input into the NBS data base. Moreover, these forms must allow for the recording of unanticipated problems. Two basic types of forms are required; a form similar to the one shown in Section 3.2 .5 for use in collecting field maintenance data and a computer compatible transcription form that can be used to transcribe these data in a manner compatible with the requirements of Parts Three and Four of this plan.

\subsubsection{Recording and Review of Data on Collection Forms}

The HUD and ERDA demonstration program management contractors and their various subcontractors have the primary responsibility for collecting and recording the data defined in this plan. All data forms must be reviewed for completeness and accuracy by professional personnel of the contracting firm responsible for recording the data.

It is beyond the scope of this report to address transcription, error analysis, or computer processing of the data; however, computer analysis of the data is within the scope of this report, and will be briefly addressed in section 4.3. A schematic flow chart depicting the interrelationship of the various elements of non-instrumentation data processing is presented in figure 1.3 .

A team of professionals or highly skilled technicians in which all technical disciplines are represented should be formed to transcribe the data from the data collection forms onto the coding sheets. The team should work as a group, so that everyone can benefit from discussions concerning the proper coding symbols for the events, causes, action taken, etc., for the data found on the data collection forms. Data not included in the initial coding dictionary provided to the team should be identified by the team for inclusion in subsequent coding dictionary revisions.

\subsection{Data Analysis}

Data processing programs need to be developed to establish trends, compile data on the most frequently reported events, and ferret out events data which may be infrequently reported but could have serious effects on solar hardware systems. The programs should be capable of (1) processing the entire data base and causing the computer to print out summations for events that occur during the operational phases of the residential and commercial demonstration programs and (2) correlating these events with the identification, materials and performance data defined in Part Two of this plan.

A detailed description of the data analysis process, including sections on the use of the data summation tables is presented in Part Four of this plan. 


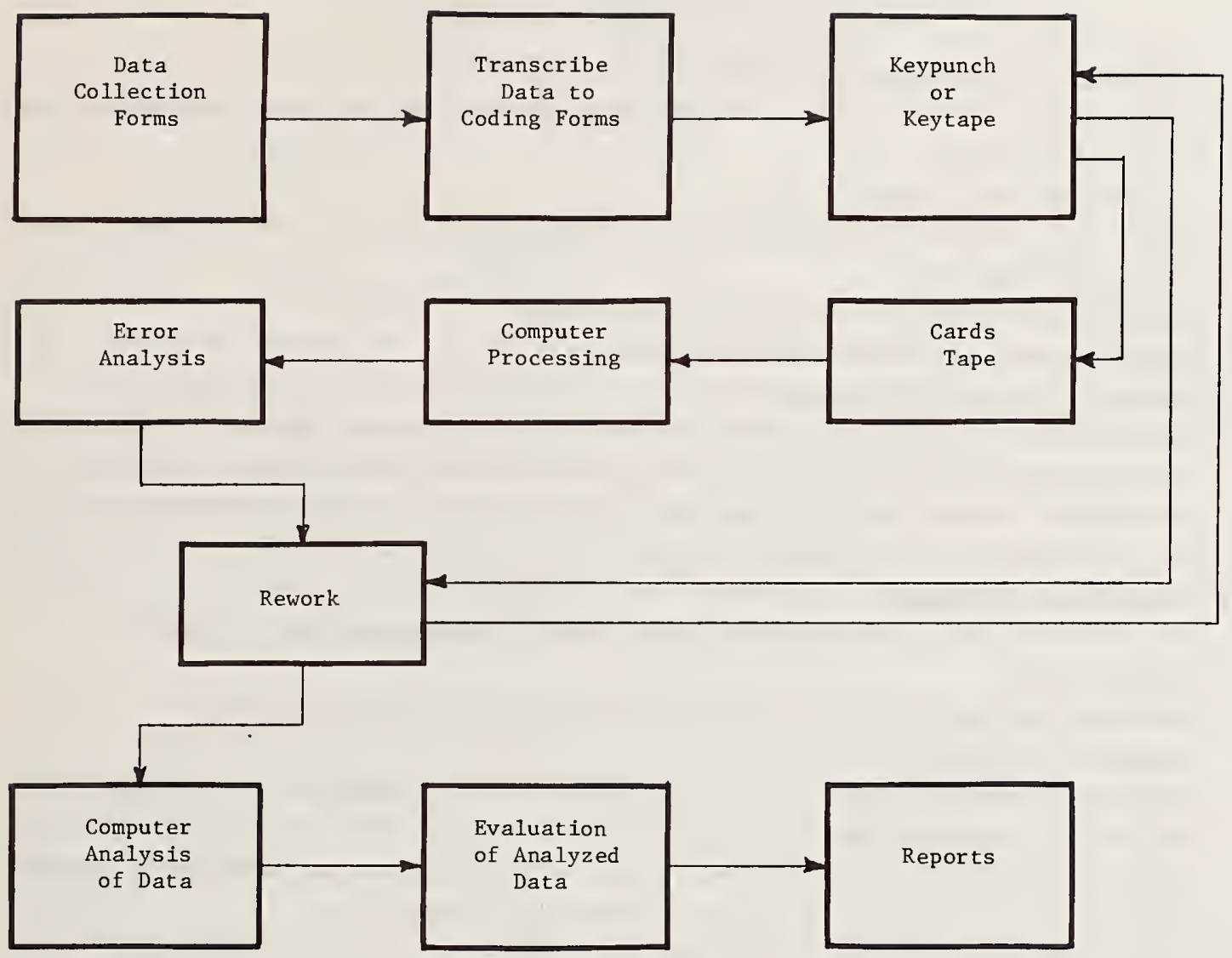

Figure 1.3

Schematic Flow Chart for Proceșsing

of the Non-Instrumentation Data 
The non-instrumentation technical data to be collected during the demonstration programs and methods of collection, computer processing of data, and recommendations for output format, are presented in this document. The various tasks required to implement the data requirements plan are listed below.

- Development of Data Collection Forms

In order to efficiently collect the data listed in Parts Two and Three appropriate forms must be developed.

- Instructions and Training

Instructions and training of personnel to adequately fill out the data collection forms need to be developed.

- Collection of Forms

Data forms must be collected on a periodic basis.

- Transcribe Data to Coding Forms

Once the forms have been collected, the data must be processed. The first step in data processing is to transcribe the data onto coded forms such that the data is machine processable. This includes the development of the coding symbols, training and supervision of the personnel who are to transcribe the data.

- Keypunching or Keytape

The data must then be keypunched on cards or tape for automatic data processing.

- Error Analysis

Once the data has been put into the computer it must be checked for errors.

- Computer Processing

Programs must be developed to perform the data analysis requirements of Part Four.

- Evaluation of Analyzed Data

Data will be analyzed to extract the information needed to develop definitive performance criteria and to perform other studies as discussed in Section 1.2. 


\section{BUILDING/SITE/SOLAR ENERGY SYSTEM}

\section{IDENTIFICATION, MATERIALS}

AND PERFORMANCE

\subsection{INTRODUCTION}

The data requirements contained in this part provide information needed to (1) 1ocate and characterize the building, (2) provide a description of the major subsystems and components of solar heating and cooling systems and (3) provide data required for system thermal design and calculation of building thermal heating and cooling loads. The data contained herein will be used to calculate predicted thermal performance which can then be compared with actual performance and used to establish a valid basis on which to formulate solar energy system design standards. In addition, these data will be used in combination with the data defined in Part Three of this report to categorize durability, rellability, maintainability and failure problems during the solar demonstration program.

The data are subdivided into two major categories; (1) data requirements for the building and (2) data requirements for the solar energy system. The major portion of the data in the latter category is devoted to characterizing solar collectors, thermal storage, and energy transport; since these subsystems are the least developed of all those in the total hardware system.

Half size or larger sets of final architectural drawings including plot and landscape plans and mechanical, electrical and structural drawings as we11 as specifications should be readily available to aid in the evaluation process. These sets of drawings should be provided by the architect/engineer responsible for solar system/building integration.

Most of the items in subsection (f) of section 2.0 are concerned with the determination of building heat loads. In cases where just solar hot water systems are used, only those items marked with an asterisk (*) need to be provided in this subsection.

The data 1ists that are presented in this report are intended to serve as a basis for computer coding. They are open ended in nature and will be expanded on an as needed basis. More detailed data requirements are presented in the Appendix. These data will be required for a selected number of instrumented demonstration systems on which comprehensive thermal analyses will be performed. These systems will be identified during the course of the demonstration program. 
2.0 BUILDING/SITE

a. Building Identification Number

b. Building Location, Owner and Architects/Engineers

(1) Location

- Street address

- City, county

- State and zip code

(2) Owner/Builder/Developer

- Name

- Street address

- City, county

- State and zip code

- Telephone number

(3) Architect/Engineer

- Firm name

- Street address

- City, county

- State and zip code

- Telephone number

c. Type of Solar System Integration and Governing Codes

(1) Integration of the solar system took place concurrently with the design of the building.

(2) Integration of solar equipment occurred after the building design was fixed.

(3) Integration of the solar system was a retrofit into an existing building.

(4) Governing Codes

- State Code

- Local Code

- Uniform Building Code (ICBO)

- Southern Standard Building Code (SBCC)

- Basic Building Code (BOCA)

- National Building Code (AIA)

- Minimum Property Standards (HUD) 


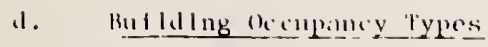

(1) Residerucess

- Singla raml ly hetached

- Singlo liamlly At taclied

- Muplex

- Irlplox

- (lamdraplex

- Rowlunusic (sitate mumber of unfts)

- Moblila Home

. Singla Wide

- Mouble Wide

(2) Sitores:

- Sinall Store

- Varlely siture

Supormatkot

- Departmont sloro

- Shopping M:1ll

(3) Commerctal and l'ublle Buildings

- Dining and lintertininent Center

- Restaurimt

- Cafeteria

- Bar and Niglut (:1ub

- ()ffice Building

- Library and Museum

- Bowling Center

- Communication Center (Telephone \& Teletype Buildings, Radio \& TV Stations)

- Transportation Center and Underground Garage

- Post office

- Fire Station

(4) Places of Assembly 
- Church

- Auditorium (Motion Picture Theaters, Legitimate Theaters,

Concert Halls, School)

- Sports Arena

- Gymnasium

- Convention and Exhibition Center

- Swimming Pool (Design capacity, gal. (I-7 $\pm 3 \%) *$ and water temp., ${ }^{\circ} \mathrm{F}\left(\mathrm{I}-2 \pm 2^{\circ}\right)$

(5) Multiple Dwelling and Domiciliary Facilities

- Apartment House (state number of units)

- Low rise (1 to 3 stories)

- Medium rise (4 to 7 stories)

- High rise ( 8 or more stories)

- Dormitory (state number of units).

- Hote1 and Mote1 " " "

- Nursing Home " " " "

(6) Educational Facilities (classrooms, lecture rooms, assembly rooms, auditoriums)

(7) Health Facilities

- Hospital

- Clinic

(8) Warehouses

(9) Laboratories

(10) Industrial Buildings

- Light Industry

- Heavy Industry

(11) Greenhouses

e. Category of Occupancy

(1) Commercia1

(2) Institutional

- Elementary school

- High school

- University and college
* Letters and Numbers in parenthesis refer to the precision and accuracy of the data. The terms $I$ and $F$ are used to indicate field width for integers and fractional numbers, respectively. For example, I-7 indicates a number with seven integers (e.g. $1,600,101$ ) and F-4.1 indicates that four spaces are required, one of which is for an integer after the decimal point. The remaining three spaces are for a decimal point and two integers before the decimal point $(\mathrm{e} . \mathrm{g} \cdot 26.1)$. The term A indicates the field width for letters. For example, the term A-2 indicates two letters (e.g. NE) . 
- $\operatorname{Religious}$

- Medical

(3) Governmenta1

- Municipa1

- County

- State

- Federal

(4) Private

- Owner occupied

- Renter occupied

\section{f. Building and Climatic Factors}

*(1) Latitude $\mathrm{N}\left({ }^{\circ} \mathrm{N}\right)\left(\mathrm{I}-2 \pm 1^{\circ}\right)$

*(2) Altitude, $\mathrm{ft}(\mathrm{I}-4 \pm 5 \%)$

(3) Normal cooling degree days $\left({ }^{\circ} \mathrm{F}\right.$ days/yr)(I-4 $\left.\pm 2 \%\right)$

(4) Average summer temperature $\left({ }^{\circ} \mathrm{F}\right)\left(\mathrm{I}-3 \pm 2^{\circ}\right)$

(5) Cooling hours per year (per ASHRAE) (I-6 $\pm 2 \%$ )

(6) Normal heating degree days $\left({ }^{\circ} \mathrm{F}\right.$ days/yr) (I-4 $\left.\pm 2 \%\right)$

(7) Heating degree days for January(I-3 $\pm 2 \%)$

(8) Average winter temperature $\left({ }^{\circ} \mathrm{F}\right)\left(\mathrm{I}-3 \pm 2^{\circ}\right)$

*(9) Average total horizontal solar radiation for January (Btu/ft ${ }^{2}-$ day) (I-5 $\left.\pm 5 \%\right)$

*(10) Average total horizontal solar radiation for July (Btu/ft $\left.{ }^{2}-\mathrm{day}\right)(\mathrm{I}-5 \pm 5 \%)$

(11) $971 / 2 \%$ heating outdoor design temperature $\left({ }^{\circ} \mathrm{F}\right)\left(\mathrm{I}-3 \pm 2^{\circ}\right)$

(12) Heating indoor design temperature $\left({ }^{\circ} \mathrm{F}\right)\left(\mathrm{I}-2 \pm 2^{\circ}\right)$

(13) $21 / 2 \%$ cooling outdoor design temperature $\left({ }^{\circ} \mathrm{F}\right)\left(\mathrm{I}-2 \pm 2^{\circ}\right)$

(14) Cooling indoor design temperature $\left({ }^{\circ} \mathrm{F}\right)\left(\mathrm{I}-2 \pm 2^{\circ}\right)$

(15) Front of building faces (N, NE, NW, SE, S, SW, E, W) (A-2 $\left.\pm 221 / 2^{\circ}\right)$

*(16) Design monthly average wind direction (N, NE, NW, SE, S, SW, E, W) (A-2 $\left.\pm 22^{\circ} 1 / 2^{\circ}\right)$

*(17) Design monthly average wind velocity (MPH) $(\mathrm{I}-2 \pm 10 \%)$

(18) Outdoor design dew point (cooling only) (I-2 $\left.\pm 3^{\circ}\right)$

(19) Design shaded glass area - heating season $\left(\mathrm{ft}^{2}\right)(\mathrm{I}-5 \pm 2 \%)$

(20) Design shaded glass area - cooling season ( $\mathrm{ft}^{2}$; ( I $\left.-\underline{5 t} 2 \%\right)$

* In cases where just solar hot water systems are used, only those ttems marked with an asterisk (*) need to be provided. 
*(2I) Estimated daily hot water load [ gal. $(\mathrm{I}-3 \pm 10 \%)$, outlet temp. $\left({ }^{\circ} \mathrm{F}\right)\left(\mathrm{I}-3 \pm 5^{\circ}\right)$ and average source temp. $\left.\left({ }^{\circ} \mathrm{F}\right)(\mathrm{I}-2 \pm 10 \%)\right]$

(22) Building load calculations and worksheets $\dagger$

g. Building

(1) Number of Stories

- above the ground

- below the ground

(2) Total height above ground (average, ft.) (I-4 $\pm 5 \%)$

(3) Conditioned floor areas

- Floors _through __ each contain _ sq ft (I-5 $\pm 2 \%)$

(List all groups of floors with different floor areas; see following

example: Floors 1 thru 6, $900 \mathrm{sq}$ ft each

Floors 7 thru 9, $600 \mathrm{sq}$ ft each; in addition, identify floor areas which utilize solar energy.)

(4) Wall geometry - The data listed in this section is required for each wall of the building

- Wa11 identification number

The numbering system for wall is as follows:

The front of the building is always identified as wall number one.

The remaining walls are numbered consecutively as they are encountered

in proceeding clockwise around the building starting with the center

of the number one wall tangent to the hour circle at $12 o^{\prime}$ clock.

- Wall geometry

- Height at highest part of the wall if it is not the same as the total height of the building.

- Total area of door openings sq ft $(I-4 \pm 2 \%)$

- Total area of windows sq ft $(\mathrm{I}-5 \pm 2 \%)$

(5) Roof

- Flat

- Sloped (specify pitch angle)

$\dagger$ For residential dwellings and small commercial buildings the building load can be calculated using Manual $\mathrm{J}$ or an equivalent method. An appropriate procedure utilizing hourly simulations should be followed for large commercial buildings. Detailed building data requirements for instrumented sites are listed in Appendix A. 
(6) Attic

- Ventilated

- Unventilated

(7) Crawl space

- vented

- unvented 
3.0 SOLAR ENERGY SYSTEM OR SYSTEMS IN THE BUILDING

a. System Description

(1) System function

- Domestic hot water or service hot water (HW)

- Space heating (H)

- Space cooling (C)

- $\mathrm{HW}+\mathrm{H}$

- $\mathrm{HW}+\mathrm{C}$

- $\mathrm{HW}+\mathrm{H}+\mathrm{C}$

$\circ \mathrm{H}+\mathrm{C}$

(2) Type of system

- Active, air

- Active, liquid

- Passive

- Window type

+ Directly irradiated storage

+ Indirectly heated storage

+ Combined directly and indirectly heated storage

- Thermosyphon

$+\operatorname{Air}$

+ Liquid

- Liquid bag type

- Air plenum

- Evaporator

- Hybrid systems (indicate types and functions as specified above)

b. Drawings

(1) Solar energy system schematic drawings, materials schedules, and specifications shall be provided identifying major components along with valves, pumps, controls and sensors in a manner consistent with figure 2.1. Separate schematic drawings shall be provided showing control temperature setpoints, heat transfer fluid flow rates and directions for each system operational mode. Standard ASHRAE symbols and hardware designations shall be used. 


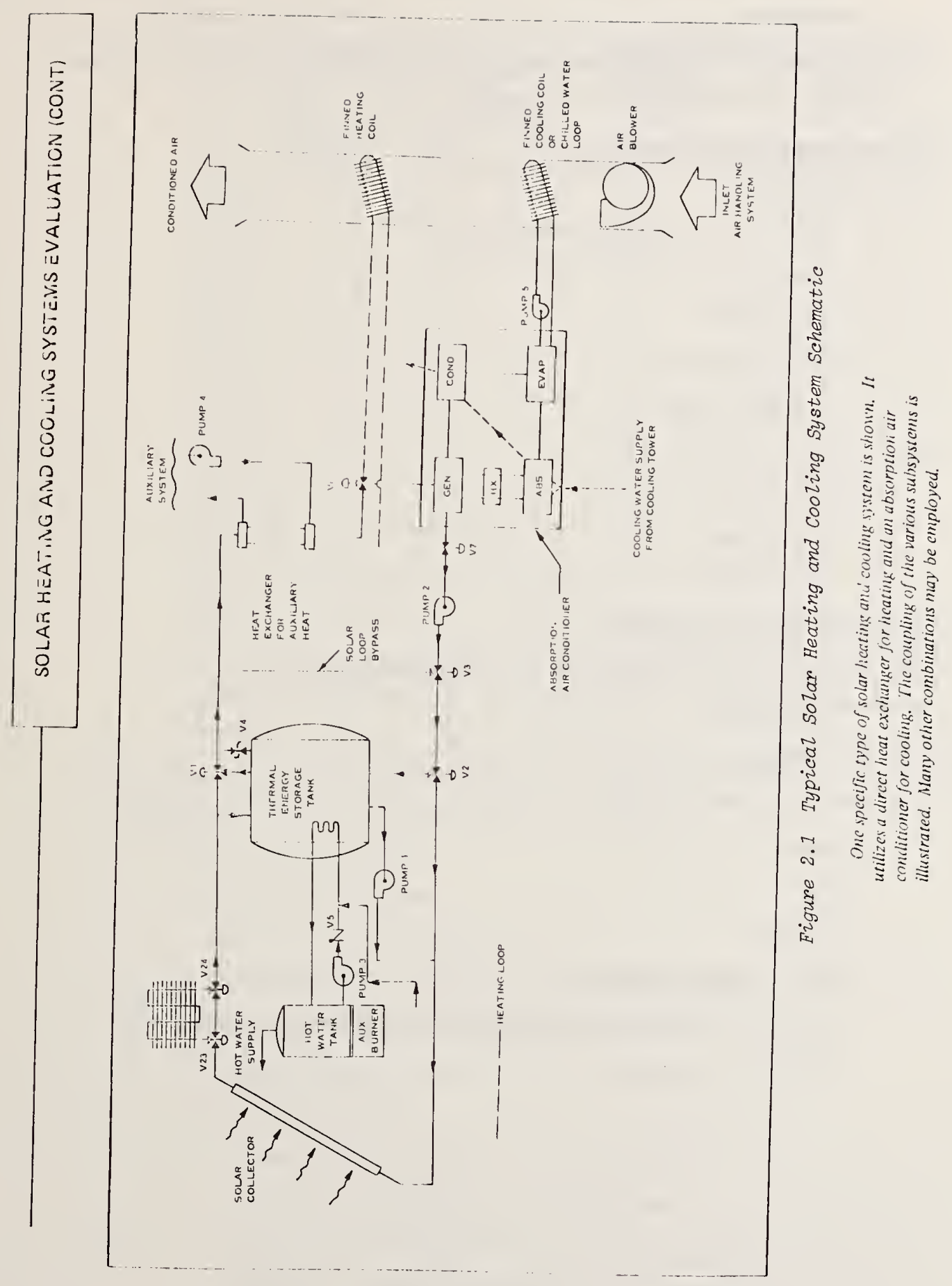


(2) A schematic drawing showing solar energy system and distribution systems integration.

(3) A schematic drawing showing the location of the major solar energy system components with respect to the building.

c. System Designer/Manufacturer

(1) Name/Location

- Name of system designer/manufacturer

- Street address

- City, county

- State, zip code

- Telephone number

(2) System identification

- Model name

- Mode1 number

- Serial number

d. System Predicted Performance

(1) Type of analytical model used for performance calculation

- Steady state

- Transient

(2) Simulation time period

- Hourly

- Daily

- Monthly

(3) Analytical Mode1 Designation

- Data used as inputs to the TRNSYS Simulation Program are listed in Appendix B 
(4) Monthly performance

\begin{tabular}{|c|c|c|c|c|c|c|c|c|c|}
\hline \multirow{3}{*}{ Month } & \multicolumn{3}{|c|}{ Tota1 Load } & \multicolumn{6}{|c|}{ Energy to Load Supplied By } \\
\hline & \multirow{2}{*}{$\begin{array}{c}\text { F5. } 2+5 \% \\
\text { Hot } \\
\text { Water } \\
\text { Htg. } \\
\text { Btu x } 10\end{array}$} & \multirow{2}{*}{$\begin{array}{l}\text { 5.2+5\% } \\
\text { Bldg. } \\
\text { Htg. } \\
\text { Btu x } 10^{6}\end{array}$} & \multirow{2}{*}{$\begin{array}{c}\text { F5.2+5\% } \\
\text { Bldg. } \\
\text { Cooling } \\
\text { Btu x } 10^{6}\end{array}$} & \multicolumn{3}{|c|}{$\begin{array}{l}\text { (F5.2+5\%) } \\
\text { Solar System* } \\
\text { Btu } \times 10^{6}\end{array}$} & \multicolumn{3}{|c|}{$\begin{array}{l}\text { F5.2+5\% } \\
\text { Auxiliary } \\
\text { Btu } \times 10^{6}\end{array}$} \\
\hline & & & & DHW & $\mathrm{H}$ & $\mathrm{C}$ & DHW & $\mathrm{H}$ & $\mathrm{C}$ \\
\hline Jan. & & & & & & & & & \\
\hline Feb. & & & & & & & & & \\
\hline Mar. & & & & & & & & & \\
\hline Apr. & & & & & & & & & \\
\hline May & & & & & & & & & \\
\hline Jun. & & & & & & & & & \\
\hline Jul. & & & & & & & & & \\
\hline Aug. & & & & & & & & & \\
\hline Sep. & & & & & & & & & \\
\hline Oct. & & & & & & & & & \\
\hline Nov. & & & & & & & & & \\
\hline Dec. & & & & & & & & & \\
\hline Total & & & & & & & & & \\
\hline
\end{tabular}

* Specify combined energy in first column if not available separately and so indicate.

e. Collectors (repeat for each collector type used)

(1) Discrete collector type

- Liquid tube and plate

- Liquid flat plate trickle type

- Liquid flat plate pressure diffusion bonded passage

- Liquid flat plate deformed and spot welded

- Liquid flat plate, heat trap (e.g., honeycomb)

- Liquid concentrating

- Fresnel lens and absorber on tracking mount

- Reflector and absorber on tracking mount

- Reflector on tracking mount with fixed absorber

- Absorber on tracking mount with fixed reflector

- Liquid evacuated tube 
- Air evacuated tube

- Air flat plate, finned

- Air flat plate, black gauze matrix

- Air flat plate, black glass

(2) Integrated Collector/Storage Combinations

- Liquid

- Wa11

+ Enclosed

- Roof

+ Bag type

+ Open pond

- Solid

- Wa11

- Roof

- Floor

(3) Manufacturer's name

- Street address

- City

- State, zip code

- Telephone number

(4) Collector identification

- Mode1 number

- Model name

(5) Collector location

- On ground

- On roof of building

- On walls of building

- On separate structure

(6) Collector Tilt and Orientation

- Flat plate reflector angle of tilt (degrees from horizontal)(I-2 $\pm 2^{\circ}$ )

- Orientation (degrees $\mathrm{E}$ or $\mathrm{W}$ of $\mathrm{S}$ ) based on true $\mathrm{N}\left(\mathrm{I}-3 \pm 5^{\circ}\right)$

- Adjustable range (degrees) specify whether tilt, orientation or both (I-2 $\pm 5^{\circ}$ )

- Non-adjustable 
(7) Array and collector physical characteristics

- Number of collector panels of each size

- Total area of array (outside) $\left(\mathrm{ft}^{2}\right)(\mathrm{I}-5 \pm 2 \%)$

- Effective array aperture area $\left(f t^{2}\right)(I-5 \pm 1 \%)$

- Length of each collector pane1 size (in)(F-5.1 $\pm 2 \%$ )

- Width of each collector panel size (in) $(F-3.1 \pm 2 \%)$

- Depth of frame of each collector pane1 size (in) F-4.1 $\pm 5 \%$ )

- Height of standoff of each collector panel size (in)(I-3 $\pm 10 \%)$

- Weight (1b/collector panel)

- Empty $(\mathrm{I}-3 \pm 5 \%)$

- Ful1 (I-3 $\pm 5 \%)$

- Weight of filled array and support structure (1b) (I-5 $\pm 5 \%)$

(8) Amount of collector array shading

- Area shaded on June 21 between 10:00 a.m. and 2:00 p.m.

solar time (\% of aperture) (I-2 $\pm 5 \%$ )

- Area shaded on December 22 between 10:00 a.m. and 2:00 p.m.

solar time (\% of aperture) (I-2 $\pm 5 \%)$

- Maximum \% shaded during functional season ( $\mathrm{I}-2 \pm 5 \%$ )

(9) Cover plates (specify none, 1, 2, 3 and repeat information for each cover plate starting with the outermost plate)

- Manufacturer's name

- Product identification name and number

- Window materia1 (substrate)

- Sheet

+ Glass

- Tempered

- P1ate

- Single strength

- Double strength

- Water white

- Normal iron content 
+ Fiberglass reinforced plastic

- Polyester filler (plastic)

- Epoxy filler (plastic)

+ Polycarbonates (Lexan)

+ Acrylic

- Films

+ Ted1ar

+ Mylar

+ Tef1on

+ Polycarbonate

- Physical dimensions of cover plate

- Thickness (in) (for each cover plate) (F-4.3 \pm .001$)$

- Length (in) $(F-5.1 \pm .1)$

- Width (in) $(F-5.1 \pm .1)$

- Optical Properties (in the solar and infrared regions for each cover plate)

. Transmittance $(\mathrm{F}-3.2 \pm .02)$

- Reflectance $(\mathrm{F}-3.2 \pm .02)$

- Emittance $\left(70^{\circ} \mathrm{F}\right)(\mathrm{F}-3.2 \pm .02)$

- Edge and/or surface treatment (specify for each treated cover plate, edge or surface)

- Mechanical

+ Sand Blast

+ Grind

+ Polish

- Chemical etch

- Fire polish

- Coating

+ Function

- Reflective

- Anti-reflective

- Protective 


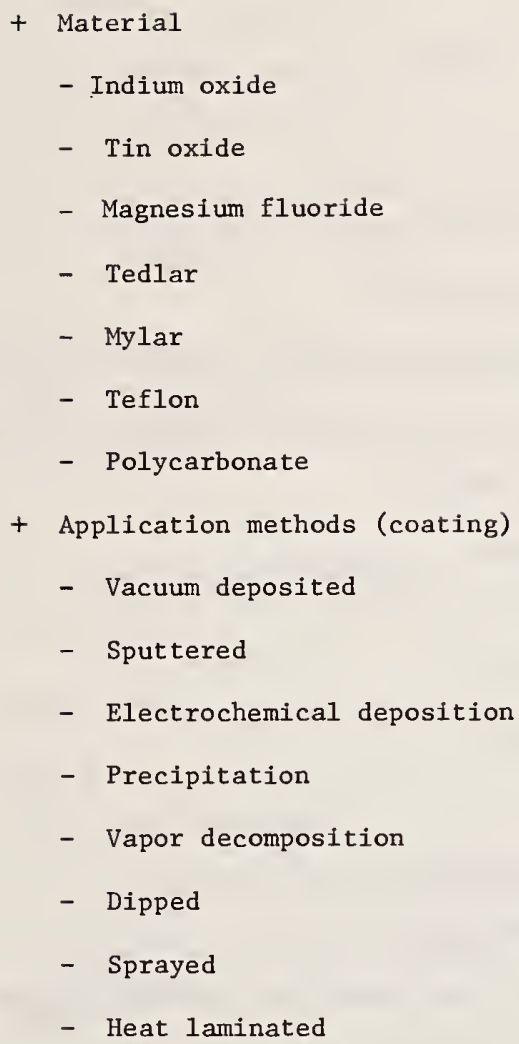

(10) Passive collector heat transfer control

- Louver

- Shade

- Bead

- Board

- Screen

(11) Absorber

- Manufacturer's name

- Mode1 number

- Mode1 name

- Absorptive coating/surface

- Material

+ Flat black paint

- Alkyd ename1

- Acrylic enamel 
- Inorganic

- Silicone

- Lead sulfide/silicone

+ Ceramic enamel

+ Black zinc paint

+ Copper oxide over aluminum

+ Black copper over copper

+ Black chrome over nickel (specify bright or dull nickel)

+ Black nickel over nickel (specify bright or dull nickel)

+ Black iron over steel

- Method of application

+ Painted

+ Vacuum deposited

+ Chemically plated

+ Sputtered

+ Chemical decomposition

+ Chemical vapor deposition

- Optical properties (in the solar and infrared regions)

+ Absorptance $(F-3.2 \pm .02)$

+ Emittance (specify normal or hemispherical at $\left.70^{\circ} \mathrm{F}\right)(\mathrm{F}-3.2 \pm .02)$

$\circ$ Substrate

- Material

+ Aluminum (alloy designation)

+ Copper (alloy designation)

+ Steel (a1loy designation)

+ Brass (alloy designation)

+ Plastic (generic type)

- Thickness (in) $(F-4.3 \pm 5 \%)$

- Heat transfer fluid passages

- Materials

+ Aluminum (alloy designation)

+ Copper (alloy designation) 
+ Steel (a1loy designation)

+ Brass (a1loy designation)

+ Plastic (generic type)

- Wall Thickness (in) (F-4.3 $\pm 5 \%)$

- Internal diameter (in) $(F-4.3 \pm .010)$

- Protective coating

+ Anodized

+ Galvanized

+ Conversion type

+ None

- Tube passage bond to substrate

+ Soldering

+ Welding

+ Brazing

+ Mechanical connection

- Heat transfer compound (specify)

- Without heat transfer compound

+ Adhesive

(12) Insulation

- Location and number of layers

- Sides - number of layers

- Back - number of layers

(Complete the following for each layer of insulation)

- Manufacturer's name

- Product identification name

- Product identification number

- Material

- Glass fiber

- Isocyanurate

- Polyurethane

$+\mathrm{CO}_{2}$ blown

+ Freon blown 
- Styrofoam

- Glass foam

- Mineral wool

- Calcium silicate

- Binder content (\%) by wt. (I-2 $+5 \%)$ and type (specify)

- Thickness (in) (F-4.1 $\pm 5 \%)$

- Density (lb/cu ft) $(\mathrm{I}-3+5 \%)$

- Thermal resistance ( $R$ value) $(I-2 \pm 5 \%)$

(13) Gaskets and Sealants

- Manufacturer's name

- Product identification name and number

- Location

- Cover plate inner

- Cover plate outer

- Backing plate

- Piping penetration

- Frame joints

- Sealant type

- Oil base

- Buty1 skinning type

- Buty1 non-skinning type

- Acrylic solvent release type

- Acrylic water release type

- Polysulfide one component

- Polysulfide two component

- Polyurethane one component

- Polyurethane two component

- Silicone

- Gaskets

- Cork

- Rubber (generic type)

- Plastic (generic type) 
(14) Mounting frame

- Manufacturer's name (if factory assembled unit)

- Model name

- Product identification name or number

- Material

- Steel (alloy designation)

- Aluminum (alloy designation)

- Wood (generic type)

- Plastic (generic type)

- Protective coating

- None

- Galvanized

- Anodized

- Painted

- Galvanized/painted

- Anodized/painted

- Conversion coating/painted

- Number of attachment points

- With or without standoffs (specify)

(15) Collector performance - use the slope intercept method per ASHRAE 93-77, provide a minimum of four points over the inlet temperature range of $100^{\circ}-$ $180^{\circ} \mathrm{F}$ and insolation range of $150-300 \mathrm{Btu} / \mathrm{ft}^{2} \mathrm{hr}$ at design flow rates. (One curve may be sufficient for liquid systems but several flow rates and curves are required for air systems.) A plot of the thermal efficiency versus the difference in temperature between the average collector fluid temperature and ambient divided by the incident insolation for the range of exposure conditions will provide the basic thermal performance at near normal incident angles. Additional data regarding the following features shall be included. 
- Angle modifier

- $45^{\circ}(\mathrm{F}-3.1 \pm 5 \%)$

- $60^{\circ}(\mathrm{F}-3.1 \pm 5 \%)$

. $75^{\circ}(\mathrm{F}-3.1 \pm 5 \%)$

- Thermal response time constant (min) (F-3.1 $\pm 10 \%)$

- Back \& edge thermal loss (Btu/hr-ft $\left.{ }^{2}-{ }^{\circ} \mathrm{F}\right)(\mathrm{F}-3.1 \pm 10 \%)$

- Total heat loss coefficient, $U_{L},\left(B t u / h r-f t^{2}{ }^{\circ} F\right)(F-3.2 \pm 10 \%)$ specify design wind speed $(F-3.1 \pm 10 \%)$

- Design flow rates, Liquid: (gpm) Air: (cu $\left.f t / f t^{2}-m i n\right)(F-3.1 \pm 1 \%$ )

(16) Reflector

- Substrate materia1

- Aluminum (a1loy designation)

- Steel (alloy designation)

- Glass

- Plastic (generic type)

- Reflective surface

- Polished substrate

- Aluminum

+ Vacuum deposited

+ Electroplated

- White paint

- Protective coating

- None

- Anodized

- Clear coating

- Physical dimensions (thickness, length, and width inches) $(F-3.1 \pm 5 \%)$

- Shape (specify flat, cylindrical, parabolic)

- Concentration factor $(\mathrm{F}-4.1 \pm 10 \%)$ and solar reflectance $(\mathrm{F}-3.1 \pm .02)$

(17) Desiccants (specify location and whether self regenerating)

- Silica Ge1

- Anhydrous calcium chloride 
f. Thermal Storage (repeat for each storage unit used)

(1) Storage container design

- Number of containers

- Volume (cu ft) (I-4 $\pm 5 \%)$

- Dimensions (specify shape cubical, rectangular, cylindrical, etc.)

- Length (ft) $(\mathrm{I}-3 \pm 2 \%)$

- Width (ft) $(\mathrm{I}-2 \pm 2 \%)$

- Height (ft) $(\mathrm{I}-2 \pm 2 \%)$

- Diameter (in) $(I-3 \pm 2 \%)$

- Thermal gradients

- Number of segments

- Temperature gradient - each segment $\left({ }^{\circ} \mathrm{F}\right)(\mathrm{I}-2 \pm 20 \%)$

(2) Storage maximum and minimum usable design temperatures (specify for heating and cooling separately) (I-3 $\pm 5 \%)$

(3) Storage medium

- Sensible heat

- Liquid types

+ Water

+ Ethylene glycol/water

+ Propylene glycol/water

+ Silicone fluid

+ Alkylated phenol

+ Paraffinic oil

+ Immiscible oil/water

- Liquid composition by $\%$ of total volume (I-2 $\pm 10 \%)$

- Physical properties of the liquid

+ Specific heat $\left(\mathrm{Btu} / 1 \mathrm{~b} /{ }^{\circ} \mathrm{F}\right)(\mathrm{F}-4.3 \pm 1 \%)$

+ Density $(1 \mathrm{~b} / \mathrm{cu} \mathrm{ft})(\mathrm{I}-3 \pm 1 \%)$

+ Viscosity over working temperatures range (poises) $(F-5.2 \pm 5 \%)$

+ Boiling point $\left({ }^{\circ} \mathrm{F}\right)\left(\mathrm{I}-3 \pm 3^{\circ}\right)$

+ Freezing point $\left({ }^{\circ} \mathrm{F}\right)\left(\mathrm{I}-3 \pm 3^{\circ}\right)$

$+\mathrm{pH}$ factor $(\mathrm{F}-4.1 \pm 5 \%)$ 
+ Inhibitor type (generic name)

+ Inhibitor type $\%$ of total weight $(\mathrm{I}-3 \pm 10 \%)$

+ Maximum recommended use temperature $\left({ }^{\circ} \mathrm{F}\right)(\mathrm{I}-3 \pm 5 \%)$

+ Flash point temperature $\left({ }^{\circ} \mathrm{F}\right)(\mathrm{I}-3 \pm 5 \%)$

+ Toxicity

- Potable

- Unfit for human consumption

- Solid Types

+ Materials

- Crushed stone

- Smooth surfaced stone

- Concrete

- Brick

- Concrete block

+ Packing Characteristics

- Size ranges

$11 / 2$ to $21 / 2$ inches

$21 / 2$ to $31 / 2$ inches

$31 / 2$ to $41 / 2$ inches

$41 / 2$ to $51 / 2$ inches

- Weight per cu. ft of packed material (1b) $(\mathrm{I}-3 \pm 10 \%)$

- Total weight of storage medium (1b) (I-5 $\pm 10 \%)$

+ Physical properties

- Specific heat of solid material (Btu/1b/ $\left.{ }^{\circ} \mathrm{F}\right)(\mathrm{F}-4.3 \pm 1 \%)$

- Heat capacity of packed material (Btu/ft $\left.{ }^{3} /{ }^{\circ} \mathrm{F}\right)(\mathrm{F}-3.1 \pm 5 \%)$

+ Flow rate of heat transport $\left(\mathrm{ft}^{3} / \mathrm{min}\right)(\mathrm{I}-3 \pm 5 \%)$

+ Pressure drop between inlet and outlet (psi) (F-3.1 $\pm 10 \%)$

- Latent Heat

- Materials

+ Salt hydrates

- Calcium chloride hexahydrate 
- Sodium carbonate decahydrate

- Disodium phosphate dodecahydrate

- Sodium sulphate decahydrate

- Sodium thiosulfate pentahydrate

+ Eutectic mixtures

- $\mathrm{CaCl}_{2} \mathrm{MgCl}_{3}-\mathrm{H}_{2} \mathrm{O}$

$-\mathrm{Mg}\left(\mathrm{NO}_{3}\right)_{2}-6 \mathrm{H}_{2} \mathrm{O}-\mathrm{Al}\left(\mathrm{NO}_{3}\right)_{3}-9 \mathrm{H}_{2} \mathrm{O}$

- Acetamide-stearic acid

- Urea

+ Paraffin

- Homogeneous

- Encapsulated and suspended in liquid

- Additives

+ Nucleating agents

- Generic type

- Percent by weight

+ Thickening agent

- Generic type

- Percent by volume

- Physical properties of medium

+ Type of transformation

- Solld - 1iquid

- Dissolution-recrystallization

- Solid - solid

+ Transformation temperature $\left({ }^{\circ} \mathrm{F}\right)\left(\mathrm{I}-3 \pm 5^{\circ}\right)$

+ Latent heat of transformation $(B t u / 1 b)(I-3 \pm 2 \%)$

+ Specific heat above transformation (Btu/1b/ $\left.{ }^{\circ} \mathrm{F}\right)(\mathrm{F}-3.2 \pm 2 \%)$

+ Specific heat below transformation (Btu/1b/ $\left.{ }^{\circ} \mathrm{F}\right)(\mathrm{F}-3.2 \pm 2 \%)$

+ Viscosity of liquid phase over working temperature range (poises) $(\mathrm{F}-5.2 \pm 5 \%)$

+ Density of solid phase $\left(1 \mathrm{~b} / \mathrm{ft}^{3}\right)(\mathrm{I}-3 \pm 2 \%)$

+ Density of liquid phase $\left(1 \mathrm{~b} / \mathrm{ft}^{3}\right)(\mathrm{I}-3 \pm 2 \%)$ 
+ Botling point $\left({ }^{\circ} \mathrm{F}\right)\left(\mathrm{I}-3 \pm 3^{\circ}\right)$

+ Total volume of medium $\left(\mathrm{ft}^{3}\right)(\mathrm{I}-3 \pm 2 \%)$

+ Maximum recommended use temperature $\left({ }^{\circ} \mathrm{F}\right)\left(\mathrm{I}-3 \pm 10^{\circ}\right)$

+ Flash point temperature $\left({ }^{\circ} \mathrm{F}\right)\left(\mathrm{I}-3 \pm 10^{\circ}\right)$

+ Toxicity

- Potable

- Unfit for human consumption

(4) Tank or container construction

- Container Material

- Concrete

- Concrete block

- Steel

- Aluminum

- Wood

- Plastic (generic type)

- Glass fiber reinforced plastic (resin generic type)

- Filters (include manufacturer's name and product designation)

- At inlet

- At outlet

- At both inlet and outlet

- None

- Tank or container lining

- Epoxy compounds

- Neoprene

- Hypalon

- Porcelain enamel

- Buty1 rubber

- Glass

- Stone

- Tank or container location

- Above ground 
+ On site

+ On roof of building

+ In walls of building

+ In attic of building

+ In room of building

- Below ground

+ On site

+ In basement

+ Below foundation

+ In foundation

- Tank or container insulation

- Insulation material

+ Glass fiber

+ Calcium silicate

+ Mineral fiber

+ Cellular rubber

+ Polyurethane foam

+ Styrofoam

+ Reflective foil

+ None

- Insulation thickness (in) $(F-3.1 \pm 5 \%)$

- Insulation density ( $1 \mathrm{~b} / \mathrm{cu} \mathrm{ft})(\mathrm{I}-2 \pm 5 \%)$

- Thermal resistance ( $R$ value) $(I-2 \pm 5 \%)$

- Exterior finish (moisture barrier)

+ Asphalt

+ Asphalt and felt

+ Metal cladding (generic name and alloy designation)

+ Plastic coating (generic name)

+ Paint (generic name)

+ Cementitious material

+ None 
- Material for racks, troughs, etc., holding latent heat material inside the storage container

- Plastic (specify)

- Metal (specify)

- Provisions for auxiliary built-in heaters

- Quantity (specify none, 1,2, etc.)

- Manufacturer

+ Manufacturer's name

+ Model number

- Capacity (kw) $(\mathrm{I}-3 \pm 5 \%)$

(5) Heat Exchangers (repeat for each heat exchanger and identify by number on system schematic drawing, section 3.0 (b) )

- Type of exchange

- Air to air

- Air to 1iquid,

- Liquid to 1iquid

- Type flow

- Parallel flow

- Counter flow

- Cross flow

- Heat exchanger design

- Shell and tube

+ Number of tube passes

+ Number of shell passes

- Fin-coil

- Special types

+ Heat pipe

+ Tube around tank

+ Tube inside tank

- Number of walls

- Single

- Double 
- Effectiveness (specify flow conditions) $(F-3.2 \pm 10 \%)$

- Materials

- Copper (alloy designation)

- Aluminum (alloy designation)

- Steel (alloy designation)

- Combinations of metals (specify)

- Overall heat transfer coefficient (UA) (I-5 $\pm 5 \%)$

- Flow rate hot side (gpm) liquid, (cfm) air ( $1 \mathrm{~b} / \mathrm{hr}(\mathrm{I}-3 \pm 2 \%)$

- Flow rate cold side (gpm) liquid, (cfm) air ( $I-3 \pm 2 \%)$

g. Energy Transport Subsystems (repeat for each circulation loop and identify loop by number on system schematic drawing, 3.0 (b) )

(1) Liquid type

- Flow rate (GPM) $(\mathrm{I}-4 \pm 2 \%)$

- Normal maximum operating temperature $\left({ }^{\circ} \mathrm{F}\right)(\mathrm{I}-3 \pm 5 \%)$

- Heat transfer medium

- Material

+ Water

+ Ethylene glycol/water

+ Propylene glycol/water

+ Silicone fluid

+ Alkylated phenol

+ Paraffinic oil

+ Immiscible oil

+ Glycerine/water

- Physical properties of the liquid

+ Specific heat $\left(\mathrm{Btu} / \mathrm{Ib} /{ }^{\circ} \mathrm{F}\right)$ over working temperature $(\mathrm{F}-3.2 \pm 2 \%)$

+ Density (Ibs/cu ft) $(\mathrm{I}-3 \pm 2 \%)$

+ Viscosity over working temperature range (poises) $(F-5.2 \pm 5 \%$ )

+ Boiling point $\left({ }^{\circ} \mathrm{F}\right)\left(\mathrm{I}-3 \pm 2^{\circ}\right)$

+ Freezing point $\left({ }^{\circ} \mathrm{F}\right)\left(\mathrm{I}-3 \pm 2^{\circ}\right)$

+ Maximum recommended use temperature $\left({ }^{\circ} \mathrm{F}\right)(\mathrm{I}-3 \pm 5 \%)$

$+\mathrm{pH}$ factor 
+ Chemical feeder to maintain $\mathrm{pH}$ (specify)

+ Inhibitor type (generic type)

+ Inhibitor type (\% of total weight) (I-2 $\pm 10 \%)$

+ Flashpoint temperature $\left({ }^{\circ} \mathrm{F}\right)(\mathrm{I}-3 \pm 5 \%)$

+ Toxicity

- Potable

- Unfit for human consumption

- Piping/Manifolds

- Rigid piping/manifold material

+ Copper (a11oy designation)

+ Aluminum (alloy designation)

+ Iron (alloy designation)

+ Brass (alloy designation)

+ Steel (alloy designation)

+ Plastic (generic name)

+ Glass

- Protective coating (interior)

+ Anodized

+ Galvanized

+ Plating

+ Porcelain

+ Conversion

+ Rubber

+ Plastic (generic type)

+ None

- Flexible couplings

+ Material

- Rubber (generic name)

- Plastic (generic name)

- Metal (name and alloy designation)

+ Reinforcement

- Glass fiber

- Fabric (generic name) 


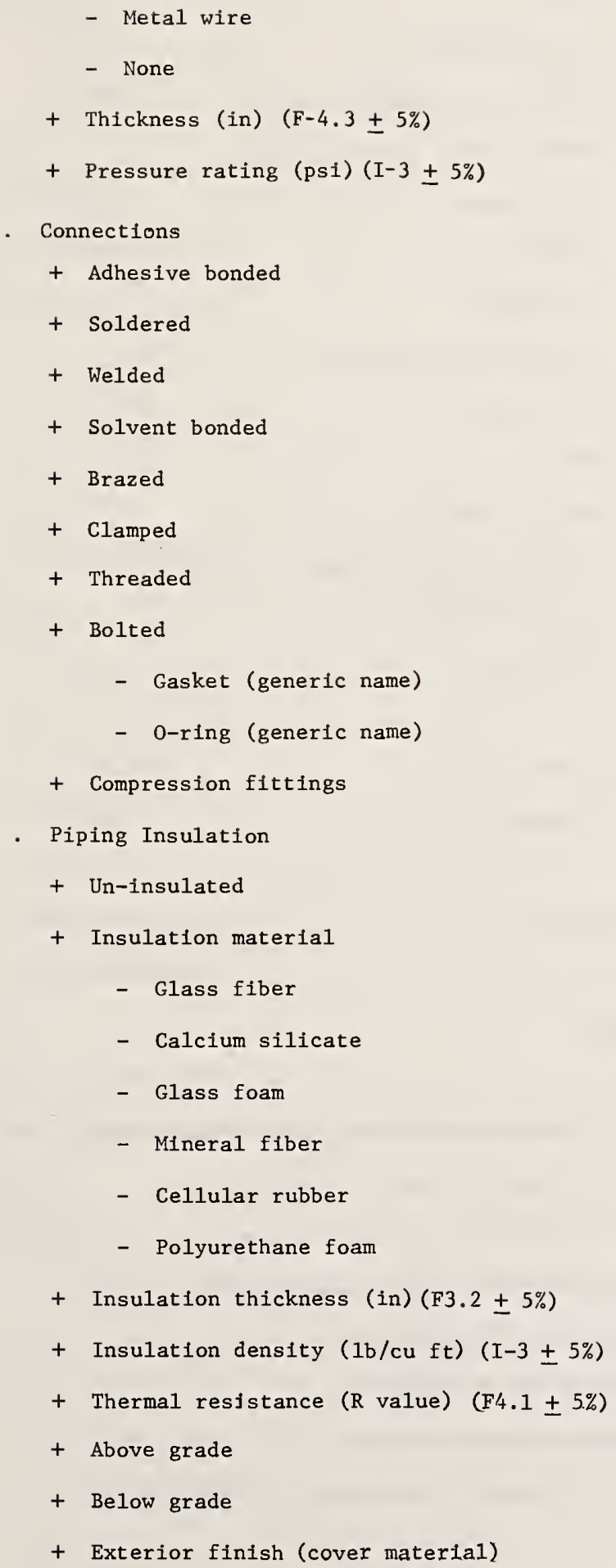


- None

- Foil scrim kraft

- Plastic film (generic type)

- Rigid plastic (generic type)

- Metal jacket

- Asphalt

- Glass cloth

- Cement cloth coated fabric

+ Joint treatment

- None

- Tape and mastic

- Pressure sensitive tape

- Heat sealed tape

- Metal band

Pumps

- Manufacturer's name

- Mode1 designation

- Type

+ Centrifugal

+ Gear

+ Piston

+ Vane

- Capacity (GPM) over operating head pressure range ( $-4 \pm 5 \%$ )

- Operating pressure (psi) $(I-3 \pm 5 \%)$

- Maximum recommended operating temperature $\left({ }^{\circ} \mathrm{F}\right)\left(\mathrm{I}-3 \pm 10^{\circ}\right)$

- Material exposed to heat transfer fluid

+ Brass (alloy designation)

+ Steel (alloy designation)

+ Plastic (generic type)

- Pump motor operating horsepower (F-3.2 $\pm 10 \%)$ 
- Filtering

- Filtered

- Unfiltered

- Getters

- Magnesium

- Valves (for each valve)

- Function

+ Flow switching

+ on - off

+ Drain

+ Bleed

+ Flow adjusting

- Type

+ Globe

+ Gate

+ Butterfly

+ Needle

$+\mathrm{BaII}$

- Manufacturer's name

- Model name/number

(2) Air type

- Flow rate (CFM) (I-4 $\pm 5 \%)$

- Normal maximum design operating temperature $\left({ }^{\circ} \mathrm{F}\right)\left(\mathrm{I}-3 \pm 10^{\circ}\right)$

- Ducting

- Rigid

+ Aluminum (alloy designation and thickness in inches) $(\mathrm{F}-4.2 \pm 5 \%$ )

+ Steel (alloy designation and thickness in inches) (F-4.2 $\pm 5 \%$ )

+ Plastic (generic type and thickness in inches) $(\mathrm{F}-4.2 \pm 5 \%)$

+ Jacketed glass fiber (density and thickness in inches) (F.4-2 $\pm 5 \%$ )

+ Asbestos cement (thickness in inches) $(\mathrm{F}-4.2 \pm 5 \%)$ 


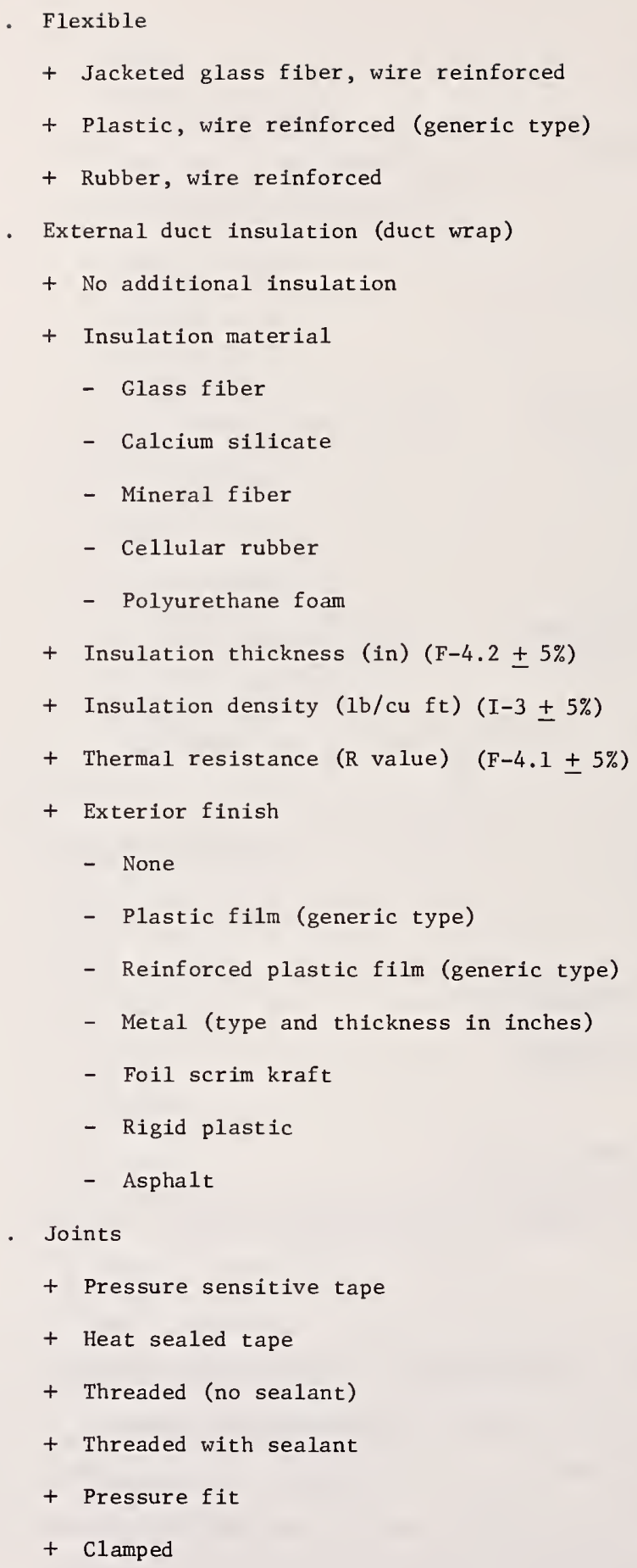


- Internal duct insulation (duct liner)

+ Insulation material

- Glass fiber

- Mineral wool

- None

+ Insulation thickness (in) $(F-4.2 \pm 5 \%)$

+ Thermal resistance ( $\mathrm{R}$ value) $(\mathrm{F}-4.1 \pm 5 \%)$

+ Insulation density (1b/cu ft) (I-3 $\pm 5 \%)$

+ Internal finish

- Neoprene

- None

- Ducting location

+ Above grade, exposed to weather

+ Above grade, inside building

+ Above grade, otherwise protected from weather

+ Below grade, exposed to soil

+ Below grade, inside culvert or utilities tunnel

- Blowers

- Type

+ Vane - axial

+ Tube - axial

+ Adjustable - pitch

+ Squirrel cage

- Capacity (CFM) $(\mathrm{I}-3 \pm 5 \%)$

- Operating pressure (psi) $(\mathrm{I}-2 \pm 5 \%)$

- Motor operating horsepower $(F-3.2 \pm 5 \%)$

- Filtering

- Filtered

- Unfiltered

- Dampers (for each damper)

- Function

+ Flow switching

+ on - off

+ Flow adjusting

- Type

+ Single blade

+ Opposed blade

+ Multilouver 
+ Multishutter

+ Splitter

- Manufacturer's name

- Mode1 name/number

h. Controls (specify for each type present)

(1) Load supply mode control unit

- Control logic selector

- Manufacturer's name

- Model name/number

- Sensors (specify locations on system schematic drawings)

- Type

+ Temperature

+ Time

+ Solar radiation

- Manufacturer's name

- Model name/number

- Actuated devices (for each device; show location on system schematic drawing)

- Type

+ Relay

+ Solenoid

+ Servomotor

- Manufacturer's name

- Model name/number

- Modes of operation (specify: collector to space, collector to storage, collector to storage and space, collector to HW, storage to space, storage to $\mathrm{HW}$, storage to auxiliary, storage and auxiliary to space, auxiliary to storage, energy dumping)

- Control setpoints, (specify for each system operating mode) ${ }^{\circ} \mathrm{F}\left(\mathrm{I}-5 \pm 2^{\circ}\right.$ ) 
(2) Collector/storage flow control unit

- Control logic selector

- Type

+ Differential thermostat

- Manufacturer's name

- Model name/number

- Sensors (specify locations on system schematic drawings)

- Type

+ Thermistor

+ Thermocouple

+ Resistance thermometer

- Manufacturer's name

- Model name/number

- Actuated devices (for each device; show location on system schematic drawing)

- Type

+ Relay

$+\quad$ Solenoid

+ Servomotor

- Manufacturer's name

- Model name/number

- Control setpoints, ${ }^{\circ} \mathrm{F}$ (specify whether differential or absolute temperature) $\left(\mathrm{I}-7 \pm 2^{\circ}\right)$

(3) Energy transport operation regulators

(Repeat for each device; specify locations on system schematic drawings)

- Flow regulators

- Type

- Manufacturer's name

- Model name/number

- Pressure regulators

- Type

- Manufacturer's name

- Mode1 name/number 
(4) Subsystem fail-safe controls (Repeat for each device; specify type and locations on system schematic drawing)

- Type

- Pressure relief valve

- Temperature relief device

- Electrical overload protection

- Vacuum relief valve

- Check valve

- Automatic drain down valve

- "Water hammer" arresters

- Automatic backfill valve

- Backflow preventer

- Manufacturer's name

- Mode1 name/number

(5) Component operation controls

- Tracking mount drive controls

- Sensor

+ Type

- Photocell

- Timer

+ Manufacturer's name

+ Model name/number

- Control unit

+ Manufacturer's name

+ Model name/number

- Actuated device

+ Type

- Servomotor

- Relay

+ Manufacturer's name

+ Model name/number 
- Storage heater thermostat

- Manufacturer's name

- Model name/number

\section{i. Auxiliary Energy}
(1) Location
- Internal with storage
- In line with storage
- In parallel with storage

(2) Type Unit

- Furnace (standard type)

- Energy required

+ oil

+ Gas

+ Electric

- Energy input (Btu/hr) (I-6 $\pm 5 \%)$

- Energy output (Btu/hr) (I-6 $\pm 5 \%)$

- Manufacturer's name

- Product identification number (mode1)

- Hot water heater (standard type)

- Manufacturer's name

- Model name/number

- Energy required

$+\quad 0 i 1$

+ Gas

+ Electric

- Tank size (gal) (I-4 $\pm 2 \%)$

- Energy input (Btu/hr) (I-7 $\pm 5 \%)$

- Energy output (Btu/hr) (I-7 $\pm 5 \%)$

- Recovery time (gal/hr) (I-4 $\pm 5 \%)$

- Outlet temperature range $\left({ }^{\circ} \mathrm{F}\right)\left(\mathrm{I}-7 \pm 10^{\circ}\right)$ 
- Heat pumps

- Type

+ Air to air

+ Air to 1iquid

+ Liquid to liquid

- Manufacturer's name

- Model name/number

- Coefficient of performance at std. operating conditions (C.OP) ( $F-3.2 \pm 5 \%$ )

- Useful therma1 output - heating (Btu/hr) (I-3 $\pm 5 \%)$

- Electrical imput - heating (kw) ( I-3 $\pm 5 \%)$

- Useful thermal output - cooling (Btu/hr) $(\mathrm{I}-3 \pm 5 \%)$

- Electrical input - cooling (kw) ( $\mathrm{I}-3 \pm 5 \%)$

- Air conditioners (state coefficient of performance - COP) (F-3.2 $\pm 5 \%$ )

- Type

+ Vapor compression

+ Rankine cycle

+ Sterling cycle

+ Absorption

+ Desiccant

- Manufacturer's name

- Model name/number

- Type of energy

+ Gas

+ Electric

- Design rate of energy input (kwh or Btu) (I-7 $\pm 5 \%$ )

- Total capacity (tons) (I-3 $\pm 5 \%)$

- Dehumidifier

- Manufacturer's name

- Model name/number

- Capacity ( $1 \mathrm{~b}$. water vapor/hr) $(\mathrm{I}-3 \pm 5 \%)$ 
- Resistance heater

- Manufacturer's name

- Model name/number

- Electrical input (kw) $(\mathrm{I}-4 \pm 5 \%)$

- Boiler

- Manufacturer's name

- Model name/number

- Energy type

$+0 i 1$

+ Gas

+ Electric

- Energy input (Btu/hr) (I-6 $\pm 5 \%)$

- Energy output (Btu/hr) (I-6 $\pm 5 \%)$

j. HVAC system operation

(1) System type

- Central air

- Single duct

+ Core

+ Perimeter

- Double duct

+ Core

+ Perimeter

- Multizone

+ Fan Coil

+ Induction

+ Radiation

- Variable air volume

- Hydronic/Air

- Fan Coil

+ Two pipe

+ Four pipe 
- Induction

+ Perimeter

+ Centra1

- Radiation

- Energy conservation

- Heat recovery

+ Heat recovery wheels

+ Heat pipes

+ Waste water heat

- Heat reclaim

- Energy storage

- Demand 1imiters

- Ventilation control

(2) Heat dissipation devices

- Evaporative condenser

- Air cooled condenser

- Cooling tower

- Liquid

- Air

(3) System operating temperature set points

- Heating

- Weekdays $\left({ }^{\circ} \mathrm{F} \&\right.$ number of hours/day) $\left(I-2 \pm 2^{\circ}\right)(\mathrm{F}-3.1 \pm 5 \%)$

- Week nights $\left({ }^{\circ} \mathrm{F} \&\right.$ number of hours/day) $\left(\mathrm{I}-2 \pm 2^{\circ}\right)(\mathrm{F}-3.1 \pm 5 \%)$

- Weekends ( ${ }^{\circ} \mathrm{F} \&$ number of hours/day) $\left(\mathrm{I}-2 \pm 2^{\circ}\right)(\mathrm{F}-3.1 \pm 5 \%)$

- Cooling

- Weekdays $\left({ }^{\circ} \mathrm{F} \&\right.$ number of hours/day) $\left(\mathrm{I}-2 \pm 2^{\circ}\right)(\mathrm{F}-3.1 \pm 5 \%)$

- Week nights ( ${ }^{\circ} \mathrm{F} \&$ number of hours/day) $\left(I-2 \pm 2^{\circ}\right)(\mathrm{F}-3.1 \pm 5 \%)$

- Weekends $\left({ }^{\circ} \mathrm{F} \&\right.$ number of hours/day) $\left(\mathrm{I}-2 \pm 2^{\circ}\right)(\mathrm{F}-3.1 \pm 5 \%)$ 
k. Freeze Protection

- Drain-down (air bleed)

- Drain-down (pressurized nitrogen backfill)

- Antifreeze

- Non-freezing fluid

- Freeze tolerant design (describe)

- Circulation of hot storage fluid

- Auxiliary heaters

- Use in non-freezing climates

1. Overheating Protection

- Collector shutters

- Energy dumping heat exchanger

- Air cooling

- Concentrator off-tracking device 


\section{DETAILED BUILDING DATA REQUIREMENTS FOR ROOM THERMAL LOAD CALCULATION}

1.0 Exterior Shell of Building

(a) Walls and Roof

Identify the overall U value, exposure designation, the materials used and thicknesses of all components comprising the exterior walls and roof of the building, starting with the interior surface and including all air spaces in the construction. State the solar absorptance (or the color) of the exterior surface. Repeat for each different wall or roof construction.

Example for Exterior Wall

- U value 0.08 (Btu/hr $\mathrm{ft}^{2}{ }^{\circ} \mathrm{F}$ ) (for roof state summer and winter value)

- Exposure designation walls 1,3 and 4 (see section 2, g, para. 4 for description)

- Construction

1/2 inch sheetrock

$31 / 2$ inch fiberglass insulation

$1 / 2$ inch plywood sheathing

4 inch face brick

- Solar absorptance $\underline{0.8}$

(b) Windows and Glass Doors

Identify the window or door type, location, dimensions, heat transfer and infiltration characteristics, internal and exterior shade devices for each type of window and glass door.

Example

- Window/door type metal frame, sliding, double glazed window

- Location walls 2,3 and 6




- U value $\underline{0.48}\left(\mathrm{Btu} / \mathrm{hr} \mathrm{ft}^{2}{ }^{\circ} \mathrm{F}\right)$

- Maximum infiltration rate 1.5 CFM c 15 MPH wind velocity

(usually certified by test) (state summer and winter values)

- Internal shading coefficient 0.57 (insulating glass with internal

venetian blind)

- External shade device overhang and vertical fin (provide drawings showing dimensions of shade devices and corresponding fenestration)

(c) Opaque Exterior Doors

Identify the door type, location, dimensions, heat transfer and infiltration characteristics for each type of opaque exterior door.

- Door type Wood door/frame, hinged with storm door

- Location Wall 1

- Dimensic.ss $3^{\prime}-0^{\prime \prime} \times 6^{\prime}-8^{\prime \prime}$

- U value $0.35\left(\mathrm{Btu} / \mathrm{hr} \mathrm{ft}^{2}{ }^{\circ} \mathrm{F}\right)$

- Maximum infiltration rate 2.0 CFM \& 15 MPH wind velocity (estimate based on primary door or storm door characteristics) (state summer and winter values)

\subsection{Interior Surfaces of Building}

(a) Floors and Ceilings

Identify the overall $\mathrm{U}$ value, materials used and thicknesses of all components of the floors and ceilings. Specify the occupancy of the space on the other side of the floor or ceiling as to thermal control i.e., state whether the other side of the floor or ceiling is another temperature controlled room or a non-controlled room such as an attic or basement.

\section{Example for Ceiling}

- $\mathrm{U}$ value $=\underline{0.05}\left(\right.$ Btu/hr $\left.\mathrm{ft}^{2}{ }^{\circ} \mathrm{F}\right)$

- Construction

$1 / 2$ incls sheetrock

6 incil fiberglass batt insulation

- Other side occupancy: Forced ventilated attic 
(b) Interior Walls

Identify the overall U value, materials used and thicknesses of all components of the primary interior walls. (Primary interior walls subdivide the floor into rooms or groups of rooms having the same thermal environments such as exterior exposure, equipment, lighting and occupant densities, and thermostat schedules.) Specify the occupancy of the space on the other side of the primary interior wa11.

\section{Example}

- $\mathrm{U}$ value $=\underline{0.43}\left(\mathrm{Btu} / \mathrm{hr} \mathrm{ft}^{2}{ }^{\circ} \mathrm{F}\right)$

- Construction

$1 / 4$ inch wood paneling

1/2 inch sheetrock

$31 / 2$ inch air space

$1 / 2$ inch sheetrock

- Other side occupancy similar room

\subsection{Room Internal Heat Release}

(a) Lighting

- Maximum load (watts/ft ${ }^{2}$ ) during weekday

- Operating schedule (24 hour profile normalized to maximum load) weekdays

weekends holidays

(b) Appliances and Equipment

- Maximum load (watts $/ \mathrm{ft}^{2}$ ) exclusive of HVAC equipment during weekday

- Operating schedule (24 hour profile normalized to maximum load)

$$
\begin{aligned}
& \text { weekdays } \\
& \text { weekends } \\
& \text { holidays }
\end{aligned}
$$

(c) Occupants

- maximum number of adult occupants (count a child as half an adult) during weekday 
- Occupancy Scliedule (24 hour profile normalized to maximum number of occupants)

weekdays

weekends

holidays

4.0 Room Temperature, Humfdity and Ventilatior. Requirements

(a) Room Temperature $\left({ }^{\circ} \mathrm{F}\right)$

- 24 hour profile of room thermostat setting during the occupied cooling day

- 24 hour profile of room thermostat setting during the occupied heating day

- Upper limit on room thermostat setting during the unoccupied cooling day

- Lower limit on room thermostat setting during the unoccupied heating day

(b) Room Humidity $\left({ }^{\circ} \mathrm{F}\right)$

- Upper limit on room relative humidity setting during the cooling day

- Lower limit on room relative humidity setting during the heating day

(c) Koom Ventilation

- Maximum outdoor air temperature for use during the occupied period to reduce the cooling load $\left({ }^{\circ} \mathrm{F}\right)$

- Flow rate of outdoor air for natural cooling during occupied day (CFM)

- Minimum and maximum outdoor temperature for use during non-occupied period to reduce cooling load $\left({ }^{\circ} \mathrm{F}\right)$

- Flow rate of outdoor air for natural cooling during unoccupied day (CFM) 


\subsection{Collectors}

- collector effective aperture area $\left(\mathrm{ft}^{2}\right)$

- collector geometry efficiency factor **

- flutd thermal capacitance (Btu/1b - ${ }^{\circ} \mathrm{F}$ )

- collector plate absorptance

- collector loss coefficient (Btu/h $-{ }^{\circ} \mathrm{F}-\mathrm{ft}^{2}$ )

- transmittance of the $\mathrm{N}$ cover(s)

- number of covers

- collector plate emittance

- loss coefficlent for bottom and edge losses $\left(\mathrm{Btu} / \mathrm{h}-{ }^{\circ} \mathrm{F}-\mathrm{ft}^{2}\right.$ )

- collector tilt and orientation (clegrees from horizontal and south, respectively)

- product of the extinction coefficient and the thickness of each cover $* *$

\subsection{Storage}

(a) Stratified Fluid Storage (with optional internal heater)

- tank volume $\left(\mathrm{ft}^{3}\right)$

- tank height (ft)

- specific heat of the fluid (Btu/lb - ${ }^{\circ} \mathrm{F}$ )

- fluid density $\left(1 \mathrm{~b} / \mathrm{ft}^{3}\right)$

- loss coefficient between the tank and the environment (Btu/h $\left.-\mathrm{ft}^{2}-{ }^{\circ} \mathrm{F}\right) * *$

- maximum rate of energy input by the heating element (kw) **

- number of the tank segment in which the heating element is located **

- number of the tank segment in which the thermostat of the heating element is located **

- set temperature of the heating element thermostat $\left({ }^{\circ} \mathrm{F}\right)$

- time of day ( 0 to 24.0 ) at which the heating element may begin t's function **

- time of day beyond which the heating element cannot function ** 
(b) Rock Bed Thermal Storage

- capacitance of air (Btu/1b - $\left.{ }^{\circ} \mathrm{F}\right)$

- effective length of rock bed in flow direction (ft)

- cross-sectional area of rock bed $\left(\mathrm{ft}^{2}\right)$

- perimeter of rock bed (ft)

- capacitance of rock (Btu/1b - $\left.{ }^{\circ} \mathrm{F}\right)$

- apparent rock bed density ( $\left.1 \mathrm{~b} / \mathrm{ft}^{3}\right)$

- loss coefficient (Btu/h- $\left.\mathrm{ft}{ }^{2}-{ }^{\circ} \mathrm{F}\right) * *$

- effective thermal conductivity in the axial direction $\left(\mathrm{Btu} / \mathrm{h}-\mathrm{ft}-{ }^{\circ} \mathrm{F}\right){ }^{* *}$

\subsection{Energy Transport}

(a) Pumps and fans

maximum flow rate

(b) Heat Exchangers

- Type

- parallel flow

- counter flow

- cross flow

- constant effectiveness

- overall heat transfer coefficient of exchanger (Btu/h $\left.-\mathrm{ft} \mathrm{t}^{2}{ }^{\circ} \mathrm{F}\right)$

- heat exchanger effectiveness

- specific heat of hot side fluid (Btu/1b - ${ }^{\circ} \mathrm{F}$ )

- specific heat of cold side fluid (Btu/1b- ${ }^{\circ} \mathrm{F}$ )

(c) Pressure Relief Valve

- boiling point of fluj.d ( $\left.{ }^{\circ} \mathrm{F}\right)$

- $\quad$ specific heat of fluid $\left({ }^{\circ} \mathrm{F}\right)$

4.0 Controls

(a) On/Off Differential Controller with Hysteresis

- upper dead band difference $\left({ }^{\circ} \mathrm{F}\right) \quad * *$

- lower dead band difference $\left({ }^{\circ} \mathrm{F}\right) \quad * *$ 
(b) Three Stage Room Thermostat

- Minimum solar source temperature for solar source utilization $\left({ }^{\circ} \mathrm{F}\right) \quad * *$

- Room temperature above which room is to be cooled $\left({ }^{\circ} \mathrm{F}\right) * *$

- Room temperature below which lst stage heating is commanded $\left({ }^{\circ} \mathrm{F}\right) * *$

- Room temperature below which 2 nd stage heating is commanded $\left({ }^{\circ} \mathrm{F}\right) * *$

\subsection{Auxiliary Energy Source}

(a) On/Off Auxiliary Heater

- maximum heating rate $(B t u / h)$

- set temperature $\left({ }^{2} \mathrm{~F}\right) * *$

- dead band temperature differential $\left({ }^{\circ} \mathrm{F}\right) * *$

- specific heat of fluid (Btu/1b - $\left.{ }^{\circ} \mathrm{F}\right)$

(b) Heat Pump (see Figure B-1)

- specific heat of liquid entering heat exchanger $A$. (Btu/Ib - $\left.{ }^{\circ} \mathrm{F}\right)$

- mass flow rate of liquid entering heat exchanger $A\left(B t u / 1 b-{ }^{\circ} \mathrm{F}\right) \quad * *$

- constant room temperature for heating mode $\left({ }^{\circ} \mathrm{F}\right) * *$

- constant room temperature for cooling modes $\left({ }^{\circ} \mathrm{F}\right) * *$

- minimum liquid source temperature for water-air heating operation $\left({ }^{\circ} \mathrm{F}\right) * *$

- minimum air source temperature for air-air heating operation $\left({ }^{\circ} \mathrm{F}\right) * *$

- number of equally spaced heating data points (See heat pump performance data required, p. 56). $* *$

- number of equally spaced cooling data points (See heat pump performance data required, p. 56). **

- minimum ambient temperature when cooling is allowed $\left({ }^{\circ} \mathrm{F}\right) * *$

- $\dot{M C}_{\mathrm{p}}$ product for room air flowing through heat exchangers $\mathrm{C}, \mathrm{D}$ and $\mathrm{E}\left(\mathrm{Btu} / \mathrm{h}-{ }^{\circ} \mathrm{F}\right) *^{*}$

- effectiveness of heat exchanger $\mathrm{C} * *$

- minimum liquid source temperature for direct heating from liquid source $\left({ }^{\circ} \mathrm{F}\right)$

- heat exchanger selection integer; 0 = heat exchanger $A, 1=$ heat exchanger $\mathrm{B} * *$

- maximum ambient air temperature when heating is allowed $\left({ }^{\circ} \mathrm{F}\right) * *$

- Heat pump performance data required

The user must supply the model with performance data for both the heating 


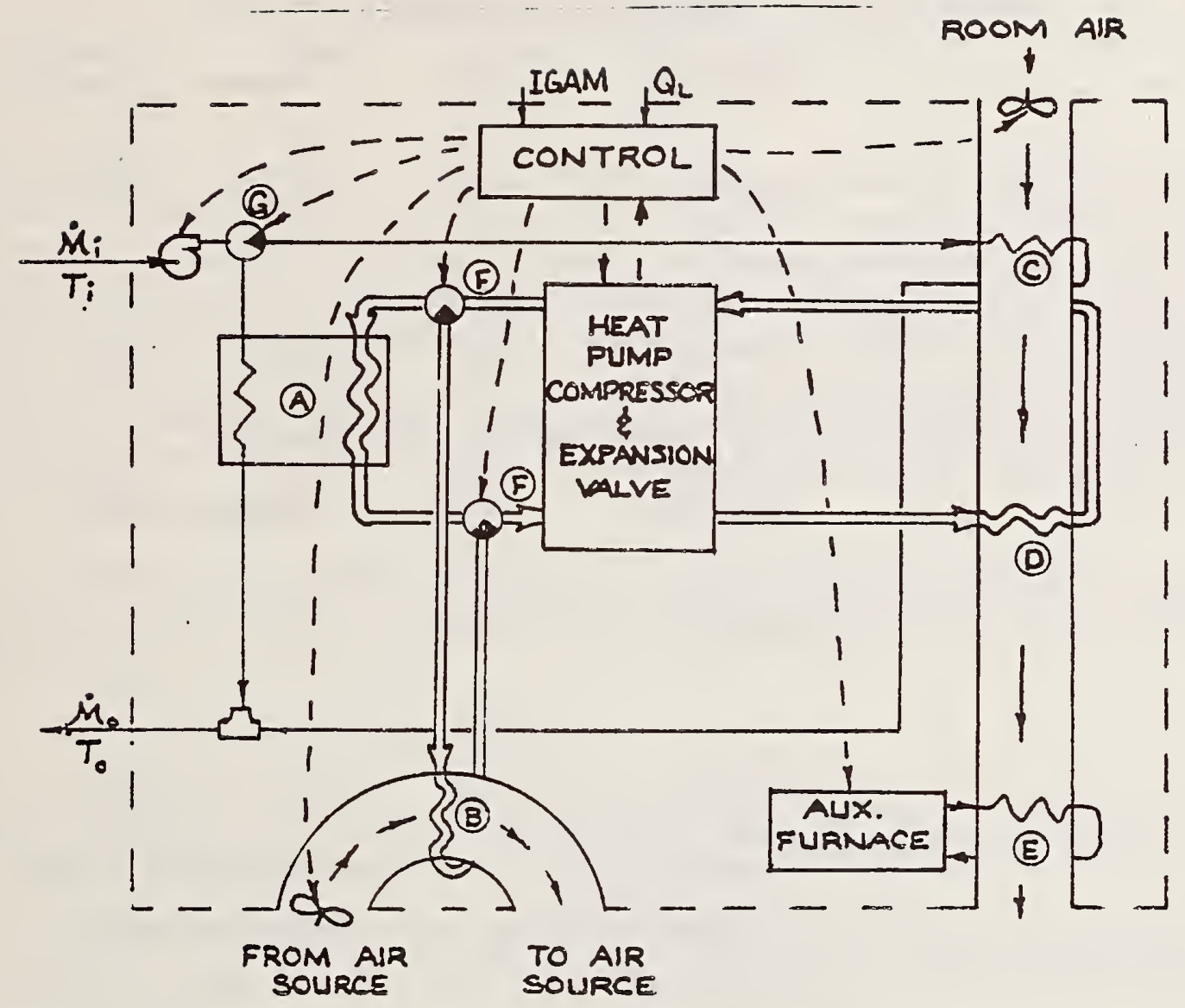

F1gure $\bar{D}-I$ Heat Pump Model Schematic.
(A) Water to refrigerant heat
(D) Refrigerant to air heat exchanger
(B) Air to refrigerant heat
(E) Auxiliary heat exchanger exchanger
(F) Refrigerant diverter vaives
(C) Direct heating heat ex-
changer
G Liquid source diverter valve 
and the cooling modes. This data must be in the following form:

Heating Data File (at constant condenser inlet temperature)

$\begin{array}{cccc}\begin{array}{ccc}\text { Evap. Fluid } \\ \text { Inlet Temp. }\end{array} & \begin{array}{c}\text { Energy } \\ \text { to Evap. }\end{array} & \begin{array}{l}\text { Energy } \\ \text { to Condenser }\end{array} & \begin{array}{c}\text { Power } \\ \text { Input }\end{array} \\ \mathrm{T}_{\mathrm{E}} & \mathrm{QA}_{0} & \mathrm{QR}_{0} & \mathrm{WA}_{0} \\ \mathrm{~T}_{\mathrm{E}}+\Delta \mathrm{T}_{\mathrm{H}} & \mathrm{QA}_{1} & \mathrm{QR}_{1} & { }^{\mathrm{WA}}{ }_{1} \\ \vdots & \vdots & \cdot & \cdot \\ \vdots & \vdots & : & \cdot \\ \mathrm{T}_{\mathrm{E}}+\mathrm{N} \Delta \mathrm{T}_{\mathrm{H}} & \mathrm{QA}_{\mathrm{N}} & \mathrm{QR}_{\mathrm{N}} & \mathrm{WA}_{\mathrm{N}}\end{array}$

Cooling Data File (at constant evaporator inlet temperature)

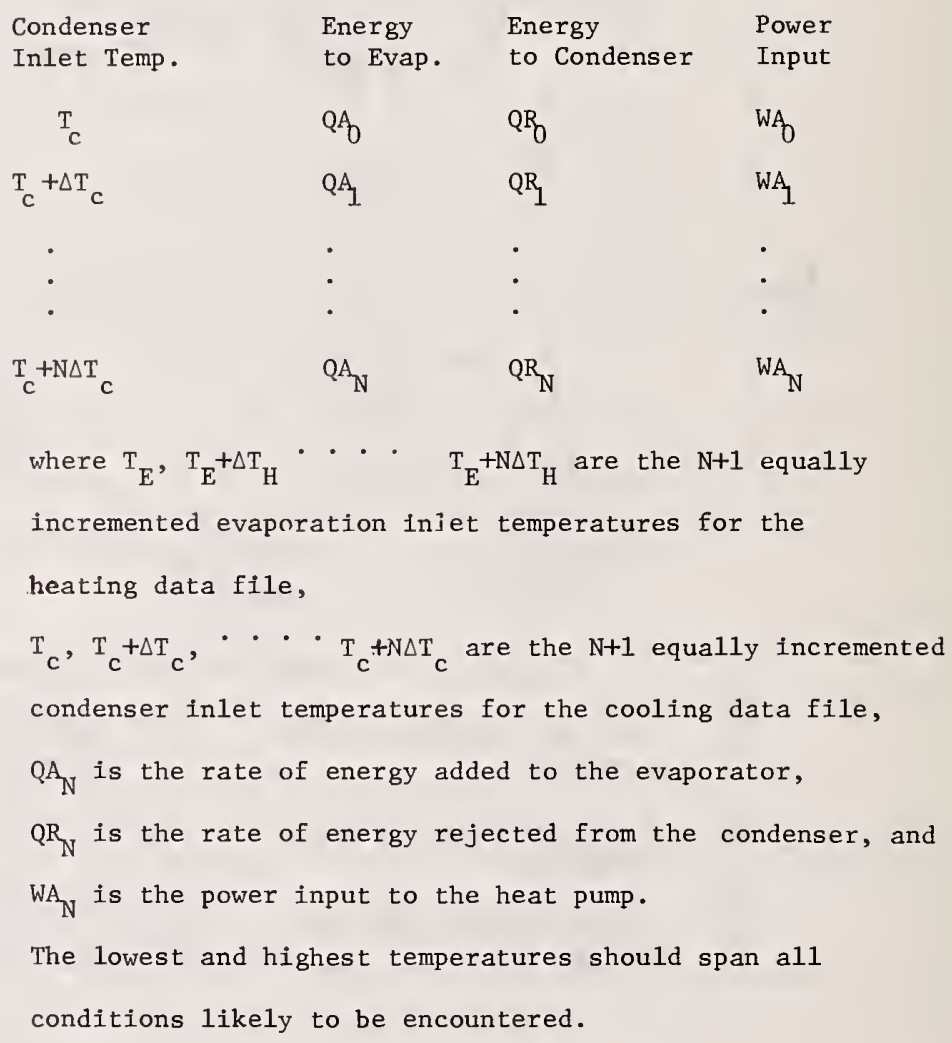

(c) Absorption Chiller

- residence heat gain constant

- room temperature setting $\left({ }^{\circ} \mathrm{F}\right)$

- constant internal heat generation

- nominal capacity of air conditioner (tons) 


\section{OPERATIONAL DATA REQUIREMENTS}

\subsection{INTRODUCTION}

The primary vehicle for identifying solar hardware failures and problems that occur during the operational phases of the solar demonstrations program is the report of maintenance performed on individual solar hardware systems. These reports will specify the actual steps taken to identify and correct problems which caused the solar system to malfunction or to be inoperative. This part will describe how these maintenance reports are to be used and how the data on them will be transcribed for data processing. These data are expected to reveal various operational problems that are peculiar to solar systems and to certain hardware components. These data are also intended to characterize system failures and problems in such a manner that they can be correlated with the building/site/solar hardware system parameters identified in Part Two of this report.

Most of the basic data will be collected by maintenance contractors who will be called in to repair system malfunctions. These maintenance data will be reported on the Maintenance Service Call Report (Form 1, Part One).

Four types of basic data are required by this form:

1. The operational problems and malfunctions (termed events in this report) identified by the maintenance contractor.

2. The repair procedures (termed actions in this report) used in eliminating the problems or malfunctions.

3. The hardware items affected by the events and on which the actions were performed.

4. Costs, downtimes and service times evolving from the performance of the actions.

This part includes listings of standard terms (dictionaries) for the events, actions and hardware items. These terms are to be used in recording the data from the maintenance report. Since the data on the maintenance report are not in the most suitable form for computer processing, a transcription process is required. This process is critical to the development of a reliable and unambiguous data base for future analyses.

The transcription of the maintenance data involves the conversion of the language of the maintenance report to standard terms, the organization of the data to show interrelationships and the encoding and entering of the data elements in a suitable computer format on transcription forms. The transcription method is described in section 3.0, and an example of the transcription method is shown in section 3.5 . The assignment of the actual codes to the standard terms in the dictionaries are beyond the scope of this report, but they will be available when they are needed. In the transcription procedures described below, it is these codes that will be used to describe the maintenance data for computer input. 


\subsection{Purpose of Dictionaries}

The four dictionaries provided in this part are to be used for three purposes:

- Source of standard terms for data identification.

- Aid in transcribing the basic data from the maintenance report.

- Aid in pinpointing the primary cause of a problem.

\subsection{Event Dictionary}

Table 3.1* is a listing of events covering a broad area of possible malfunctions and operating problems such as might be identified during routine maintenance and emergency repair actions. This listing is subdivided into the following categories to facilitate its use.

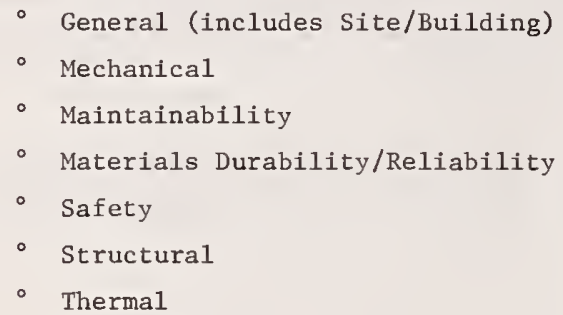

In general, the terms listed are oriented toward describing either the malfunction(s) or the cause of the malfunction(s) in the system, the building or the site surrounding the building. Some terms, especially those in the maintainability and safety categories, are oriented primarily toward identification of existing or potential problems or hazards.

\subsection{Maintenance Actions Dictionary}

Table 3.2 is a listing of the actions which will be taken to eliminate the causes of malfunctions. In general, the action taken will be a positive response to one or more of the events listed in the Event Dictionary. In some cases, no action will be taken but action is recomended. These cases will primarily involve safety and maintainability events which describe potential hazards and maintenance problems.

\subsection{Site/Building Element Dictionary}

Table 3.3 is a listing of site and building elements which might affect or be affected by solar hardware system operation. This list is shown schematically in figure 3.1 in the form of a logic tree.

\subsection{Solar Hardware System Dictionary}

Table 3.4 is a listing of all the solar hardware elements in the system. This list is organized in a format coinciding with the Hardware Logic Tree shown as figure 3.2. The various branches of the logic tree are identified by their "level" in the tree and on the list. The "level numbers" are used only for organizational purposes and do not indicate level of importance. 


\subsection{Introduction to the Transcription Process}

In the discussion which follows, it should be noted that the term "hardware" is used to indicate any element listed in either the Site/Building or the Solar Hardware System dictionary. It should also be noted that the term "maintenance item" indicates one unit of maintenance data consisting of an event and its associated hardware element and action, if any.

The transcription process involves five operations:

1. Identification of the various events, actions, and associated hardware elements (maintenance items) which were described on the maintenance report.

2. Translation of the maintenance item terms used on the maintenance report to the standard terms listed in the four dictionaries.

3. Encoding of the data for computer processing. (Codeswill be supplied 1ater)

4. Organization of the maintenance items into logical groupings.

5. Entering of all the maintenance data on a transcription form.

In general, it is expected that each maintenance report will describe a series of events involving several hardware elements and one or more actions. In some cases, only one event involving one element may be described. In other cases, more than one event involving only one element may be described. In addition, an action may not always be taken on a hardware element for each event.

It should be noted that one maintenance report may include more than one group of events and may also include one or more isolated events which are unrelated to any other event.

As an aid in the transcription process, a set of three worksheets are presented. They are:

$$
\begin{aligned}
& \text { Worksheet A - Summary of Maintenance Data } \\
& \text { Worksheet B - Grouping and Ranking Table } \\
& \text { Worksheet C - Transcription Form }
\end{aligned}
$$

The data entered on each set of worksheets should meet the following rules:

1. Each event and associated hardware element and action must have been recorded for the same maintenance call on the same solar hardware system.

2. Each event must be associated with one or more specific hardware elements identified in either the Site/Building or the Solar Hardware System Dictionary. 


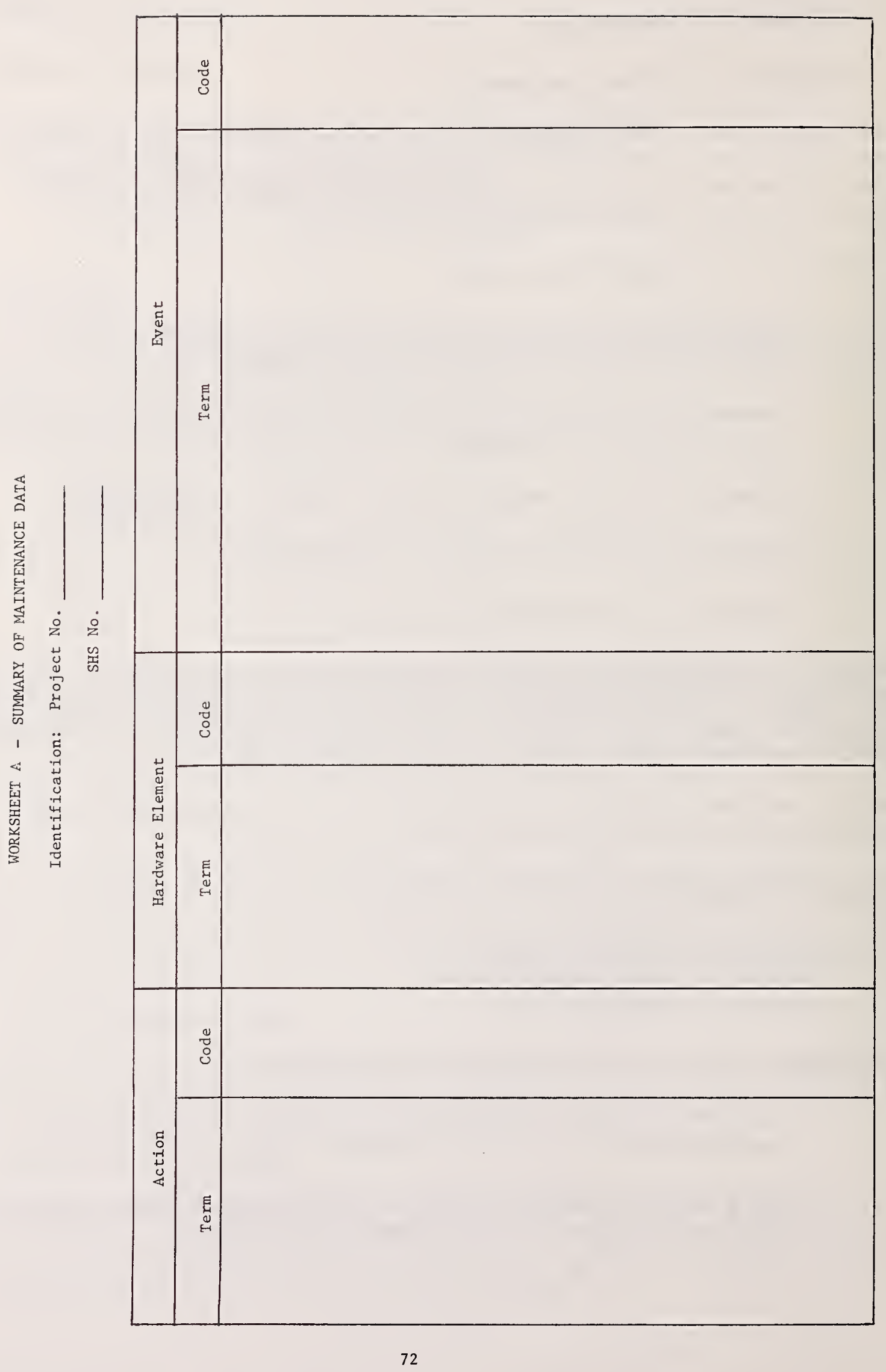




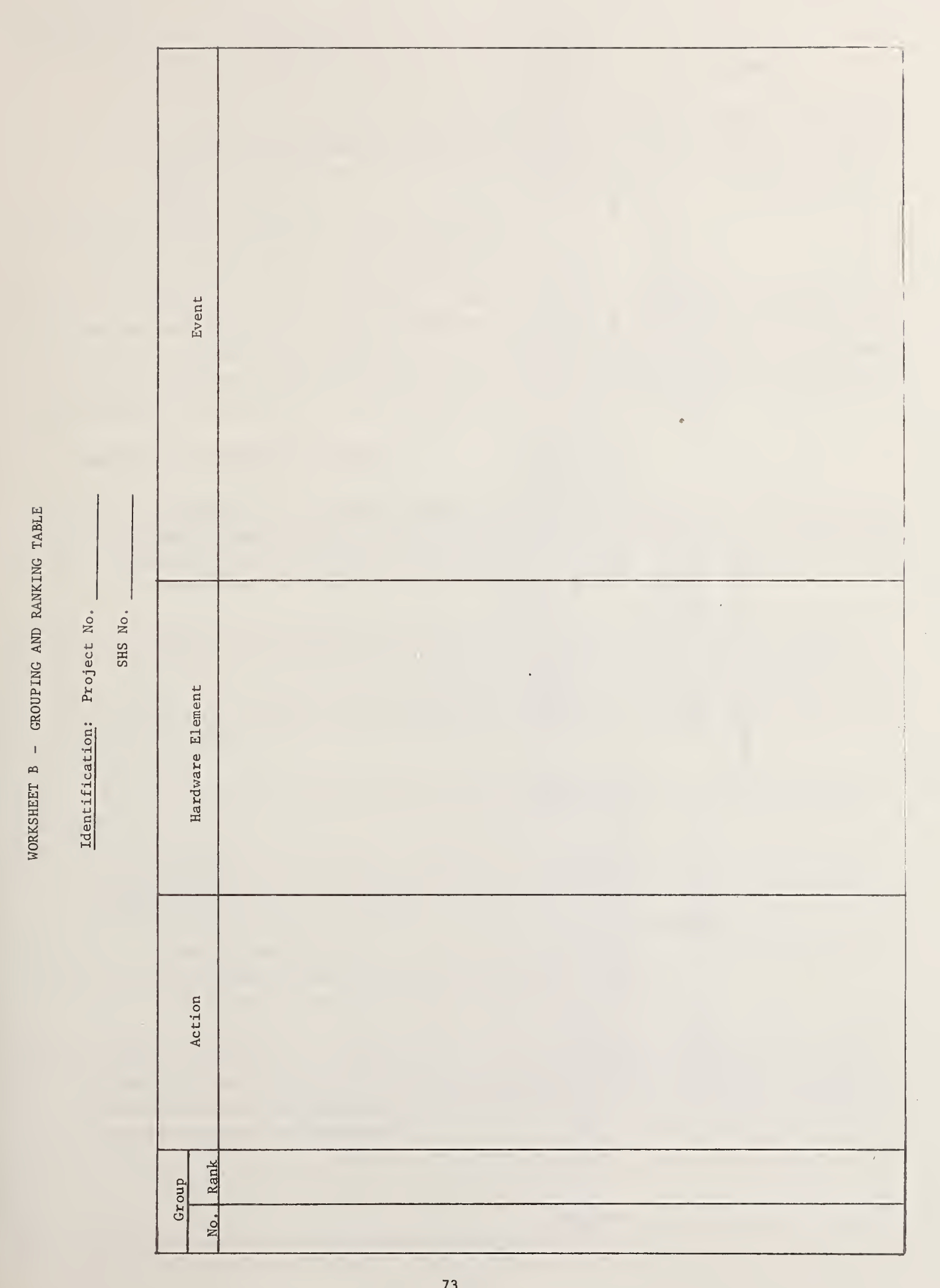




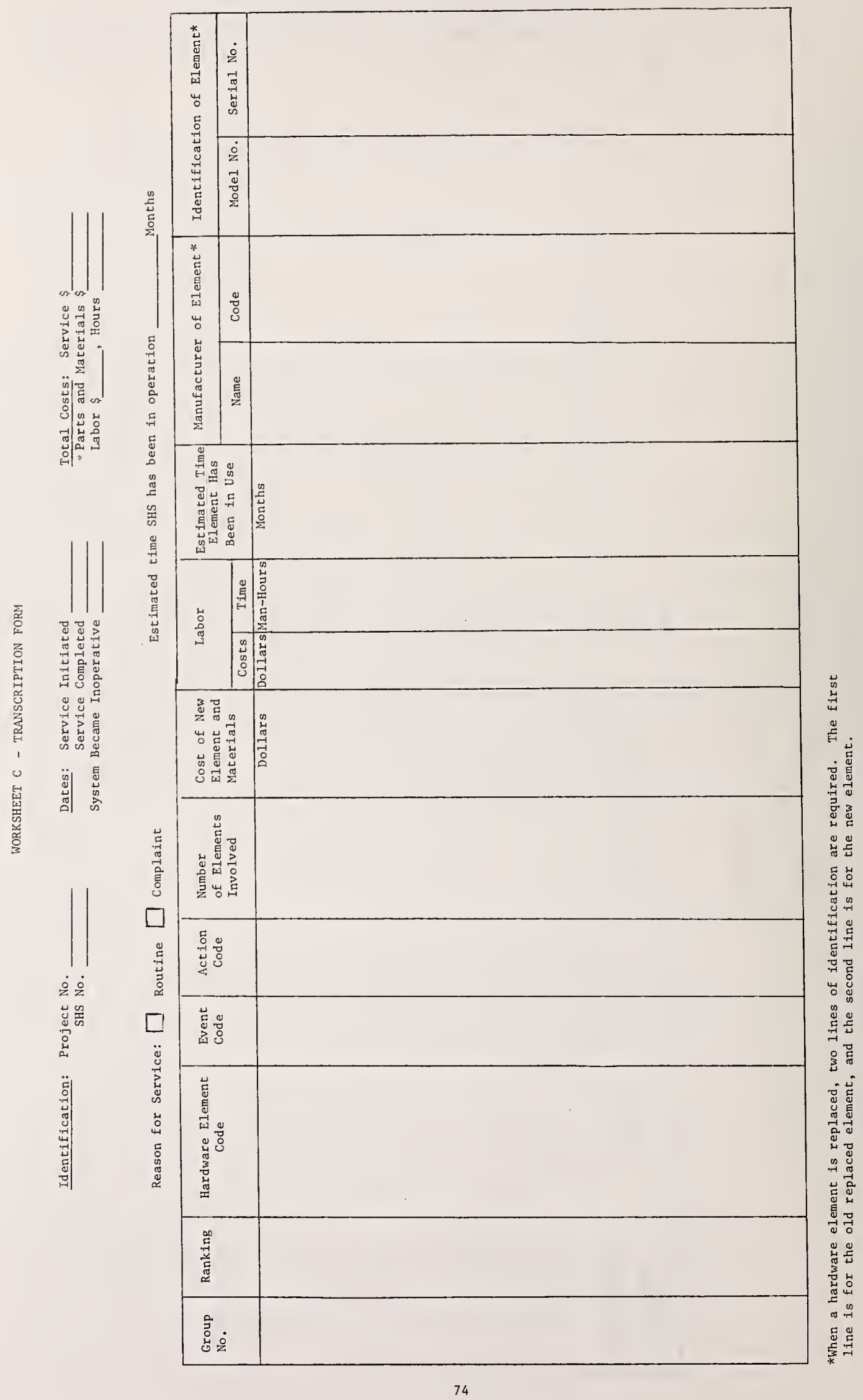


3. Each action must always be associated with an event and a hardware element.

4. Only one event and associated hardware element and action may be entered on any one 1 ine of the worksheets. When more than one event occurs to a hardware element, each event along with its associated hardware element and action, if any, is to be entered on a separate line.

\subsection{Identification and Translation of the Maintenance Items}

The data on the maintenance report will consist, in part, of a series of maintenance items which describe any actions that were performed, the hardware elements that were involved and the events that occurred to the elements. Each such maintenance item should be identified and recorded on one line of Worksheet A, using the standard terms. (When the codes become available, it would be convenient to record them on this worksheet).

\subsection{Organization of the Maintenance Items}

To ensure that the cause/effect relationships between the various events, actions and hardware elements can be recovered during computer analysis, the maintenance items should be organized in a predetermined manner. The organization method described below involves the segregation of the maintenance items into groups.

A group of maintenance items is defined as an entity in which each event within the group must have a cause/effect relationship with another event in the group (except when the event can be identified as an isolated event). That is, each event must have either caused, or been caused by, another event within the group, either directly through the domino effect, or indirectly through a maintenance action which caused an event to occur.

To assist the transcriber in grouping and ranking the maintenance items, the following steps should be followed:

Step 1 - Using the standard terms from the dictionaries, list, as described above, in the appropriate columns of Worksheet A the following:

a. All those hardware elements that are discussed in the Maintenance Service Call Report (Form 1, Part One)

b. The actions, if any, performed on those hardware elements.

c. The events associated with these hardware elements.

Step 2 - Identify on Worksheet A, by underlining the action, those maintenance items which include actions and which did not cause any of the other items on the list to occur. (Maintenance items on the 1 ist which caused other maintenance items should be considered to be associated items and should not be underlined). 
Step 3 - List on Worksheet B the first maintenance item underlined on Worksheet A.

Step 4 - Identify all the maintenance items on Worksheet A which are associated (i.e., in a cause/ effect relationship) with the item identified in step 3.

Step 5 - Develop a scenario in which the maintenance items identified in Step 4 are listed in descending order of cause and effect (i.e., Item 1 was caused by Item 2, which in turn was caused by Item 3, etc. The Hardware Logic Trees (figures 3.1 and 3.2) may be used as a guide in sequentially ordering these items).

Step 6 - On Worksheet B under the item of Step 3, list the items identified in Step 4 in the order developed in Step 5 .

Step 7 - Repeat Steps 3, 4, 5, and 6 for each maintenance item underlined in Step 2 .

Step 8 - Assign sequential numbers (i.e., 1, 2, 3, etc.) in the group number column to those items identified in Step 2.

Step 9 - Assign sequential numbers in the rank number column to each item within each group.

When these steps are completed, all the maintenance items listed on Worksheet A will have been entered and segregated into groups on Worksheet B. It is probable that some maintenance items will be entered under more than one of the items identified by step 2 .

\subsection{Entering of Maintenance Data to a Transcription Form}

Generally, this process consists of transferring the data from Worksheet $B$ to the transcription form (Worksheet $C$ ) in a systematic way and entering certain additional data for each maintenance item. The additional data consist of the associated costs, time and hardware identification data. Most of the data required by Worksheet $C$, except for the maintenance items, are transferred directly from the maintenance report. The maintenance item data will be entered in coded form together with the group and rank numbers assigned on Worksheet B. (Codes will be assigned to each item in the dictionaries as part of the design of the data base.)

In cases where the hardware elements were removed and replaced with new alements, the following special procedure applies:

Two lines on Worksheet $C$ for hardware identification data are required. One for the old replaced element and the second for the new element.

An example of the transcription process is given in section 3.5, which follows. 


\subsection{Introduction}

The purpose of this section is to provide an example of the transcription process described in section: 3.3 and 3.4 by using a sample Maintenance Service Call Report given in figure 3.3 . The information in this sample report provided the data needed to complete the sample Worksheets $A$, B, and $C$ presented as figures $3.4,3.5$, and 3.6

\subsubsection{Completion of Worksheet A}

The initial step in the transcription process, as outlined in section 3.3 , is to identify each maintenanceitem. Then, to list the standard terms for the hardware element, event, and action which descriluc: each maintenance item. This procedure was used to fill out the sample Worksheet A (figure 3.4 ) from the sample maintenance report (figure 3.3). Each line of data on this Worksheet A represents one maintenance item.

Referring to the sample report, it is clear that the hardware elements were listed because they were mentioned in the sample report as being associated with either a cause or an effect of a malfunction which required maintenance action. Collector was not listed because, although it was malfunctioning (low thermal output) because of a fogged window, the problem was eliminated by performing a maintenance action on the collector window rather than on the whole collector unit.

(In practice Worksheet A would be completed at this time by entering the codes for the standard terms. For this example the codes given in the sample worksheets are fictitious since the actual codes have not been assigned.)

\subsubsection{Completion of Worksheet B}

Using the steps given in section 3.3 of this report, the groups of maintenance items were determined by completing sample Worksheet B (figure 3.5). Based on the criteria given in Step 2 , two maintenance items, with actions, were identified as not being the cause of any other maintenance item listed on Worksheet A. These were "replace ceiling," and "replace sealant." It is clear from the information in the sample maintenance report that the damaged ceiling was a consequence of the burst pipe and that it did not, in turn, cause any other maintenance item listed on Worksheet A to occur. The damaged sealant was the effect of cleaning the window and likewise did not cause any of the other 1 isted items to occur.

"Replace ceiling" was listed first on Worksheet B in accordance with Step 3. As per Step 4, "replace pipe" and "replace fluid" were identified as maintenance items which were related through a cause/effect relationship with the damaged ceiling. In accordance with Steps 5 and 6 these were then listed under damaged ceiling as follows and entered on Worksheet B.
(1) "Replaced Pipe"
(2) "Replaced Heat Transfer Fluid"

In a similar manner, Steps 3, 4, 5, and 6 were repeated for "replace sealant." 


\subsubsection{Completion of Transcription Form}

The final step in the transcription process was to enter the required information on the sample Transcription Form, Worksheet C (figure 3.6). The groups of maintenance items were transferred from Worksheet $B$ to Worksheet $C$ in the same order as they were listed on Worksheet B. The additional information needed to fullydescribe the maintenance action performed on each hardware element was obtained from the sample maintenance report and placed in the applicable columns on Worksheet $\mathrm{C}$ as shown in figure 3.6. The entering of the information requested at the top of the worksheet completes the Transcription Form. 
Damaged by

Accident

Electrical short

Freezing

Leakage of moisture or rain

Leakage of system fluids

Between components

From system

Lightning

Maintenance aćtion

Soil erosion because of inadequate overflow provisions

Storm water run-off provisions

Vandalism

Falled to operate because it was

Broken

Burned out

Burst

Clogged or blocked

Worn out

Failed to operate because of outage of Electricity

Gas

0 il

Water

Operating, but improperly, because of

Deposition of

Condensation product

Moisture

Solid

Dust or dirt on exterior surfaces

Dust or dirt on interior surfaces

Gum or varnish

Precipitated matter

Sedimentation

Incorrect

Adjustment

Alignment

Capacity

Installation

Leakage of air

Solar shading from

off-site obstruction

On-site obstruction

Restrains use because of noise from Fluid movement

Vibration

Water hammer

Restricts use of living space because of Encroachment

Excessive air movement

Leakage of air

Odors

Solar reflection

Thermal radiation

Restricts use of outdoor space because of Fluids escaping

Solar reflection

Thermal radiation

\section{Mechanical \\ Filtration inadequate}

Flow rate was

Higher than design

Lower than design

Flow regulation inadequate

Flow sequencing not according to design for

Direction

Scheduling

Flow unbalanced

Fluid volume excessive because of inadequate provision fo: Boiling

Thermal expansion

Friction excessive because of

Foreign matter

Improper materials

Inadequate bearing surfaces

Inadequate clearance

Inadequate lubrication

overflow provisions inadequate

over loaded

Electrically

Mechanically

Passage size

Larger than design

Smaller than design

Pressure buildup higher than design during

No flow conditions

Normal operating conditions

Leakage runoff provisions inadequate

Leaking

Pressure during operation

Higher than design

Lower than design

Pressure regulation inadequate

Pressure relief inadequate

Support inadequate causing

Improper drainage

Joint failure

Low spots or sagging

Thermal movement causes excessive

Contraction

Differential movements

Expansion

Vacuum higher than design

Because of inadequate relief

Vacuum lower than design

Because of outgassing

Because of leakage

Vibration excessive because of

Inadequate, or lack of, equipment vibration

isolators

Inadequate, or lack of, water hammer arrestors

Volume insufficient

Volume too large 


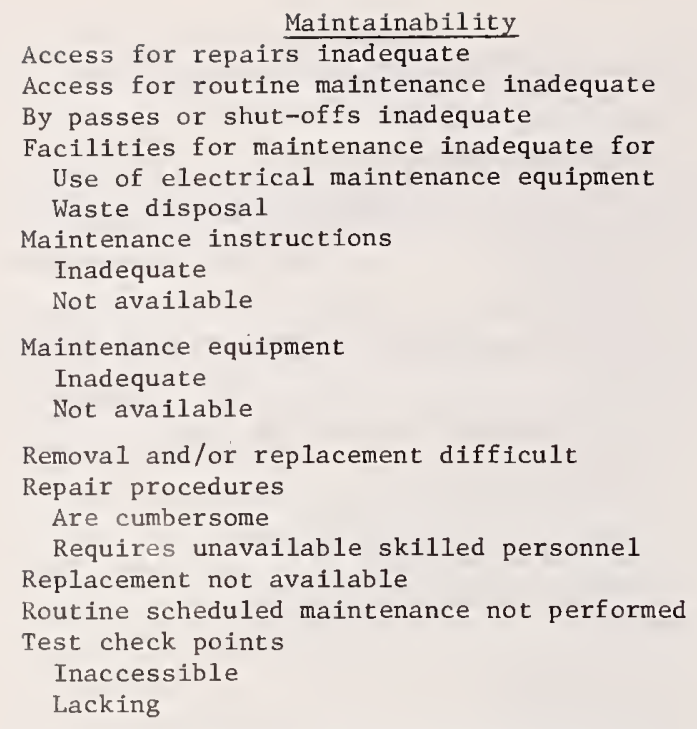

Attack by

Materials Durability/Reliabllity

Airborne Pollutant of

Hydrogen chloride (HCL)

Nitrogen oxides $\left(\mathrm{NO}_{\mathrm{X}}\right)$

Ozone

Salt spray

Sulphur dioxide

Other

Fungi

Soil

Ultra violet radiation

Vermin

Corroded by contact between

Decomposition product and metal

Dissimilar metals

Fluid \& dissimilar metals

Fluid and metal

Deterioration by

Bloating

Bond failure

Deposition of outgassed volatiles

Embrittlement

Loss of homogeneity

Precipitation

Segregation

Moisture buildup

$\mathrm{pH}$ change

Plastic flow

Softening

Surface degradation

Blistering

Cracking

Discoloration or staining

Pitting

Viscosity change

Eroded by

Airborne particulate

Fluid

Foreign matter

\author{
Failed by \\ Creep rupture \\ Excessive dimensional change \\ Freezing \\ Moisture degradation \\ Thermal cycling \\ Thermal degradation \\ Thermal shock from \\ Cold fluid on hot surface \\ Hot fluid on cold surface \\ Violent boiling \\ Wet-dry cycling
}

\section{Safety}

Fire damage (or potential damage), caused by Auto ignition temperature exceeded

Electrical arcing and/or short

Fire stops ineffective or missing

Flash point temperature exceeded

Inadequate clearance

Between combustibles and heated hardware

Between flammable fluid and spark source Overheated equipment

Solar radiation concentration

Personal injury

Allergy

Broken bone

Burn

Cut

Electric shock

Poisoned

Scratch

Strain

Person Injured

Occupant

Maintenance person

Passer by

Safety hazards (other than fire)

Access, emergency

Blocked

Inadequate

Lacking

Contact possible with

Hot fluids

Hot surfaces

Toxic sutstance

Inhalation

Drinking

Skin contact

Contamination of soil

Contamination of potable water supply by

Direct contact with toxic material

Inadequate separation of circulation loops

Improper design of toxic fluid discharge or overflow

No provision for toxic fluid leakage or overflow

Egress, emergency

Blocked

Inadequate

Lacking

Exposed sharp edges

Moving parts inadequately protected

Shut offs, emergency

Inaccessible

Inconspicuous

Lacking 
Table 3.1 Events Dictionary (continued)

Structura1

Deflections were excessive

Horizontally

Vertically

Dimensional changes were excessive because of

Creep

Differential settlement

Drying shrinkage

Moisture expansion

Thermal effects

Failed by

Bending

Buckling

Bulging

Fatigue

Fracture

Brittle

Ductile

overloaded by

Accidental loads from

Anima 1

Debris, falling

Debris, wind blown

Human

Vehicle

Dead loads

Extreme environmental loads from

Earthquake

Flood

Winds

Hurricane

Tornado

Live loads from

Equipment (Solar hardware)

Hail

Ice

Maintenance equipment or actions

Ponding of water

Snow

Vehicle

Wind

Buffeting

Horizontal

Uplift

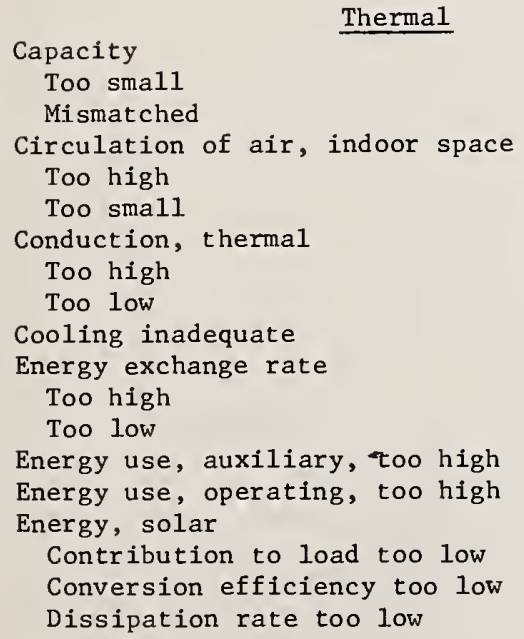

Thermal

Capacity

Too small

Mismatched

Circulation of air, indoor space

Too high

Too small

Conduction, thermal

Too high

Too low

Cooling inadequate

Energy exchange rate

Too high

Too low

Energy use, auxiliary, too high

Energy use, operating, too high

Energy, solar

Contribution to load too low

Conversion efficiency too low

Dissipation rate too low

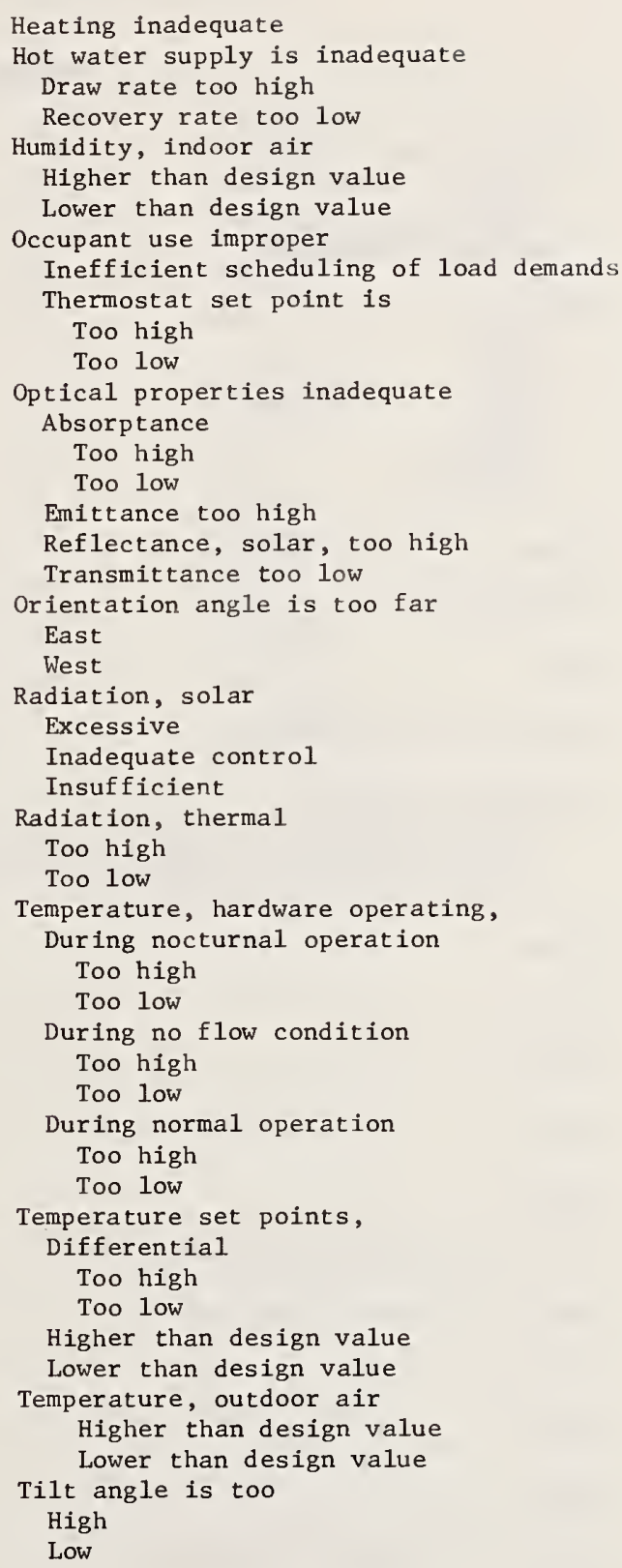

Hot water supply is inadequate

Draw rate too high

Recovery rate too low

Higher than design value

Lower than design value

Thermostat set point is

Too high

Absorptance

Too high

Transmittance too low

ientation angle is too far

East

Excessive

Inadequate control

sufficient

Too high

Too $10 \mathrm{w}$

emperature, hardware operating, Too high

Too high

Too high

Too low

Temperature set points,

Higher than design value

Lower than design value

High 
Table 3.2

Maintenance Actions Dictionary

Add

Antifreeze

Fluid

Inhibitor

Additional Hardware

Adjust

Bleed

Clean

Reset

Thaw

Tighten

Lubricate

Braze

E1iminate

None

None but action required

Occupant instructed

On the proper use of system

On the relationship between fenestration

control and energy consumption

Other

Recoat

Remove

Repack

Repaint

Replace with identical item

Replace with substitute item

Relocate

Reseal

Retape

Routine or scheduled maintenance

Solder

Weld 
Table 3.3 Site/Building Element Dictionary

$\underline{\text { Leve } 1}$

$\begin{array}{lc}1 & \text { Site/Building } \\ 2 & \text { Site } \\ 3 & \text { Surface Drainage } \\ 4 & \text { Utilities } \\ 4 & \text { Water } \\ 4 & \text { Electric } \\ 4 & \text { Sewer } \\ 3 & \text { Fuel } \\ 3 & \text { Soil } \\ 3 & \text { Plants/Trees } \\ 2 & \text { Adjacent Structures } \\ 3 & \text { Building } \\ & \text { Roof }\end{array}$

$\underline{\text { Leve1 }}$

$\begin{array}{lc}4 & \text { Roofing } \\ 4 & \text { Insulation } \\ 4 & \text { Structure } \\ 3 & \text { Ceiling } \\ 3 & \text { Wall } \\ 4 & \text { Interior } \\ 4 & \text { Exterior } \\ 3 & \text { Floor } \\ 3 & \text { Basement } \\ 3 & \text { Openings } \\ 4 & \text { Door } \\ 4 & \text { Window } \\ 4 & \text { Other }\end{array}$


Level

1 Solar Hardware System-Heating/Cooling/Hot Water-Active and Passive

2 Type I System with Discrete Subsystems and Components

2

Type II System with Self-contained Collector/ Storage Unit (active)

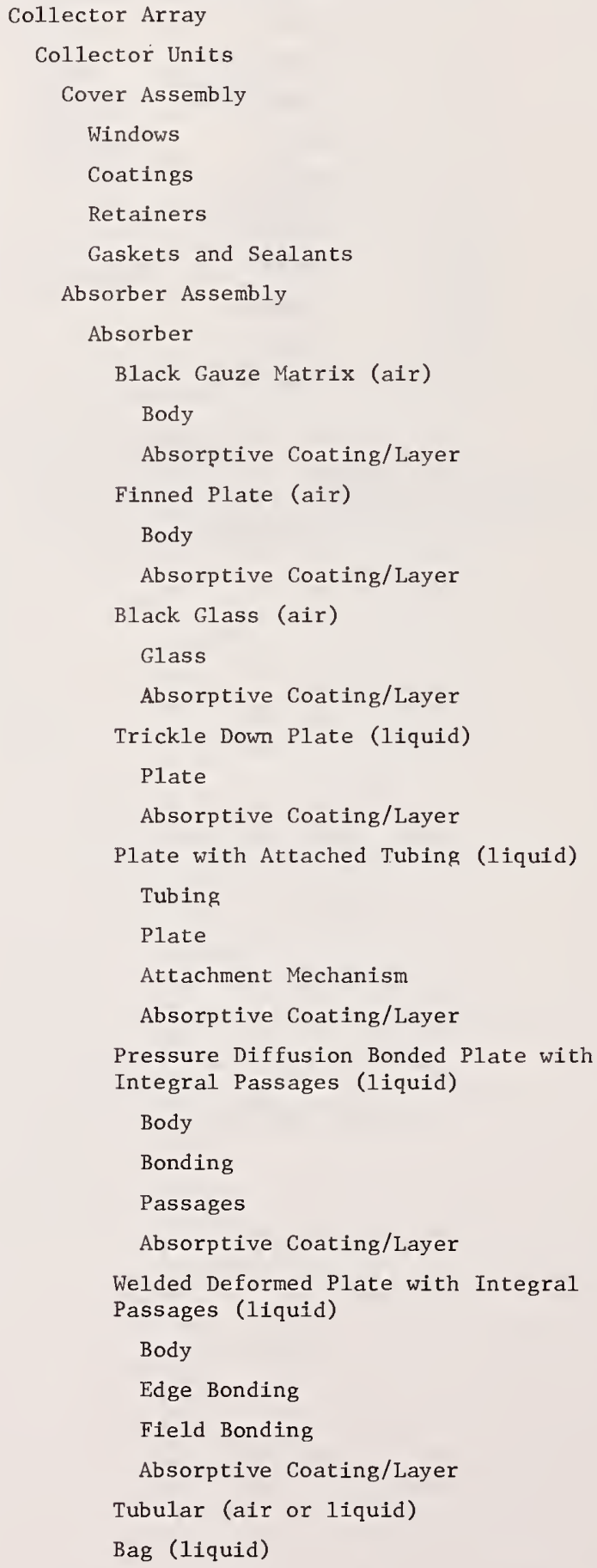

(continued on top of next column)

Leve1

6

5

6

6

\section{Fittings}

Thermal Insulation

Insulation

Therma1 Standoff

Desiccant

Internal Unit Reflector Reflective Surface

Substrate

Insulation

Case Assembly

Frame

Back Pane1

Mounting Hardware

Gaskets and Sealants

Headers and Connectors

Air Ducting Assembly

Insulation

Liners

Gaskets and Sealants

Supports

Connections

Ducts

Liquid Piping Assembly Insulation

Liners

Gaskets and Sealants

Supports

Fittings

Piping

External Reflector Field (array)

Reflector Assembly

Reflective Surface

Substrate

Structure

Insulation

Mounting Structure

Framework Structure Support

Mounting Hardware

Supporting Structure

Fixed Mount

Structural Support

Standoffs

Connection, Building/Foundation

(continued on top of next page) 
Table 3.4 Solar Hardware System Dictionary (continued)

$\underline{\text { Level }}$

7

7

7

5

6

6

6

7

7

7

7

5

6

6

6

7

7

(continued on top of next column)

Flashing

Pitch Pockets

Structural Support

F1ashing

Pitch Pockets

Structural Support

Tracking Drive Train

Flashing

Pitch Pockets

Enclosure

Thermal Storage

Tank or Container Units

Vesse1

Gaskets and Sealants

Insulation Assembly

Insulation Materia1

Protective Jacketing

Coatings or Sealants

Structural Elements

Structural Support

Foundation

Tiedowns

Storage Medium

Heat Exchangers

Collector to Storage
Leve1

Attachment Hardware

Gaskets and Sealants

Seasonally Adjustable Mount

Tilt and/or Orientation Mechanism

Connection, Building/Foundation

Attachment Hardware

Gaskets and Sealants

Tracking Mount (continuous)-Collector Unit, Reflector or Absorber

Connection, Building/Foundation

At tachment Hardware

Gaskets and Sealants

Storage Medium Containment

Vesse1 Liners or Coatings

Insulating Supports or Stand-oifs

Interna1 Racks or Troughs
6

6

6

6

5

6

6

6

$\epsilon$

3

4

5

5

6

6

6

6

She11

Tubes

Headers

Fins

Storage to Load

She11

Tubes

Headers

Fins

Energy Transport

Liquid Systems

Heat Transfer Liquid

Piping Assemb1y

Insulation

Liners

Gaskets and Sealants

Supports

Fittings

Pipes

Pumps

Motors

Impellers

Gaskets and Sealants

Filters

Case

Elements

Valves

Flow Switching

Shut-off

Down Drain

Air Bleed

Flow Adjusting

Air Systems

Duct Assemb1y

Insulation

Liners

Gaskets and Sealants

Supports

Connections

Ducts

Blowers

Motor

Fan

(continued on top of next page) 
Table 3.4 Solar Hardware System Dictionary (continued)

$\underline{\text { Leve1 }}$

5

\section{Filters}

Dampers

Flow Switching

Shut-off

Flow Adjusting

\section{Controls}

Load Supply Mode Control Unit

Control Logic Selector

Sensors

Indoor Temperature

Outdoor Temperature

Collector Outlet Temperature

Storage Temperature

Hot Water Heater Tank Temperature

Solar Radiation

Actuated Devices

Pump Motor Relays

Blower Motor Relays

Valve Solenoids

Damper Solenoids

Valve Servo-motor

Collector/Storage Flow Control Unit

Differential Thermostat Control

Sensors

Collector Outlet Temperature

Storage Temperature

Solar Radiation

Actuated Devices

Pump Motor Relays

Blower Motor Relays

Valve Solenoids

Damper Solenoids

Energy Transport Operation Regulators

Pressure Regulators

Flow Regulators

Subsystem Fai1-Safe Controls

Pressure Relief Valves

Temperature Relief Devices

Collector Shutter Actuator

Collector off-Tracking Device

Energy Dumping Heat Exchanger Circuit Bypass Valve

Cold Water Temperature Relief Valve

Electrical Overload Protection

Vacuum Relief Valves

Leve1

5

5

5

5

5

4

5

6

7

7

6

Check Valves Automatic Drain Down Valves Water Hammer Arrestors Automatic Backfill Valves

Backflow Preventors Component Operation Controls Tracking Mount Drive Controls Actuating Devices Split Photo-cell Timer

Control Unit

Actuated Devices

Servo-motor

Storage Heater Thermostat Auxiliary Energy

Internal with Storage

Resistance Heater

In-line with Storage

Furnace

Heat Pump

Air to Air

Liquid to Air

Liquid to Liquid

Boiler

Resistance Heater

Air Conditioner

Heating-Cooling off

Absorption Cycle

Rankine Cycle

Desiccant

Vapor Compressor

Evaporation Condenser

Air Cooler Condenser

Cooling Tower

Air Volume Variation

Absorption Cycle

Rankine Cycle

Desiccant

Vapor Compressor

Evaporation Condenser

Air Cooler Condenser

Cooling Tower

Air Mixing Control

Absorption Cycle 
Table 3.4 Solar Hardware System Dictionary (continued)

Leve1

7

7

7

7

7

7

6

7

7

7

7

7

7

7

5

4

5

5
Leve1

In Parallel with Storage

$$
\text { Furnace }
$$

Heat Pump

Air to Air

Liquid to Air

Liquid to Liquid

Boiler

Resistance Heater

Air Conditioner

Heating-Cooling off

Absorption Cycle

Rankine Cycle

Desiccant

Vapor Compressor

Evaporation Condenser

Air Cooler Condenser

Cooling Tower

Air Volume Variation

Absorption Cycle

Rankine Cycle

Desiccant

Vapor Compressor

Evaporation Condenser

Air Cooler Condenser

Cooling Tower

Air Mixing Control

Absorption Cycle

Rankine Cycle

Desiccant

(continued on top of next column)
Vapor Compressor

Evaporation Condenser

Air Cooler Condenser

Cooling Tower

Temperature Variation

Absorption Cycle

Rankine Cycle

Desiccant

Vapor Compressor

Evaporation Condenser

Air Cooler Condenser

Cooling Tower

Dehumidifier

Hot Water Heater

Distribution

Central Air Type

Single Duct

Core

Perimeter

Double Duct

Core

Perimeter

Multizone

Fan Coil

Induction

Radiation

Variable Air Volume

Hydronic/Air Type

Fan Coil

Two Pipe

Four Pipe

Induction

Perimeter

Central

Radiation

Energy Conservation Type

Heat Recovery

Heat Recovery Wheels

Heat Pipe

Waste Water Heat

Heat Reclaim

Energy Storage

Demand Limiter

Ventilation Control

(continued on top of next page) 
Table 3.4 Solar Hardware System Dictionary (continued)

Leve1

2 Type III System Integral With Building (Passive)

3 Collector/Storage Array

4 Cover Plate Assembly

5 Windows

5 Coatings

5 Retainers

5 Gaskets and Sealants

4 Passive Collector Heat Transfer Insulation Assembly (cover plate)

Insulating Medium

Insulated Louver

Shade

Insulating Beads

Insulation Board

Solar Control Screen

Medium Actuation Mechanism

Manual Installation/Removal

Manual Driven Mechanism

Motorized Drive Train

Blowers

Absorbing/Thermal Storage Unit

Absorptive Coating/Layer

Separate Coating

Surface Layer of Thermal Mass

Thermal Mass

Building Element

Liquid Container Assembly

Tank Container Unit

Storage Medium Containment Vessel(s)

Vessel Liners, Coating, or Bags

Gaskets and Sealants

Supporting Structure

Storage Medium

Particulate Container Assembly

Tank or Container Unit

Linings or Coatings

Gaskets and Sealants

Supporting Structure

Storage Medium

Separate Solid Structure

Leve1

3

4

5

6

6

5

6

6

6

4

Storage Medium Containment Vesse1

Internal Air Distribution Elements

(continued on top of next column)

Controls

Air Circulation Controls

Manual

Daily

Seasonal

Automatic

Space and Storage Temperature Sensor

Differential Thermostat Control

Damper Solenoid or Servo-motor

Passive Collector Heat Transfer Insulation Assembly Controls

Manual

Automatic

Actuating Device

Temperature Sensor

Radiation Sensor

Control Unit

Actuated Device

Servo-Motor

Motor Solenoid

Auxiliary Energy

Integrated Into Distribution

Completely Separate Conventional System

Distribution

Ducts

Dampers 

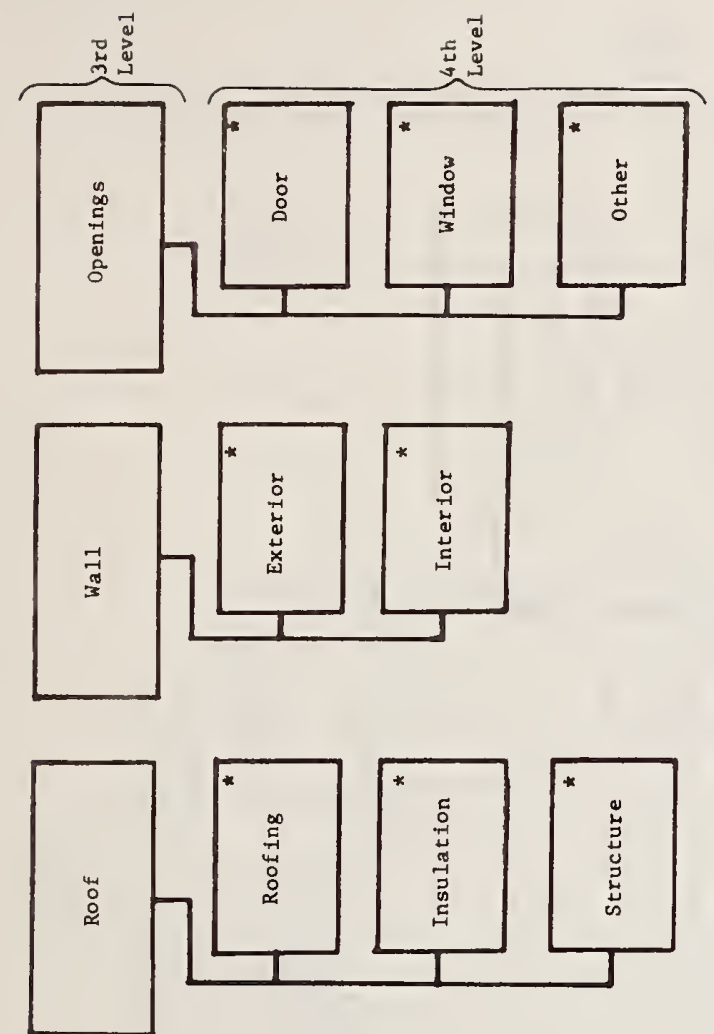

告

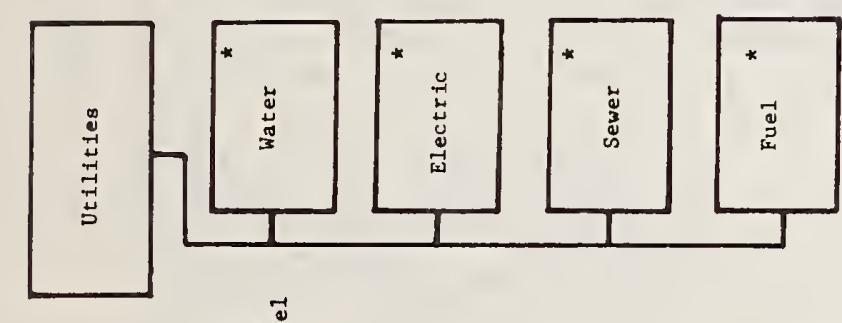

离

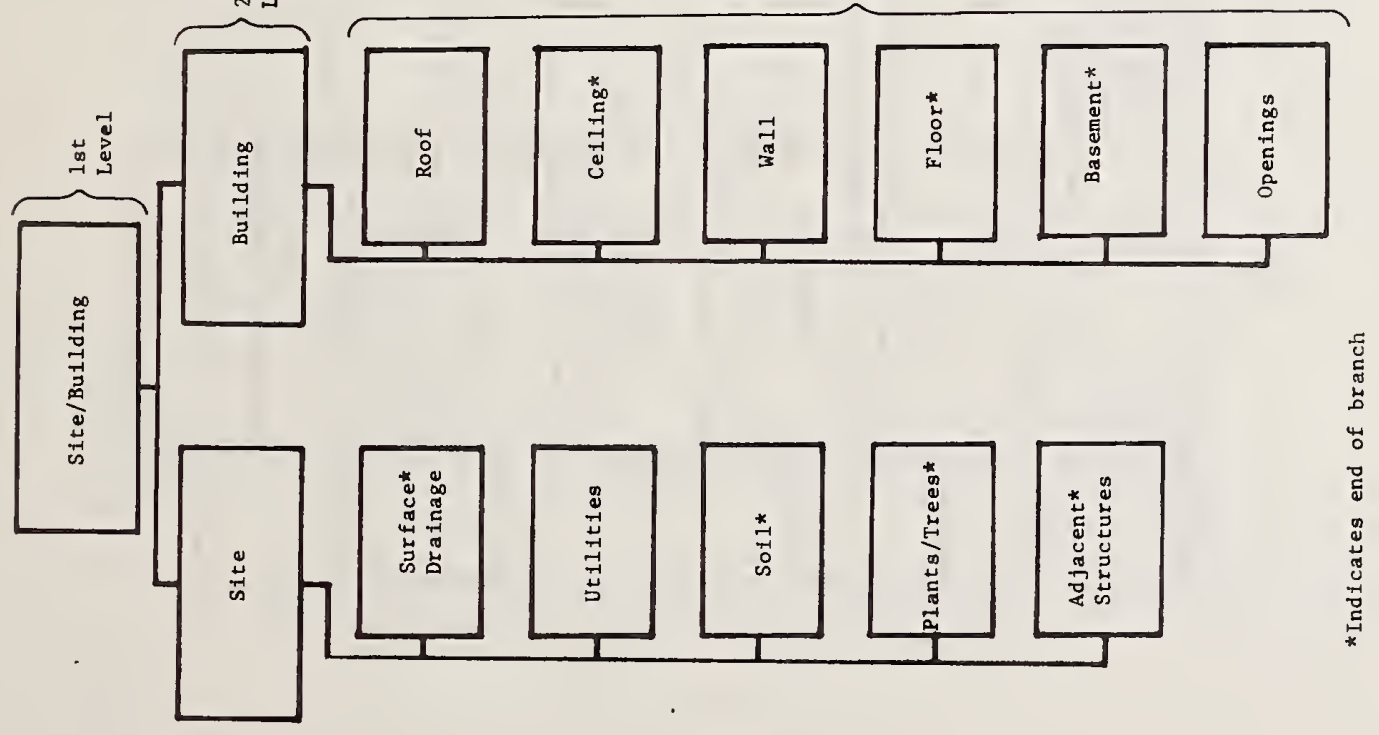




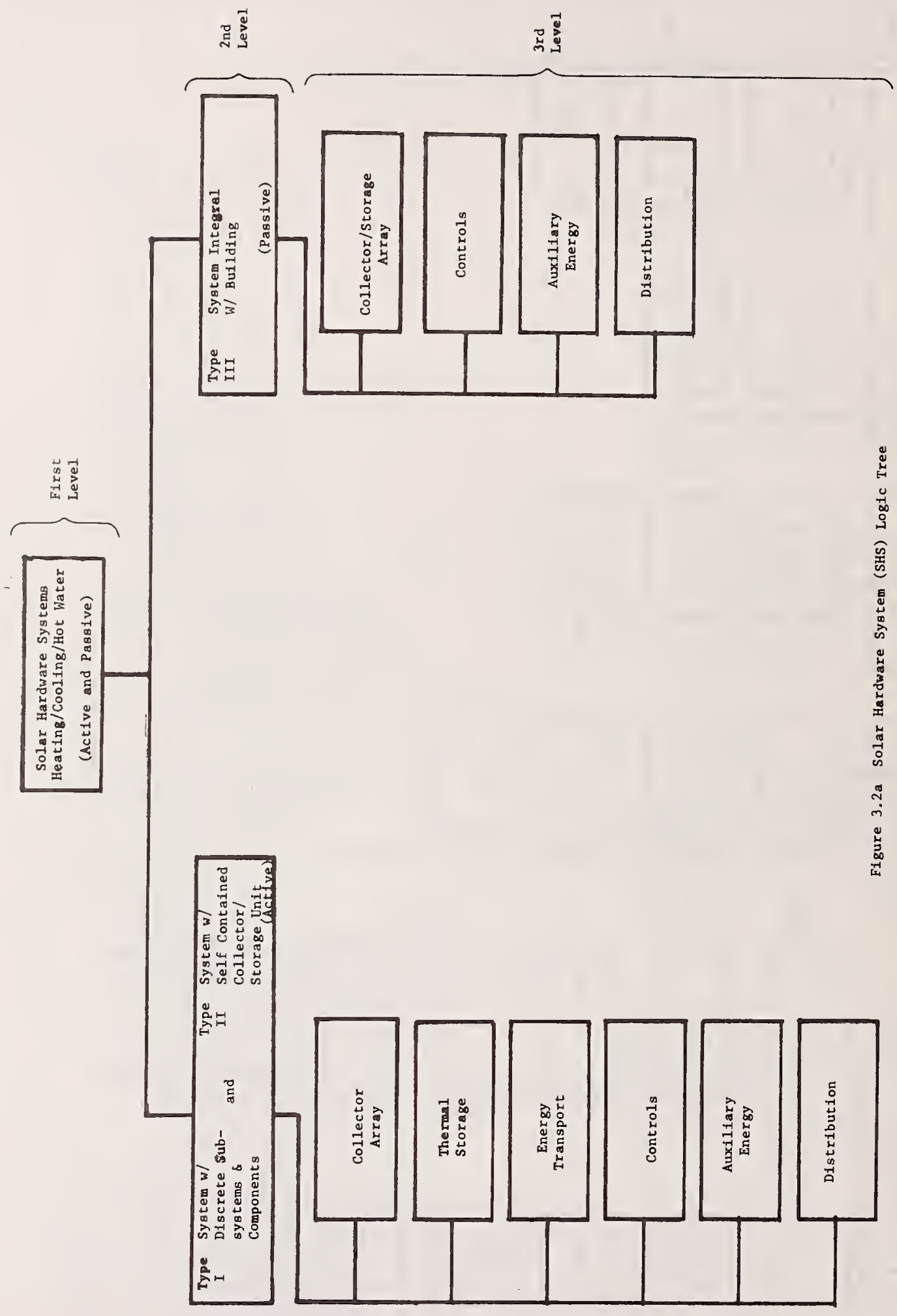




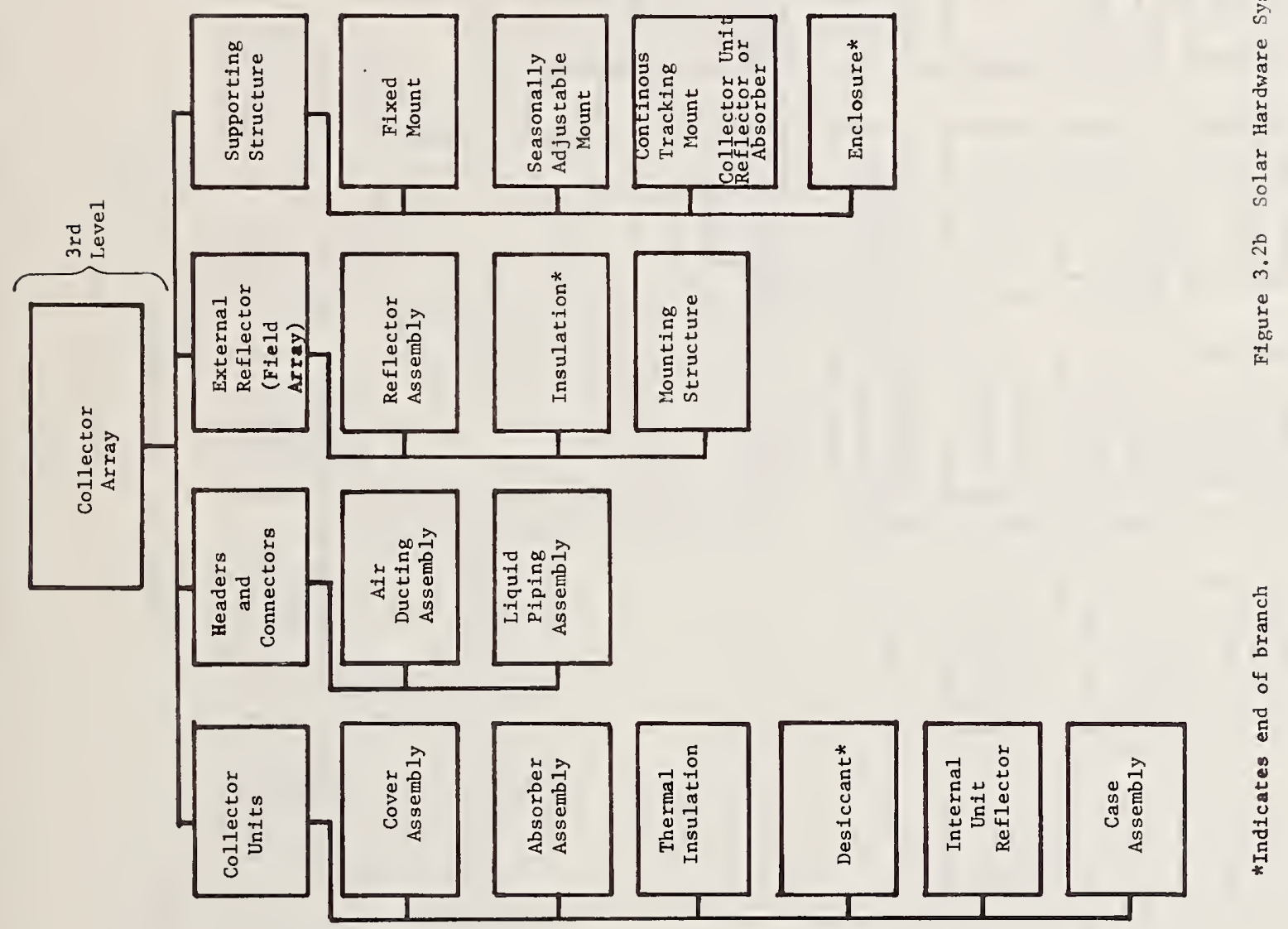




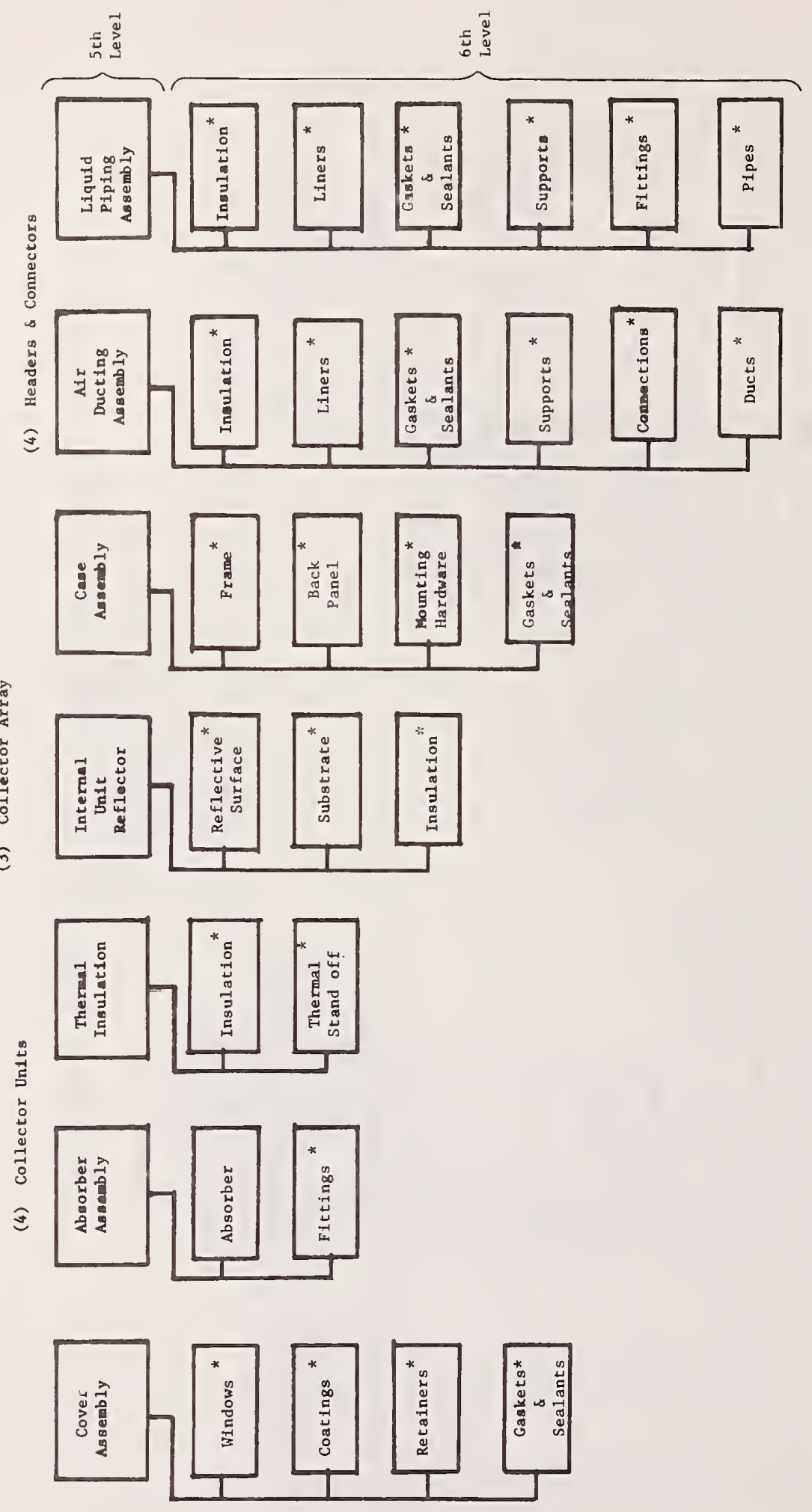

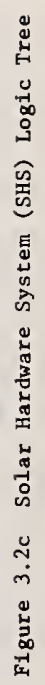

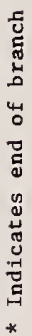



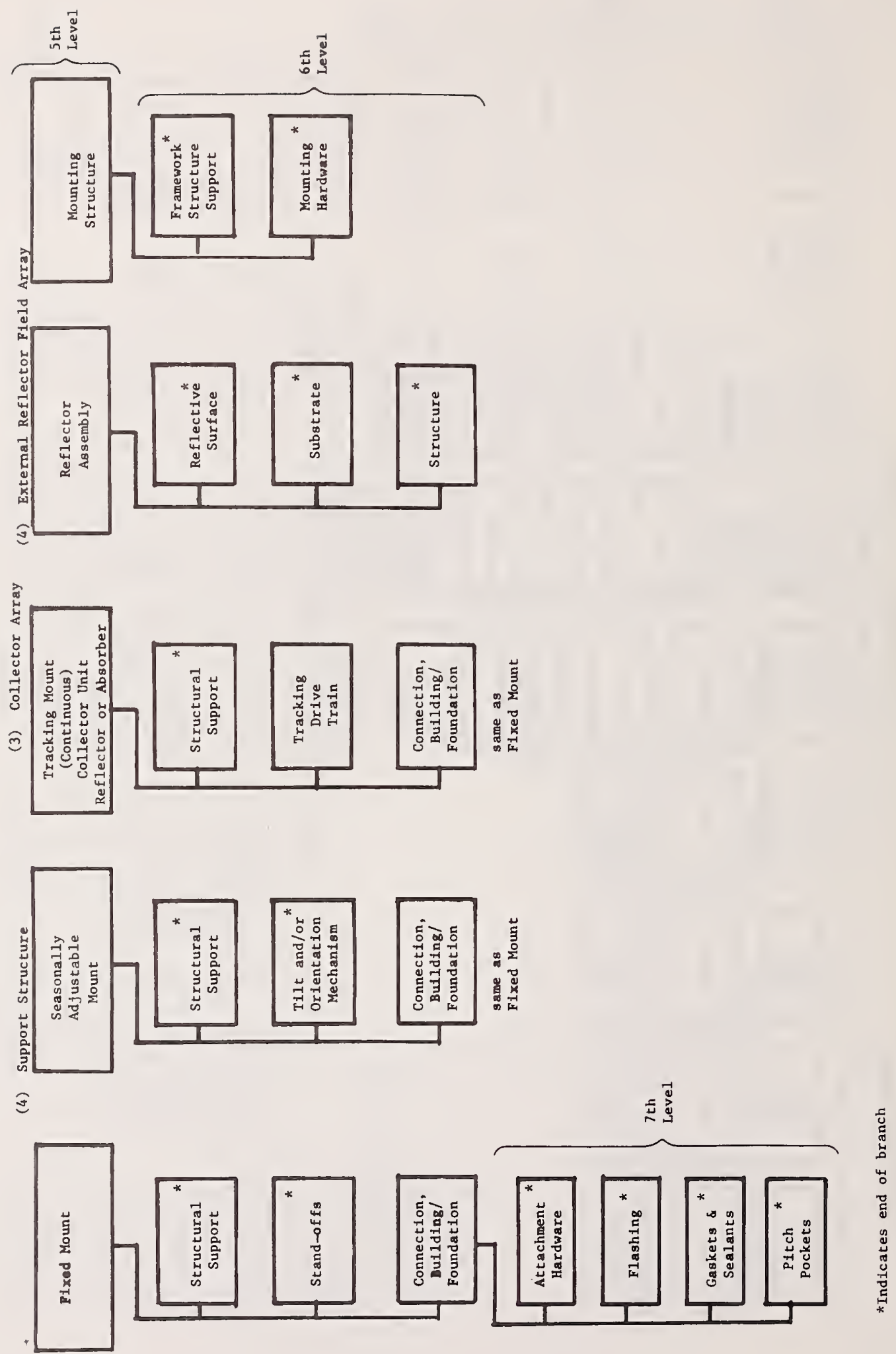

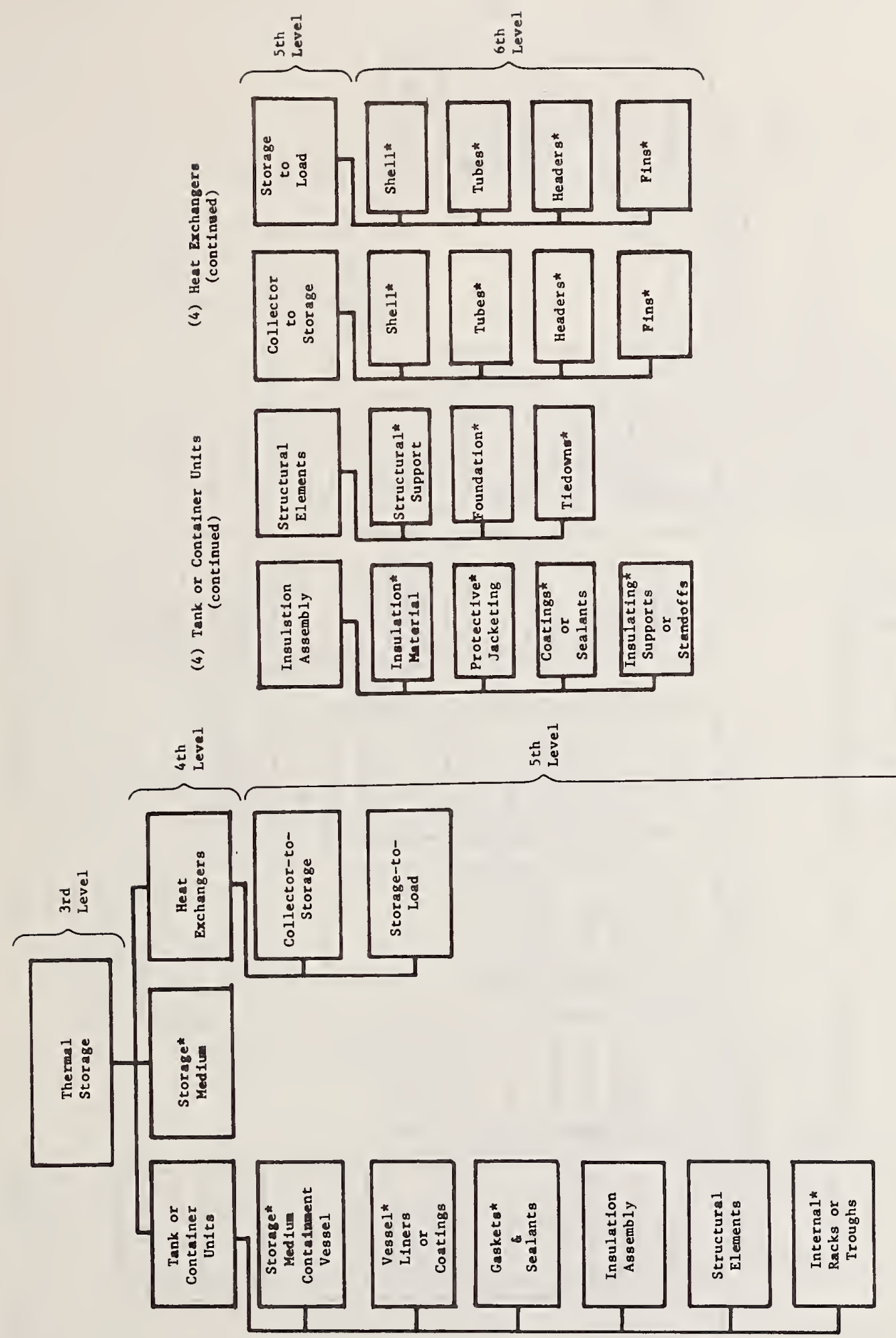

ปั 


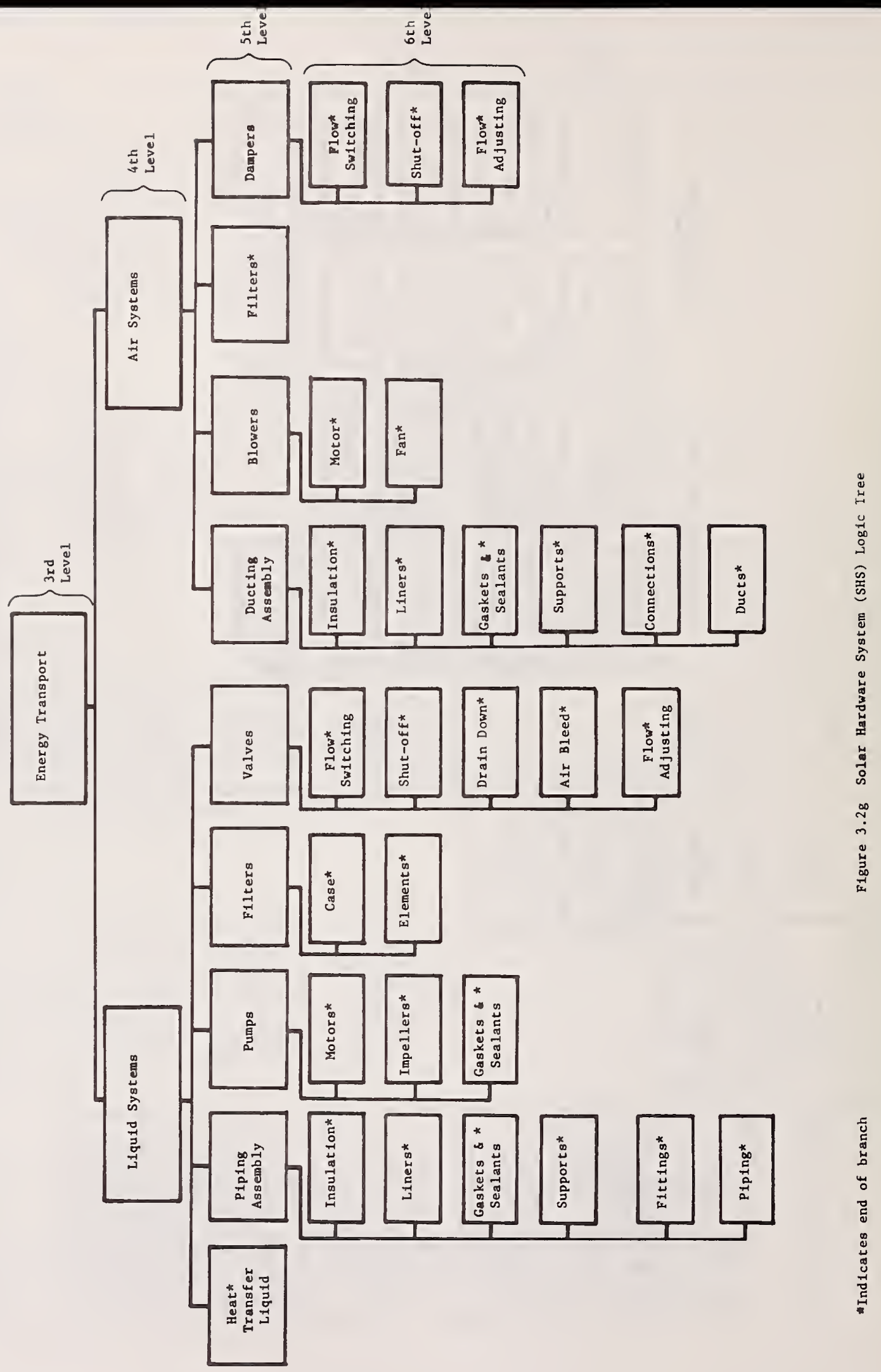




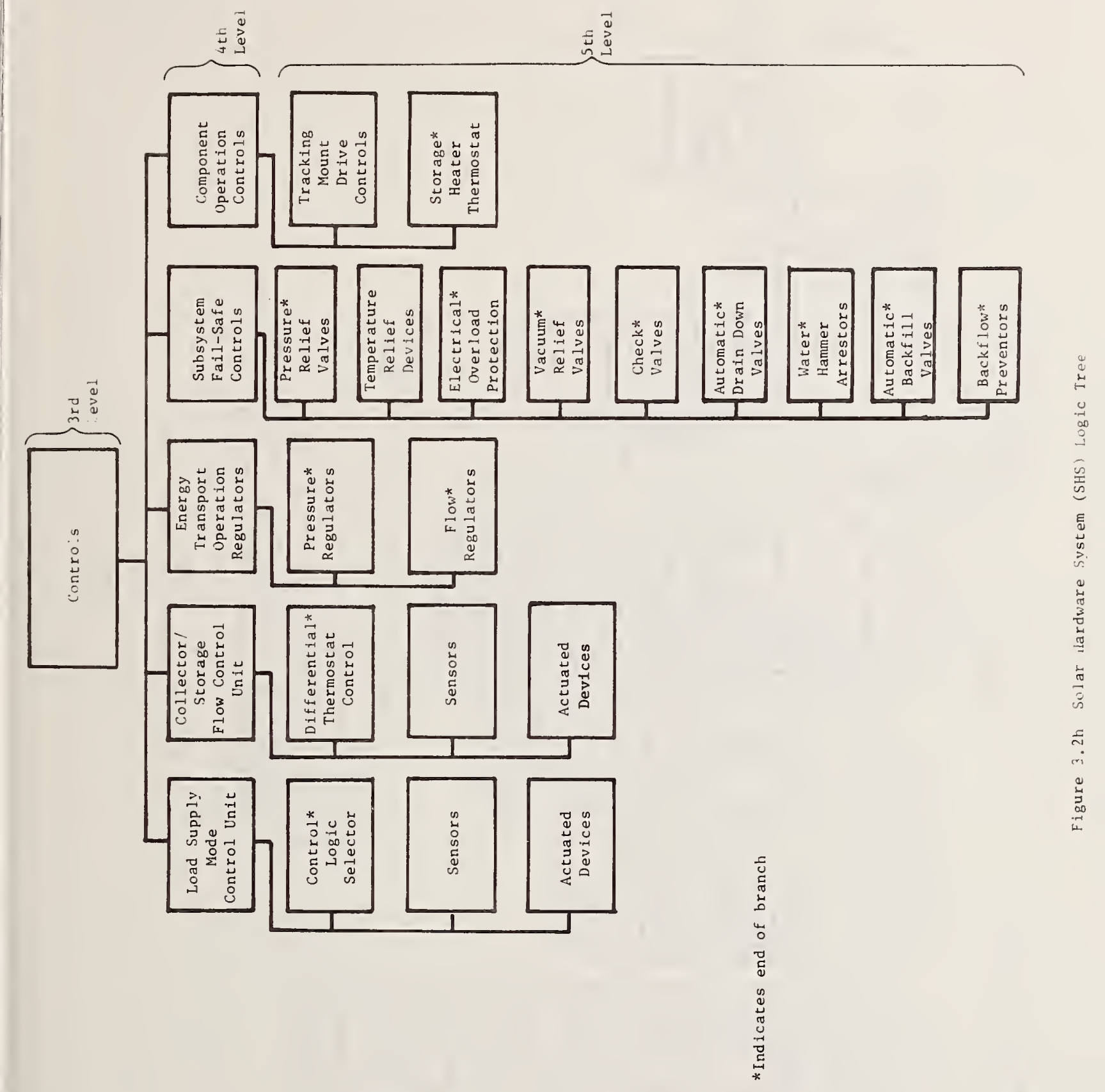




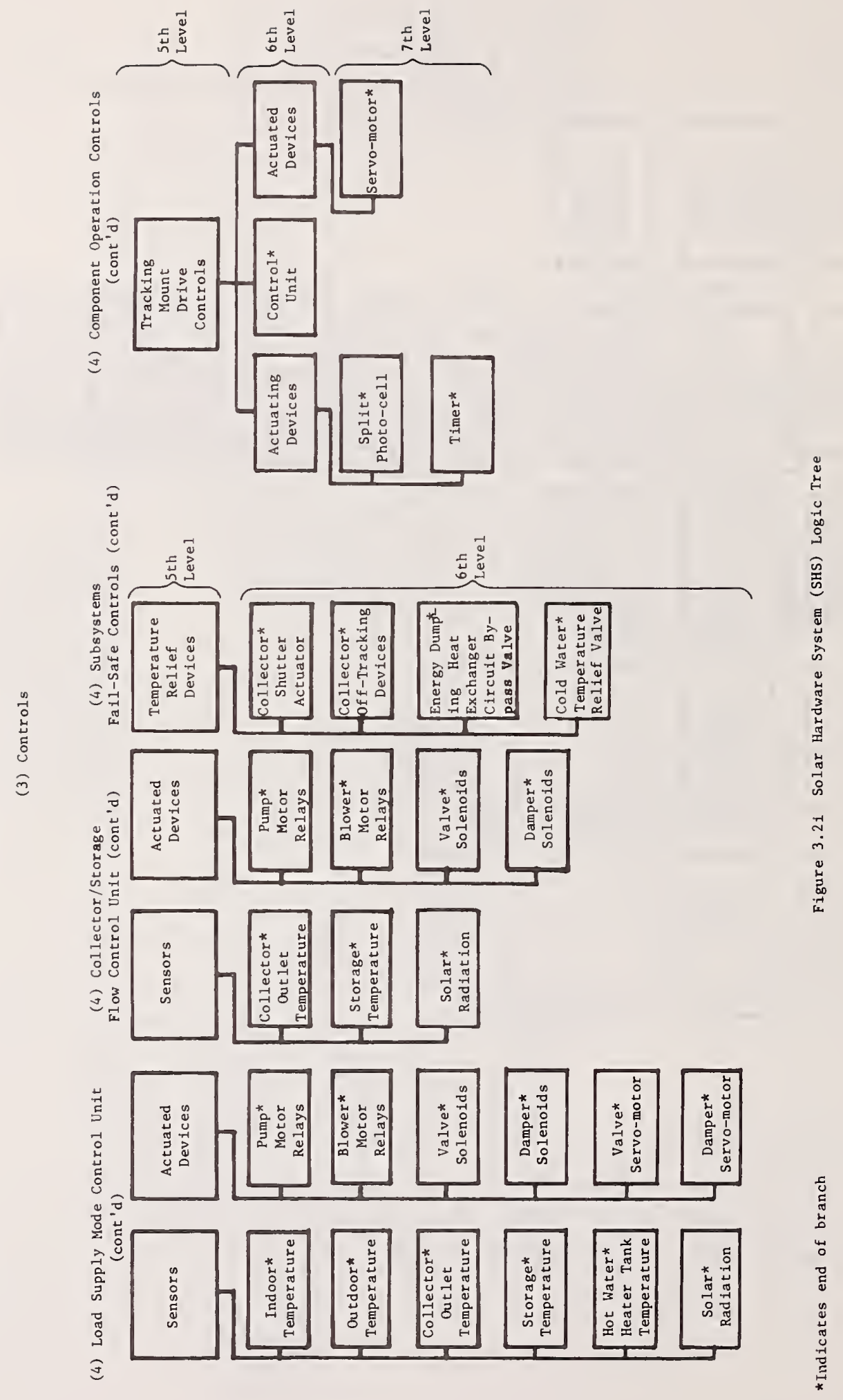




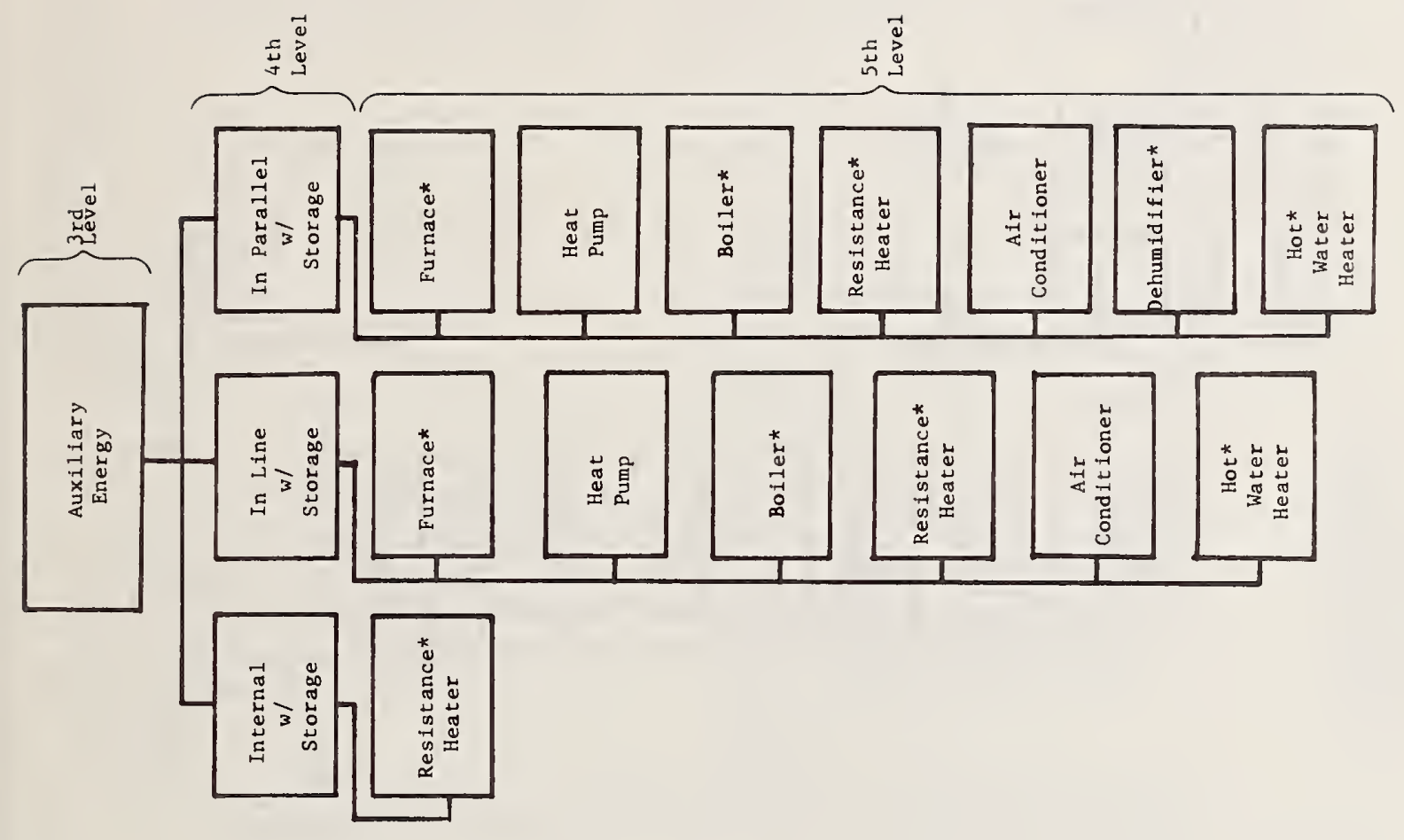

告

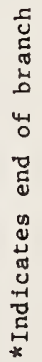




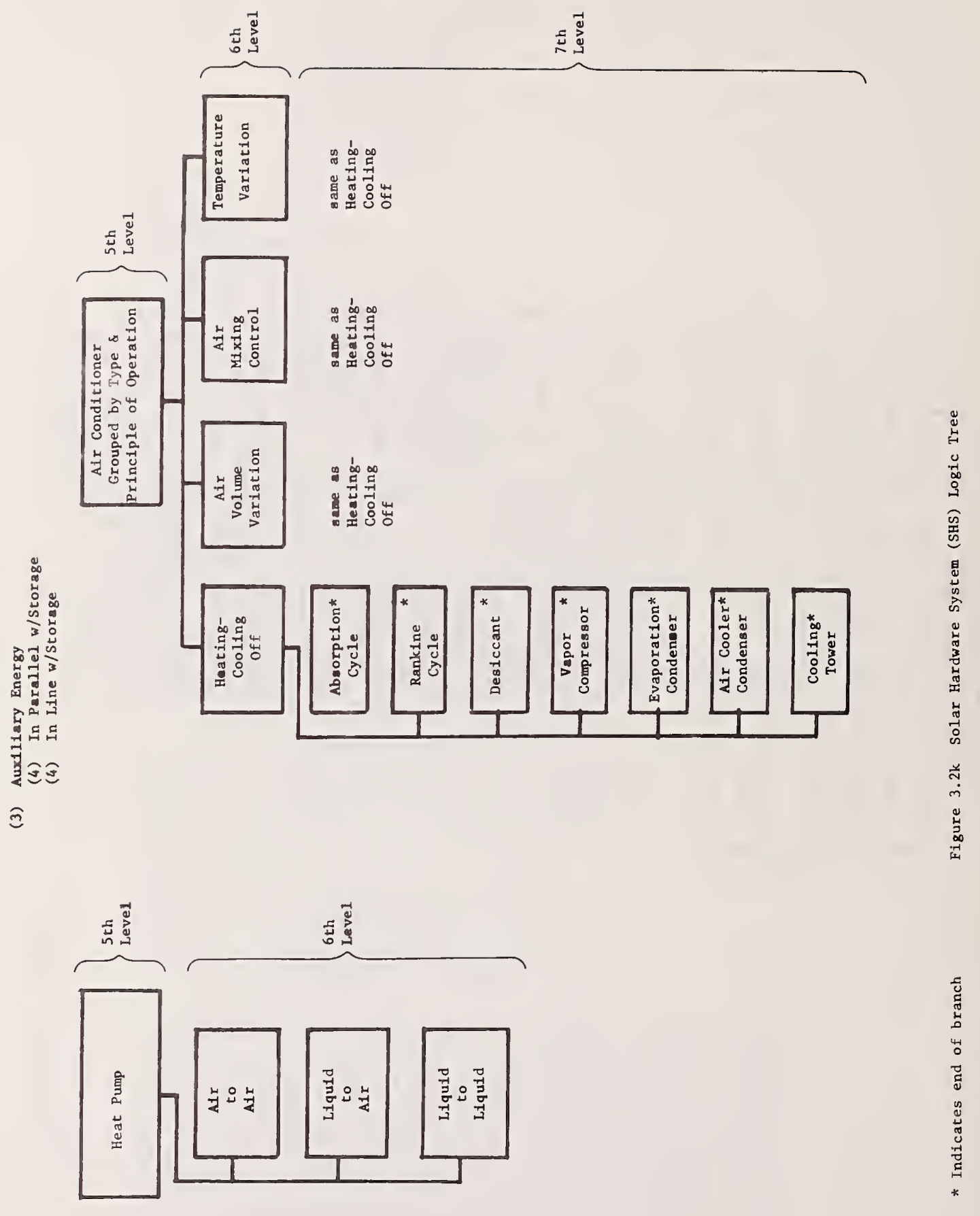




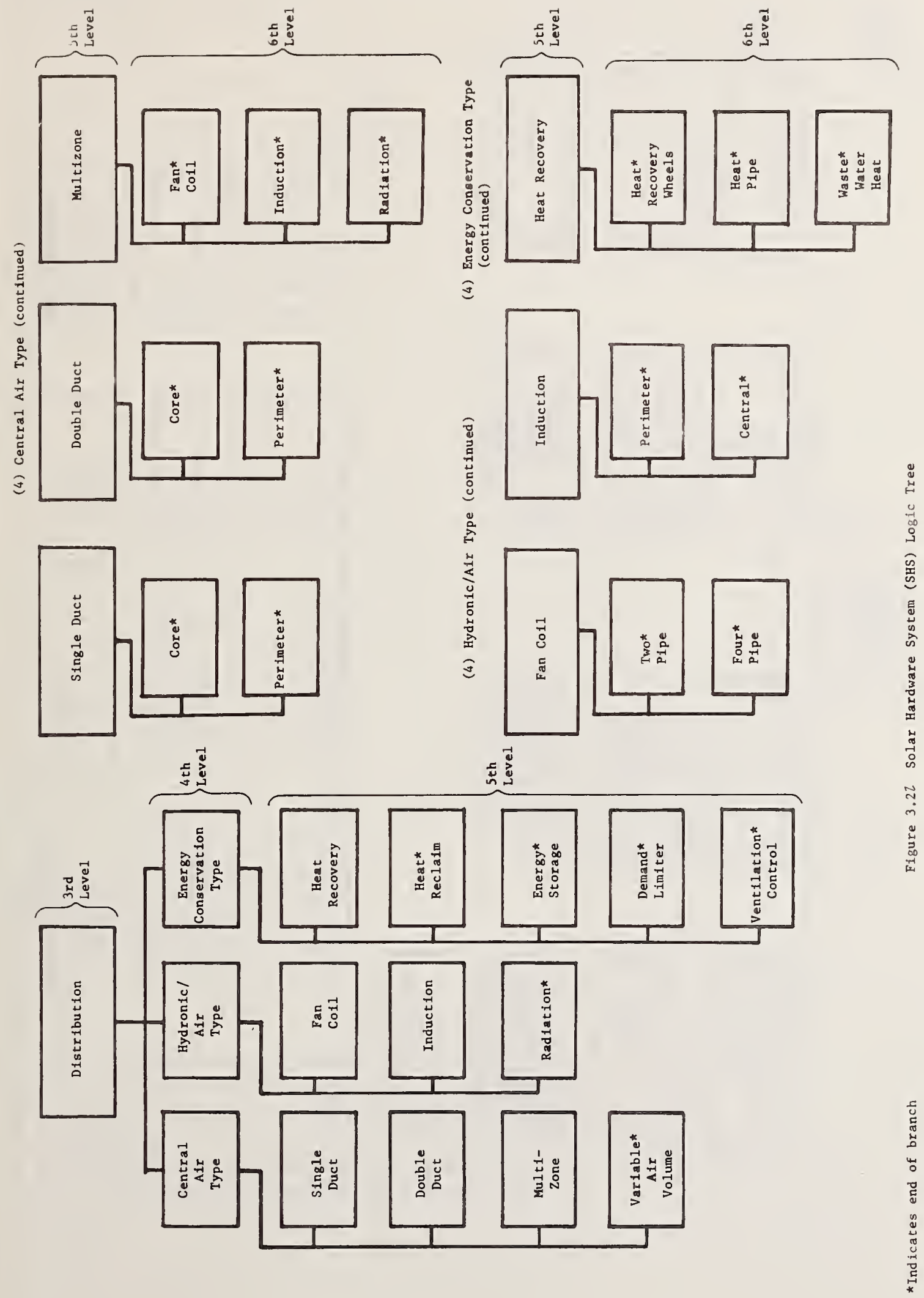




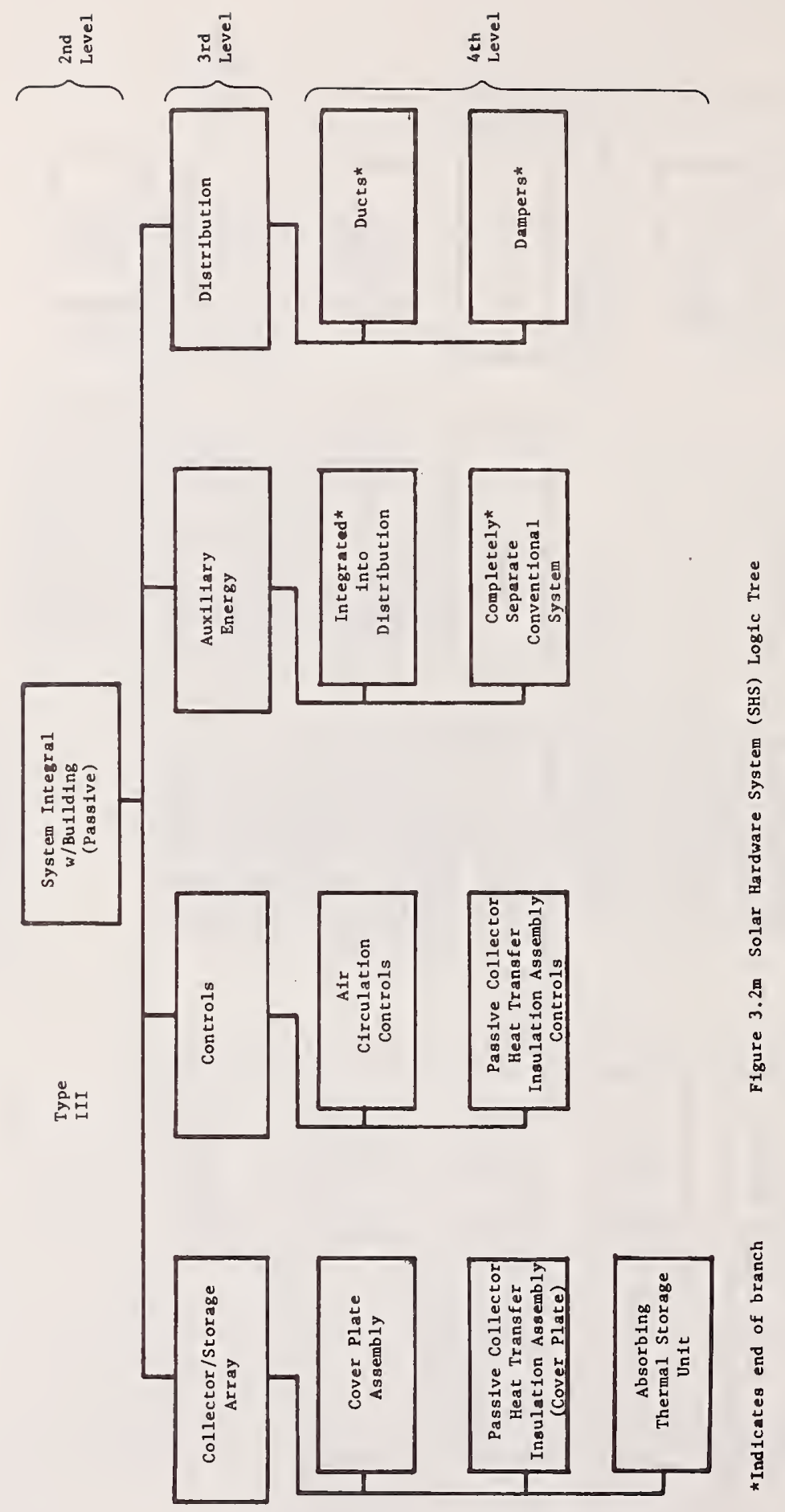




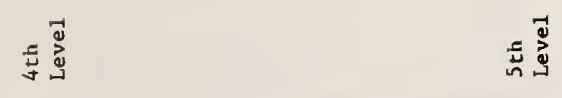

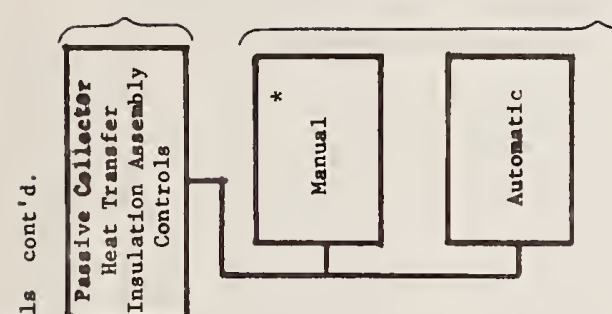

อ
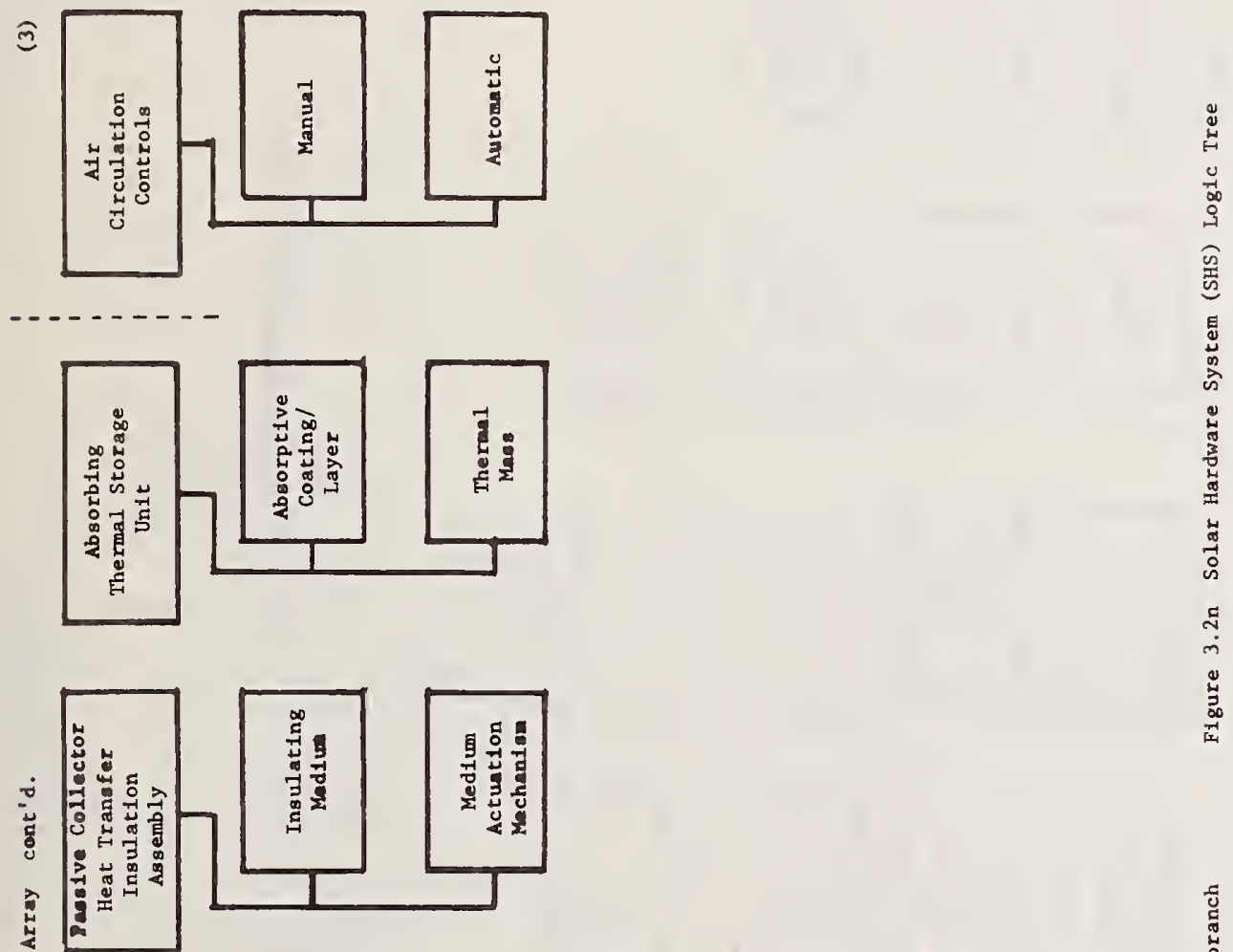

8

:

总
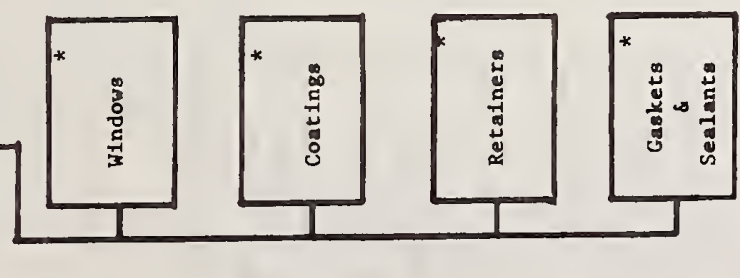

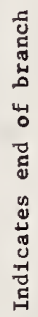




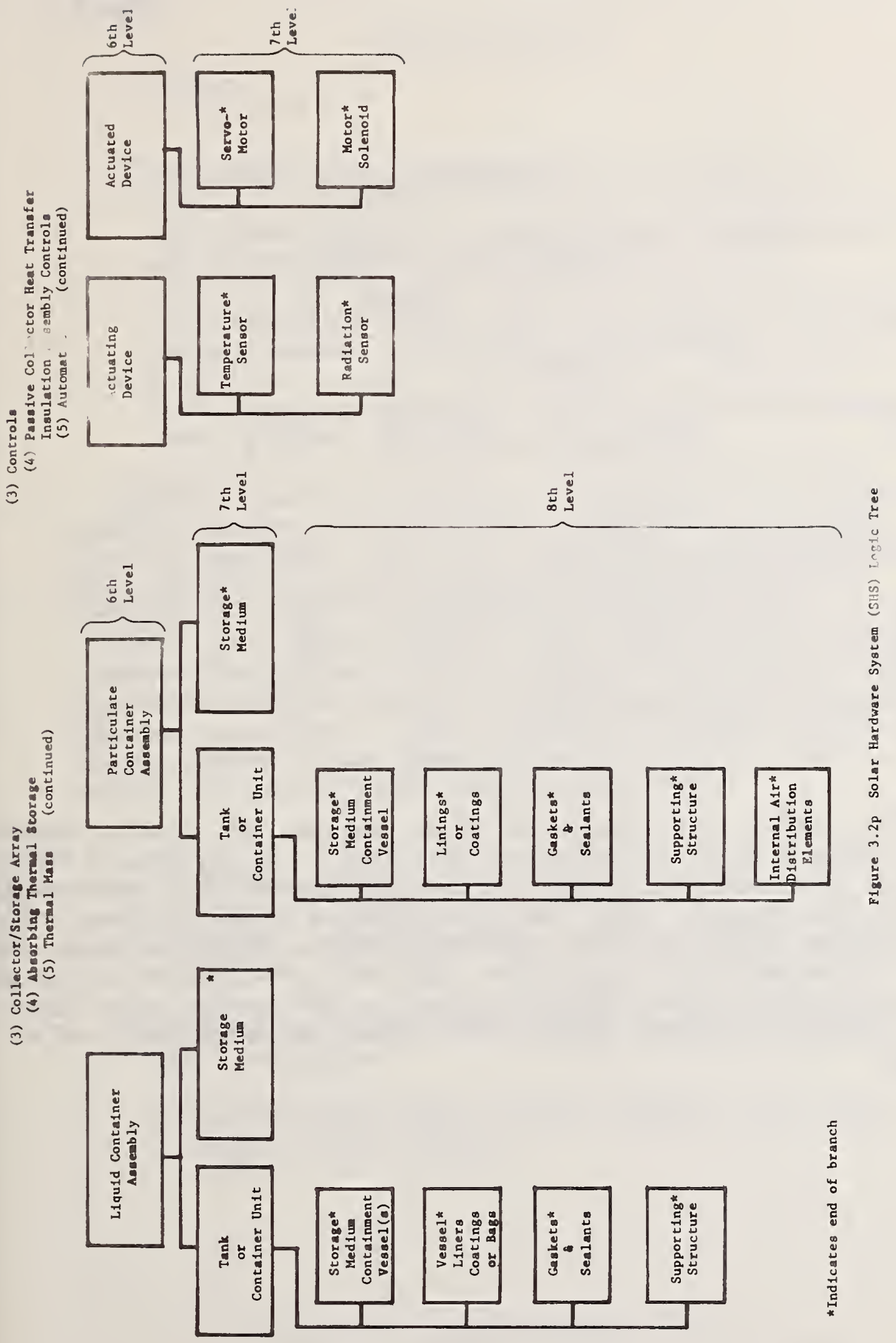


1. System Identification:

a. Project identification number $37642-B 1$

b. Solar hardware system (SHS) identification number $37642-51$

c. Buflding location:

street address 2700 Peachtree Street

city or county \& state Atlanto Geargia

d. Date SHS was originally placed in service

2. Maintenance Order Information:

a. Date of order

$2 / 3 / 77$ Complaint $\swarrow$

3. Description of Service (Maintenance Actions) Pcrformed

Describe each individual action performed: Include details related to the following:

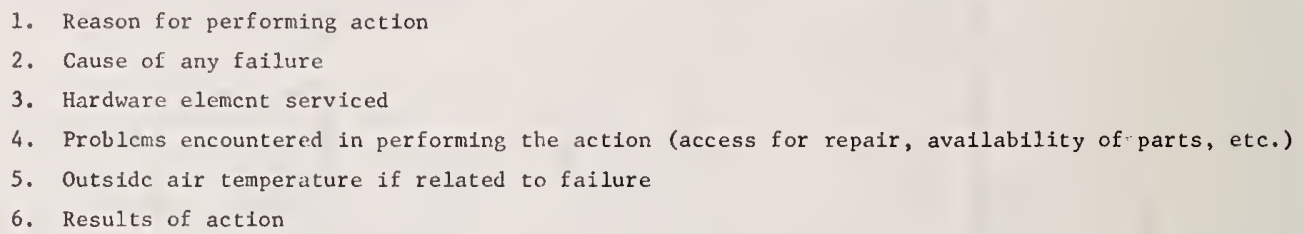

Use tables 1, 2, and 3 to describe hardware elements serviced and/or replaced and materials replaced.

The systim had been phut down because the system lequid was leabong trough the ceiling ints the fitchen. He figlid wes crming frm a gipe thlt had furst in the header aseenbly. It was assunged that de heat transfer fluid had trogen cassing the fipe to buret. She specefication callla fir 50:50 miftulu of exhlene bly col antifreege and was assumed that The grlginal mipture in the systern must have been incorrect. All the liguid had leabed out so it cruld not be
checed. 
Three actions were peyformed:

1. The bust siping was cut out and replaced woth the same type.

2 the collector/storage loge was rechajged wath the proper mixeme of artifleege and wroder.

3. The damaged gysum board in the fitchew ceileng was reflated, Spackled, and paintrat.

After the syotem was returned to operation it was found shat

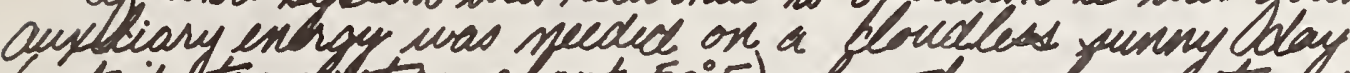
(oytsideltemperature about $50^{\circ} \mathrm{F}$ ) wen the soler sestemg should have carred the entive heateri load, according to the spesficationis. Visn inspecteril it wad frund thet 5 of the 10 cllletris had Fooged bindows. Shen Lontacted, the Collecter magufacteres cllimed that the fogging was caused fry outgasing

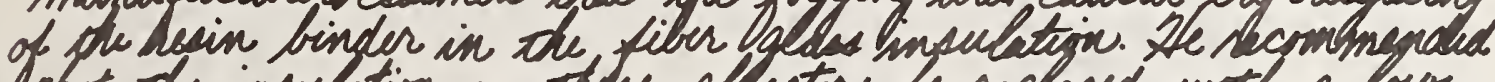
schat the insulation in stese cllectrs be zeplaced woth a bov burder content, "renge type "ineulation. He alwo said the wendreve should be cleanad wath amonia and weter.

Three actioni were performed:

4. Temoved and cleaned the windows of the five
collectors

5. Leslaced the uneulation with a "range type" fiber

6. Regealed the windoys to the collectors cares with a butyl rubler sealant.

Figure 3.3 Sample Maintenance Service Call Report (contd.) 
Solar liarlware System

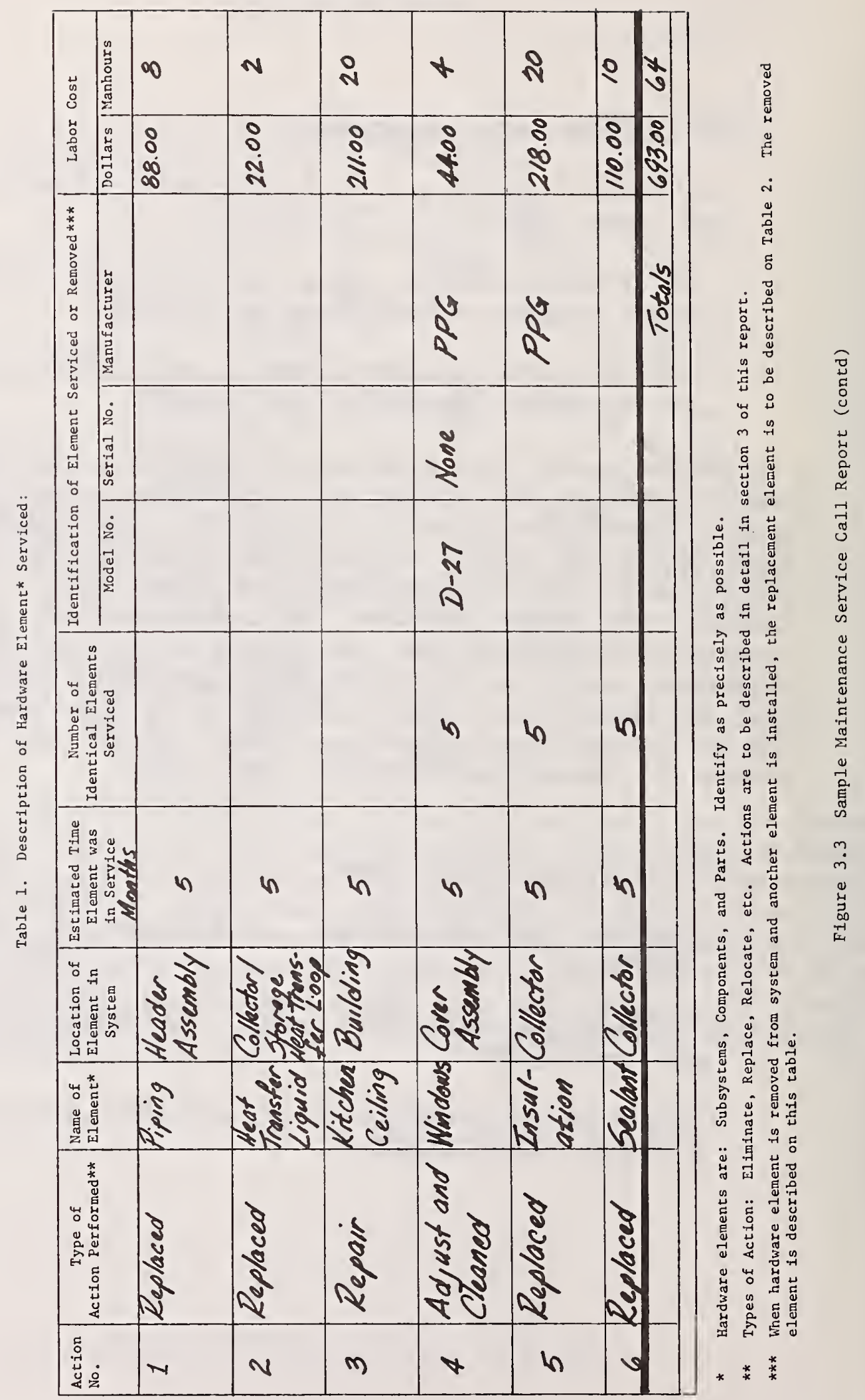


Solar Ilardware System

Table 2. Description of Replacement Hardware Element

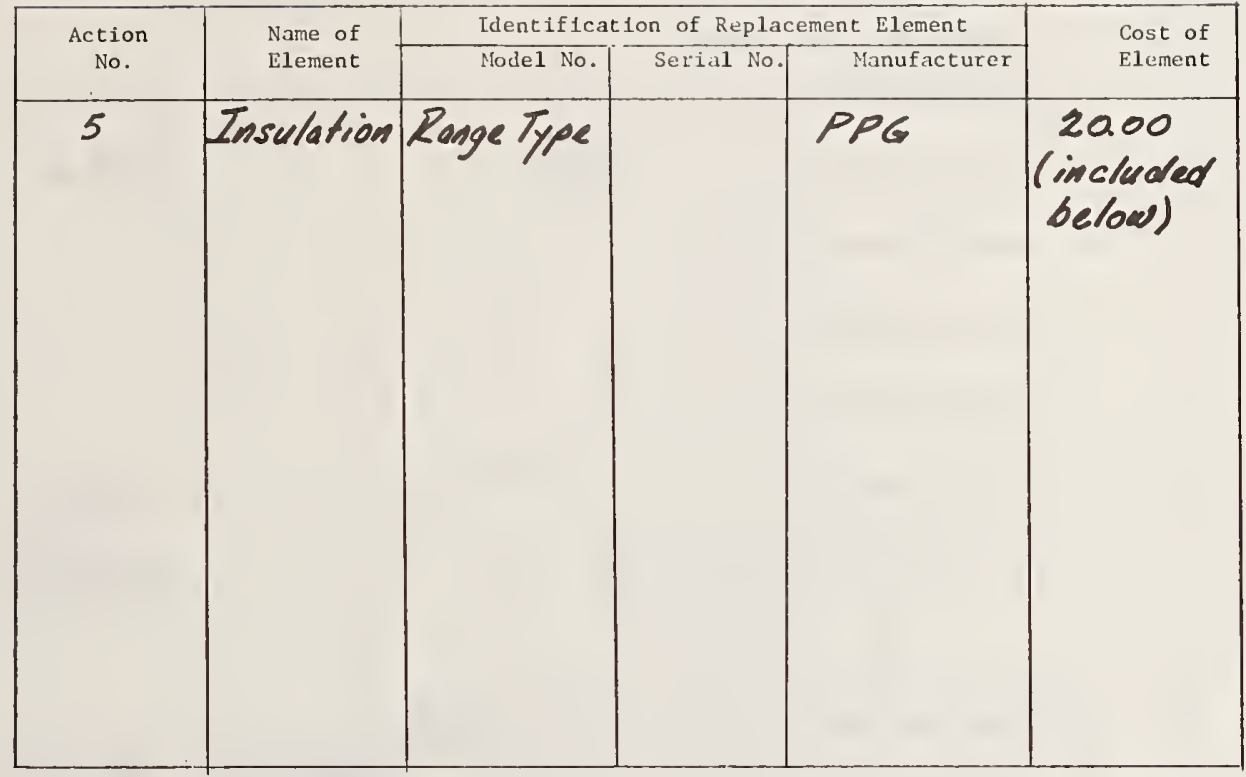

Table 3. Description of Replacement Material*

\begin{tabular}{|c|c|c|c|c|c|}
\hline $\begin{array}{l}\text { Action } \\
\text { No. }\end{array}$ & $\begin{array}{l}\text { Type of } \\
\text { Material* }\end{array}$ & $\begin{array}{l}\text { Generic, Chemical } \\
\text { or Trade Name }\end{array}$ & $\begin{array}{l}\text { Quantity } \\
\text { Replaced }\end{array}$ & $\begin{array}{l}\text { Hardware Element } \\
\text { in Which Replaced }\end{array}$ & $\begin{array}{l}\text { Cost of } \\
\text { Material }\end{array}$ \\
\hline 1 & Tubing & Copper & $20 \mathrm{ft}$. & Header Assy. & 17.00 \\
\hline 2 & Antifherze & $\begin{array}{l}50: 50 \text { mixtwre } \\
\text { of ethylene } \\
\text { glycol \& water }\end{array}$ & $7 \mathrm{gol} .5$ & $\begin{array}{l}\text { Collectorlstirage } \\
\text { Heat Transfer } \\
\text { Loop }\end{array}$ & 21.00 \\
\hline 3 & $\begin{array}{l}\text { Woll } \\
\text { Surfacing }\end{array}$ & Cypsum Boord & $\begin{array}{l}2-4 \times 8 x^{3} / 8^{11} \\
\text { Sheets }\end{array}$ & Kitgheng & 8.00 \\
\hline 4 & Detergent & Amonia & lgal. & Cover Assy. & 3.00 \\
\hline 5 & Insarlotion & 4" Fiburgloss & 200 s. 4 & Collectors & 20.00 \\
\hline 6 & Seolant & Butyl- Rubber & $20 / 6 s$ & Collectors & 40.00 \\
\hline & & & & Total & 109.00 \\
\hline
\end{tabular}

* Materials are expendable items such as: Bolts, Fluid, Gas, Gaskets, Insulation, Piplng, Sealants, Screws, Wire, etc.

Figure 3.3 Sample Maintenance Service Cal1 Report (contd) 
4. System Downtime:

a. Date and time the system became inoperative $2 / 2 / 47-11$ P.M.

b. Date and time the maintenance action(s) was initiated $2 / 4 / 77-8$. 1.1 .

c. Date and time the system was returned to operation

5. Cost of Maintenance Action(s):

a. Direct labor for each action (list labor in time and money for each action):

Totals from Table 1 hrs. $64 \quad \$ \quad 693.00$

b. Hardware elements replaced

Total from Table 2.

$\$$

c. Materials replaced

Total from Table 3

d. Total cost of maintenance actions

$\$ 802.00$

6. Personnel Identification:

a. Person completing this report . Te Seller

b. Person responsible for performing maintenance Tose 1,8 . Smith

c. Firm responsible for performing maintenance 4 pera

Phone no. $912 / 236-9843$

7. Additional Remarks Regarding System or Maintenance: Include details of personal injuries and bullding damages if connected with elther system operation or maintenance.

Figure 3.3 Sample Maintenance Service Call Report (contd) 


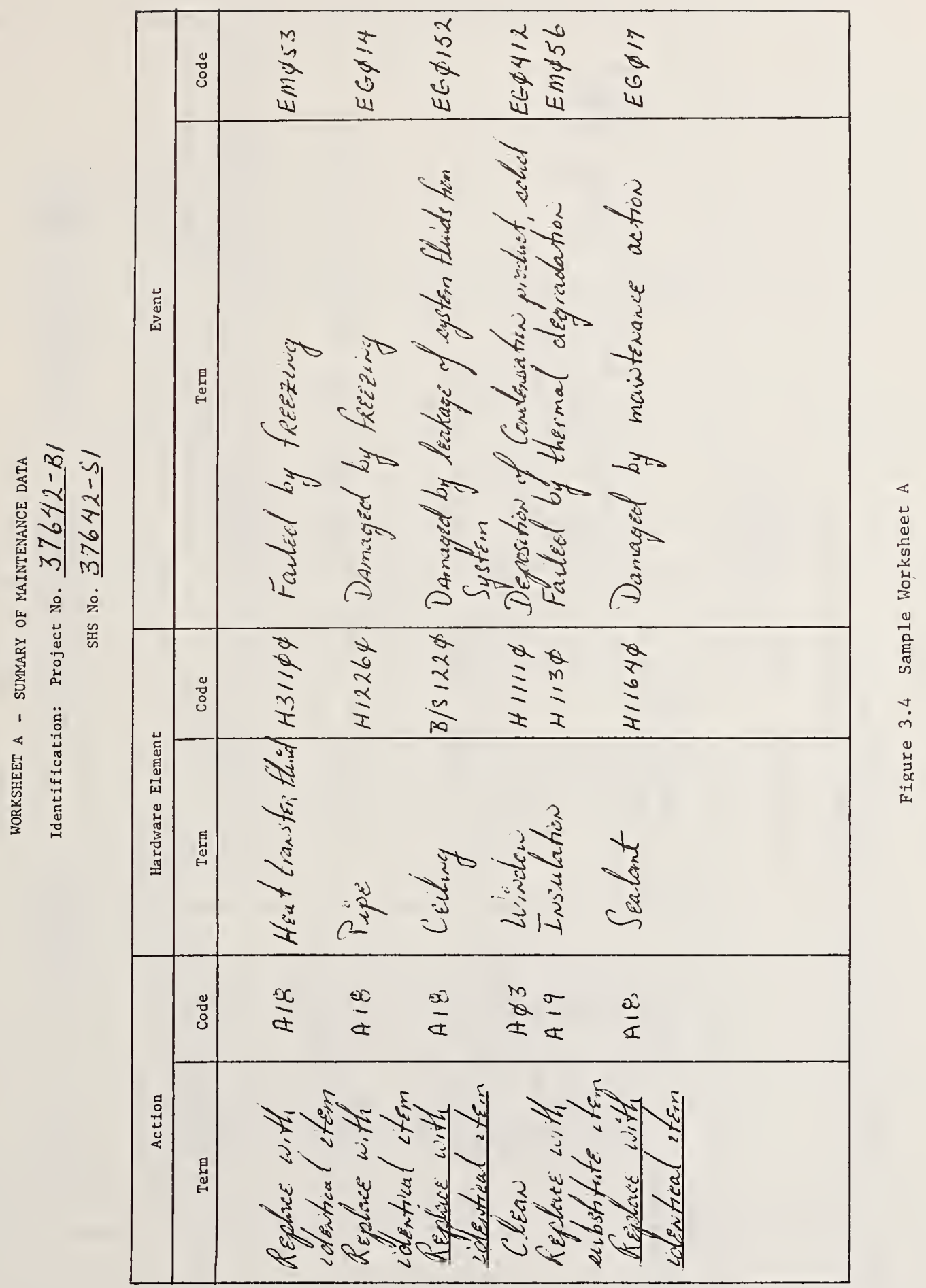




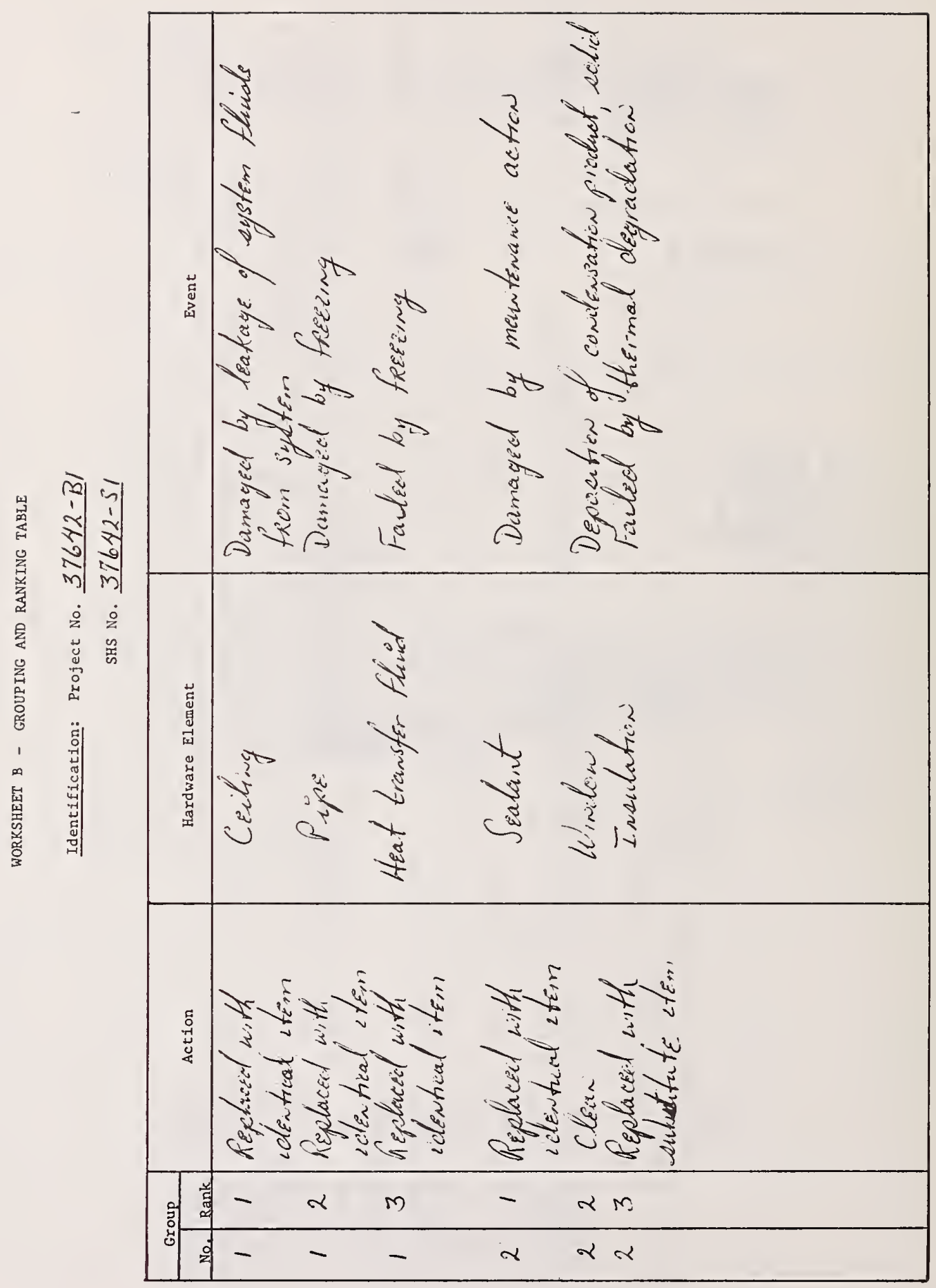



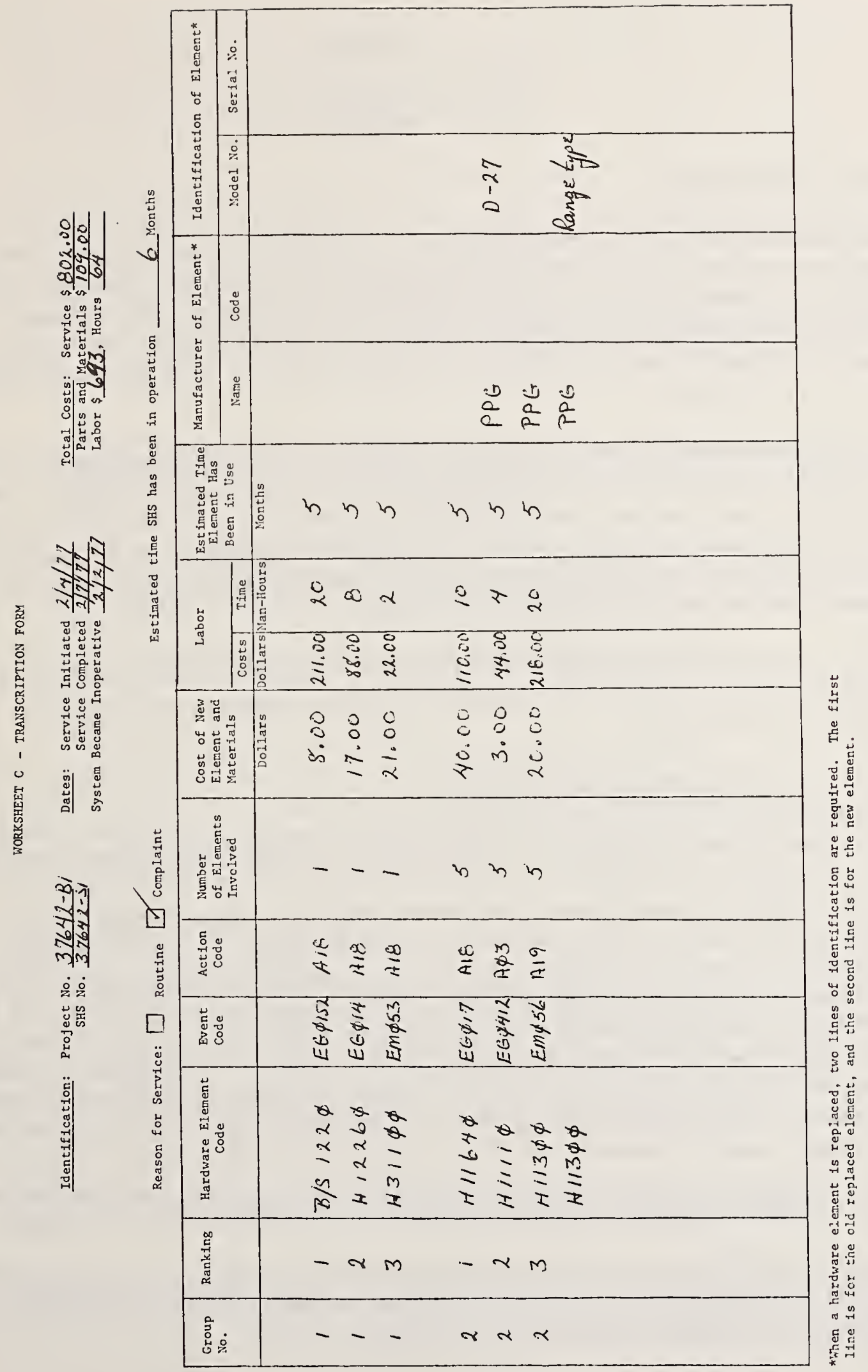

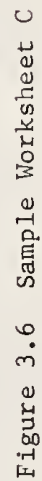


PART FOUR

TECHNICAL NON-INSTRUMENTED DATA

ANALYSIS

1.0

INTRODUCTION

The purpose of this part is to describe methods of utilizing the technical non-instrumentation (TNI) data which will be collected in accordance with Part Two (Identificaticn, Materials, and Performance Data) and Part Three (Operational Events Related Data) of this report. The TNI data are to be made available in reduced form for evaluation studies to be conducted by NBS and other users. The reduced data will be used to identify operational problem areas, causes of the problems, and possible solutions to the problems.

In order to effectively utilize the TNI data following their collection and transcription into computer processable data, programs must be developed to process the data into a form that will facilitate evaluation. One of the end products of processing the data will be the printing out of tables which efficiently display the data in a manner such that hardware performance can be evaluated. Progranming requirements are discussed in this part of the plan and examples of printouts which can be used to identify problem areas are presented and described.

When the Part Three data are being collected, it can be expected that system changes will be made which might make some of the Part Two data obsolete. Such changes should be identified and entered in the Part Two data bank.

\subsection{AUTOMATIC DATA PROCESSING (ADP)}

Performing an effective evaluation of solar hardware system performance requires a systematic evaluation of their operational performance. ADP of the actions taken and the events data described in Part Three is needed to produce routine printouts that sumarize the TNI data in the NBS data base. From these routine summaries critical malfunctioning hardware elements, or groups of elements, can be identified for further investigation. These routine summaries provide an overview of operational problems and are intended to serve as a basis for more detailed data studies in specific problem areas. These studies can be performed on an interactive basis, utilizing a data retrieval system such as MIRADS, if warranted. Moreover, printouts are needed to display the identification, materials, and performance data listed in Part Two, which (1) locate and characterize buildings, (2) provide descriptions of major subsystems and components of solar hardware systems, and (3) provide data required for thermal design of systems and calculation of heating and cooling loads for buildings.

\subsection{Sample Printouts of Identification, Materials, and Performance Data (Part Two)}

Tables 4.1 and 4.2 are sample printouts of data that will be collected in accordance with Part Two for the Site/Building and the Solar Hardware System. The sequential order of the information displayed in the tables follows that used in Part Two. 


\subsubsection{Reliability of Data}

The most reliable data are the actions taken, the hardware elements that the actions were taken on, and the associated costs, downtime and component life. Somewhat less reliable are the events data that are associated with the action since they are judgemental in nature. For example, it may be quite obvious that the glass window of a flat plate collector "fractured" (event) because it was "struck by wind borne debris" since a tree limb was observed lodged in the collector along with the fractured glass. However, the cause of the "fracture" of a pipe connecting elements which induce thermal stress cycling in the pipe during normal operation may not be obvious. Four possible causes are listed below, and there might be others.

1. The designer did not take into account the differential movement between the connected elements during which the pipe material experiences stress cycling in the plastic stress range resulting in a low cycle fatigue failure.

2. The design was adequate for the predicted performance, but actual performance caused greater differential movement than was expected, causing, again, a low cycle fatigue failure.

3. The design was adequate, but the pipe material was below standard.

4. The system was improperly installed.

In view of the above, the sumary printouts will primarily display information about the actions taken and cost data. More detailed investigative printouts will display information about events and causes. In the formulation of computer programs to produce summary and investigative printouts, care must be taken not to allow double counting of the events data.

\subsubsection{Routine Summary Tables 4.3 and 4.4}

Both routine summary tables follow the hierarchy of the Solar Hardware System (SHS) Logic Tree (figure 3.2). In Table 4.3 the information element is identified at the top of each column, and the hardware element to which each line applies is identified along the left edge of the table. In Table 4.4 the elements of information are identified along the left edge of the table, and the hardware element to which each column applies is identified at the top of the column. Since Table 4.3 is the more complex of the two tables, it will be described in detail.

The numerical data shown in the tables are ficticious: they are included only to illustrate the use of the tables.

2.2.2.1 Description of Table 4.3 Since this is a summary table for all SHS units being surveyed, no further identification after the heading "ACTIONS" is needed; however, if this table were printed out for a particular group of SHS units further identification would be necessary, such as SHS unit, building and site ID numbers.

The entry "PERIOD" indicates the length of time covered by the table, and the entry "FIRST THRU THIRD LEVEL SUMMATION" signifies that a summation is presented at each level of detail through the third level of the hardware tree. 
The third level is at an intermediate level of detail, but it does present a broad overview of the maintenance phase of the program. Greater level of detail is desirable and can be obtained by printing out tables that contain all the hardware elements through any level of detail, i.e., 4 th - 8th.

A description of each column on the table is given below; columns are identified by 1 abels located at the bottom of each column.

Column A Identifies the hardware elements (system, subsystem, component or part) on which the actions were taken.

Column $B \quad$ The entries in this column indicate the sumation of all actions taken at a discrete level on the hardware tree. For example, the entry at leve1 1 (levels are indicated in column $N$, last column on the right of the table) signifies that the total number of actions recorded is 1340 which is made up of the following:

Type I and II Systems 1161

Type III Systems

179

TOTAL

1340

The number of actions taken at a given level is the summation of actions taken at the next higher level of detail. For example, the Type I and II Systems actions taken shows a total of 1161 actions taken which is made up of the following:

[The level summation concept applies to column (B), (C), (F), (G), (I), and (J).]

\begin{tabular}{ll} 
Collector Array & 229 \\
Thermal Storage & 219 \\
Energy Transport & 210 \\
Controls & 201 \\
Auxiliary Energy & 179 \\
Distribution & 123 \\
\hline TOTAL & 1161
\end{tabular}

Column C The entries in this column are percentages of the total number of actions taken that are contained at the lowest level of detail, i.e., First level summation. For example, Type I and II Systems show a total of 1161 actions taken.

$\frac{1161}{1340} \times 100=86.6 \%$

and for Collector Array at level 3, there are 229 actions taken recorded, giving

$\stackrel{229}{2} \times 100=17.1 \%$

1340

Column D The enties in this column indicate the number of solar hardware systems where one or more actions were taken. (93 Systems were reported where Thermal Storage Actions were taken.)

Column $E$ The entries in this column are percentages of the total number of systems where one or more actions were taken. For example, in the case of Thermal Storage under Type I and II systems

$\stackrel{93}{\longrightarrow}$ X $100=78.7 \%$

122 
The entries in this column indicate the cost of the corrective action taken. For example, action taken for Thermal Storage in Type I and II Systems cost $\$ 7578.60$.

Column G The entries in this column are percentages denoting the portion of the total cost of the actions taken for those actions taken that are indicated on each line. For example, the portion of the total cost attributed to Thermal storage in Type I and II Systems is

$\frac{7578.60}{39620.07} \times 100=19.1 \%$

Column $H$ The entries in this column indicate the average cost of the actions taken on each line. For the Collector Array actions taken in Type I and II Systems, the average cost is

$\frac{\$ 7440.40}{229}=\$ 32.49$

Column I The entries in this column indicate the total amount of time in days from the time the SHS started to malfunction until an action (or actions) returned the SHS to normal operation. This is commonly called "downtime."

Column $J$ The entries in this column are percentages denoting the portion of total downtime for the actions taken that are indicated on each line. For example, Controls in Type I and II Systems have accounted for the portion of downtime indicated below.

$-\frac{171.1}{1307.5} 100=13.1 \%$

1307.5

Column $\mathrm{K}$ The entries in this column are the average number of days of downtime per action taken for the actions taken shown on each line. For Type I and II System it is

$\frac{1176.4}{1161}=1.01$ days

Column $L$ The entries in this column are the average number of days of downtime per system per year for the actions taken shown on each line; i.e., for Type I and II Systems

$\underline{1176.4}=11.65$ days

101

Column M The entries in this column indicate the length of time in months that the solar hardware systems have been in service. (Collector Array of Type I and II Systems - 13.2 months.)

Column $N$ The entries in this colum denote the level of detail for each hardware element as indicated on the Hardware Logic Tree, Figure 3.1, Part 3 (Distribution, Type I and II Systems - Leve1 3).

It should be noted that the actions taken are rank ordered by frequency-of-distribution within each level. Moreover, the programming to analyze the data and print out the tables must also be capable of suppressing hardware elements for which no data has been recorded.

2.2.2.2 Description of Table 4.4 The lines of information in Table 4.4 are denoted by the corresponding column labels in Table 4.3; the other lines of information shown in this table which are not selfexplanatory are labeled with a bracketed number and described below.

Row [1] The entries in this row indicate the total number of operational solar hardware systems in the program at the end of the reporting period for the levels of detail shown. For example, 62 Type III systems were operational at the end of the reporting period. 
The entries in this row indicate the percentage of the total number of operational systems where one or more actions were taken during the reporting period for each level of detail shown. That is, for Type III solar hardware systems. $\frac{21}{62}=33.9 \%$

Row [3]

The entries in this row indicate the average cost of actions for those systems where one or more actions were taken during the reporting period of one year. For example, for Type I and II solar hardware systems $\frac{32,501}{122}=\$ 266.40$

\subsection{Correlation/Investigative Tables (Printed)}

Two general types of printouts are being developed, (1) printouts to present a general overview of the actions taken with their related events, and (2) printouts to display very specific information about a single and associated event, action, or hardware element. Table 4.5 is an example of a printout correlating specific information identified in Part Three with the identification, materials, and performance data listed in Part Two about a single hardware element.

other tables are being developed to present detailed information about problem areas that are identified from the sumnary tables. These tables will associate the actions with the events reported, and correlate this information with the data identified in Part Two of this report. Programs must be developed to produce these printouts and also to track the data in order that double counting is avoided.

The data in Part Two are to be collected during the solar hardware system design phase of the demonstration programs. These data are then to be coded and stored in a computer, but in a different bank from the Part Three data. The codes for the Part Two data will be different than the codes for the Part Three data. Therefore, in order to correlate the stored data from the two parts a crossreference dictionary will be needed. When investigating the performance of a specific solar hardware system, correlation between the Part Two and Part Three data can be performed using the system identification number which is unique for each system. 

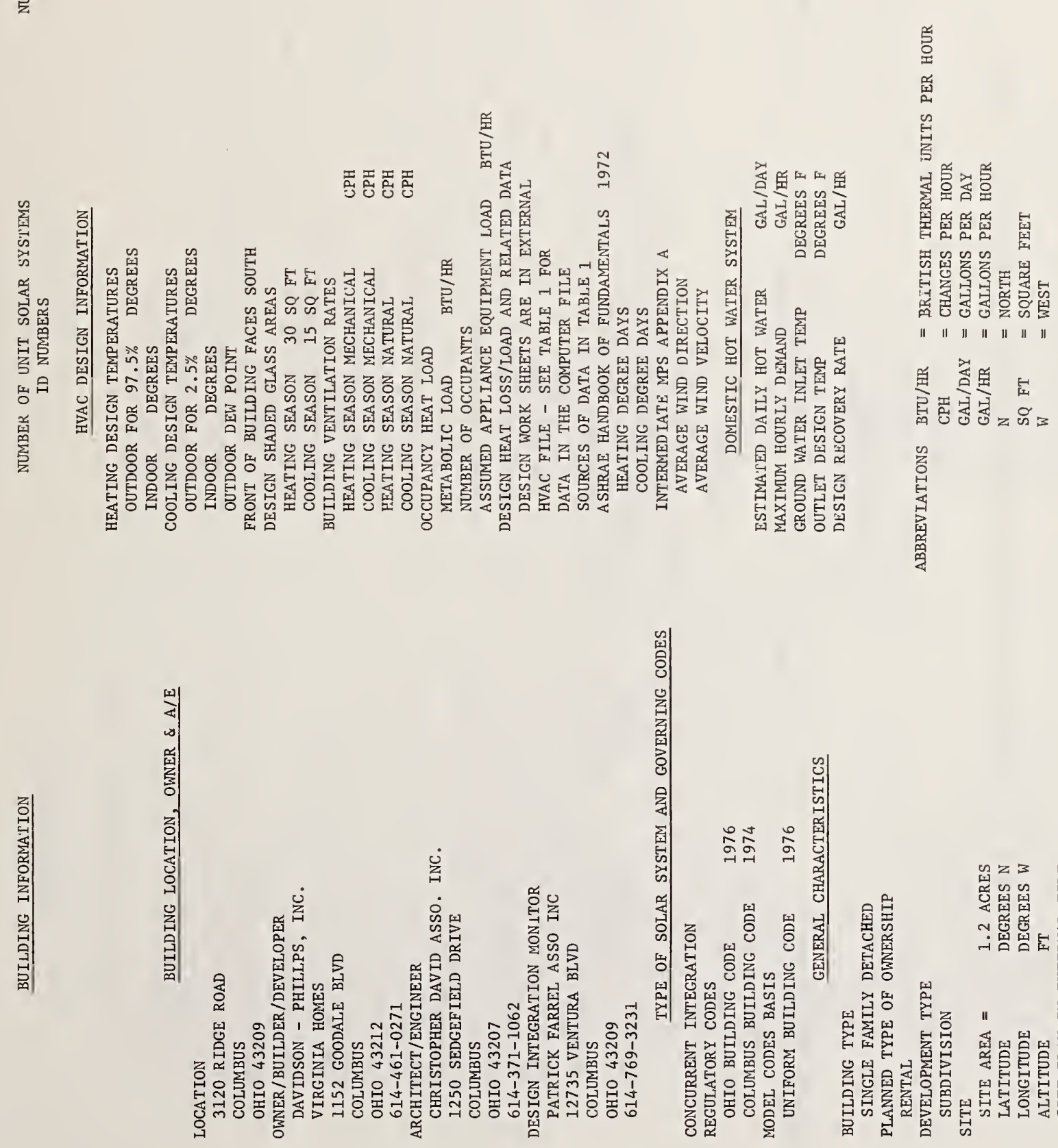

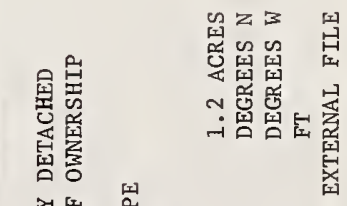

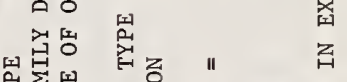

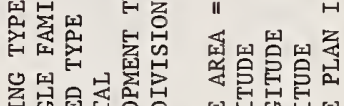

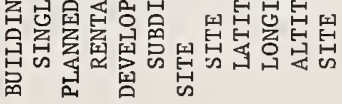




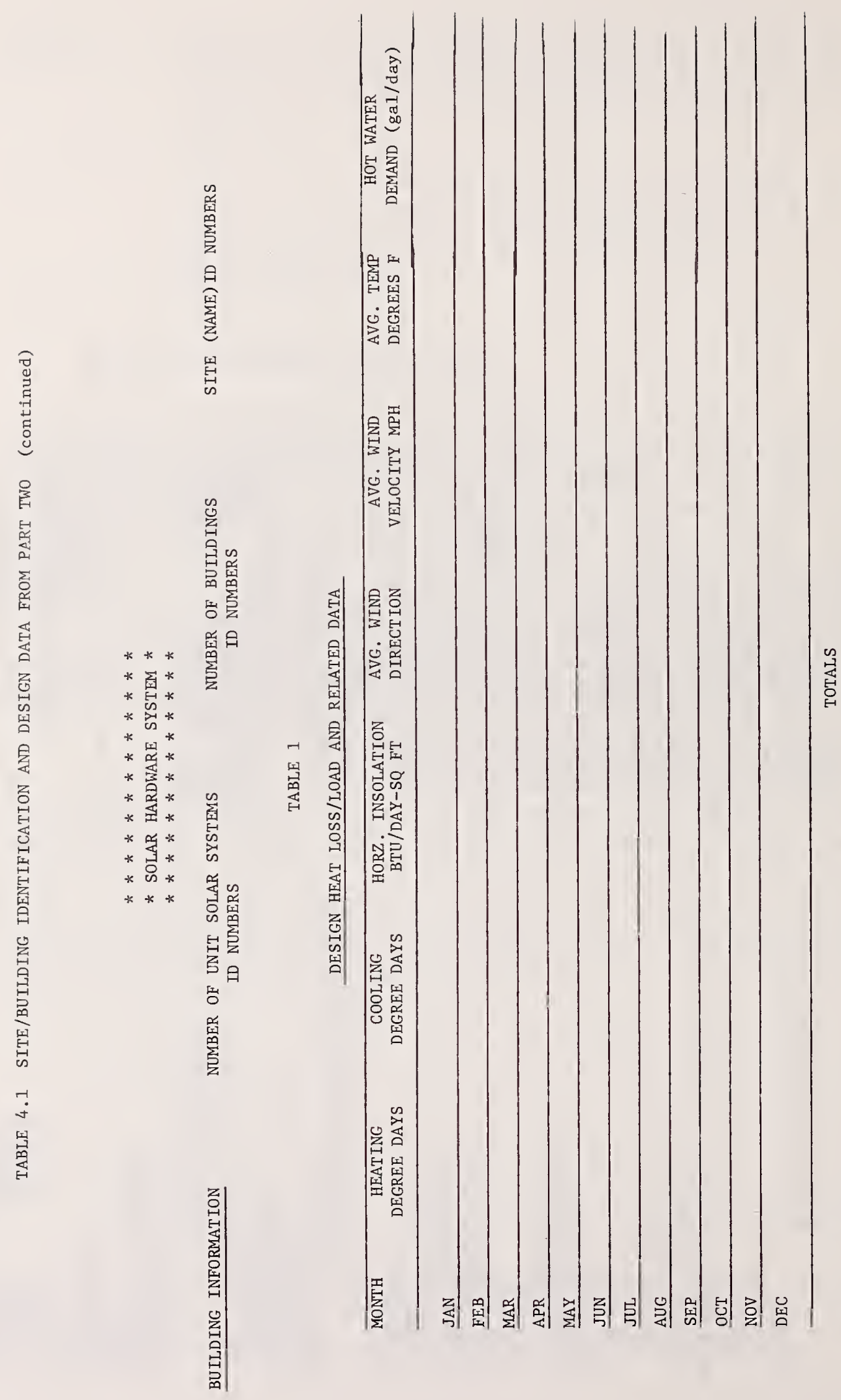




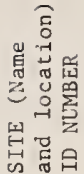

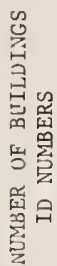

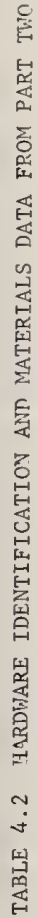
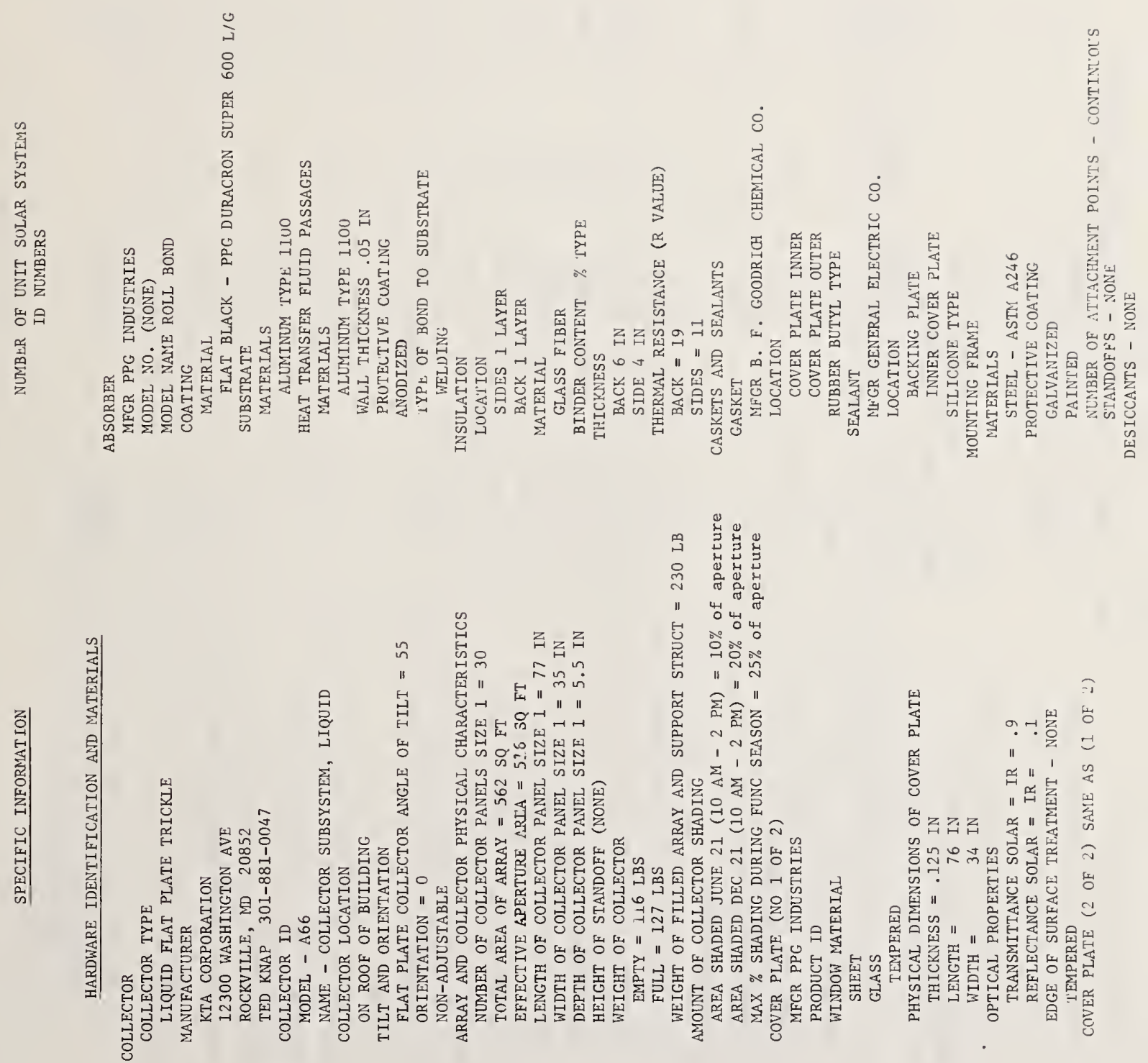


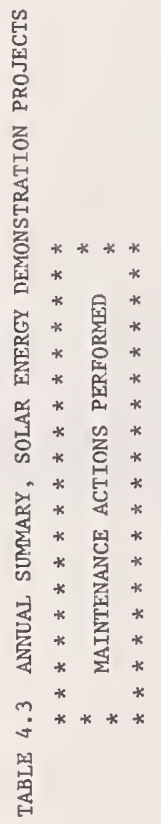

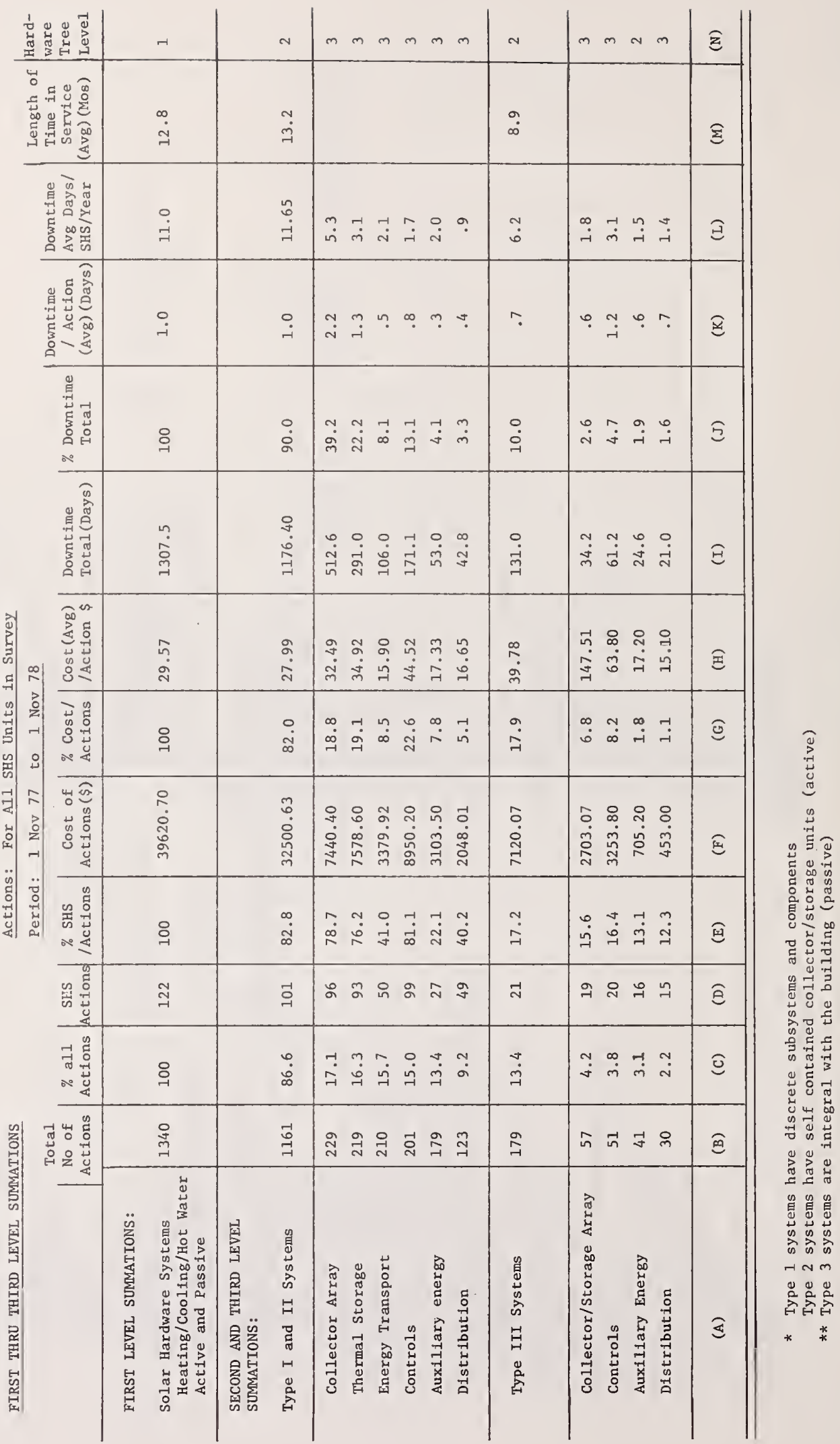




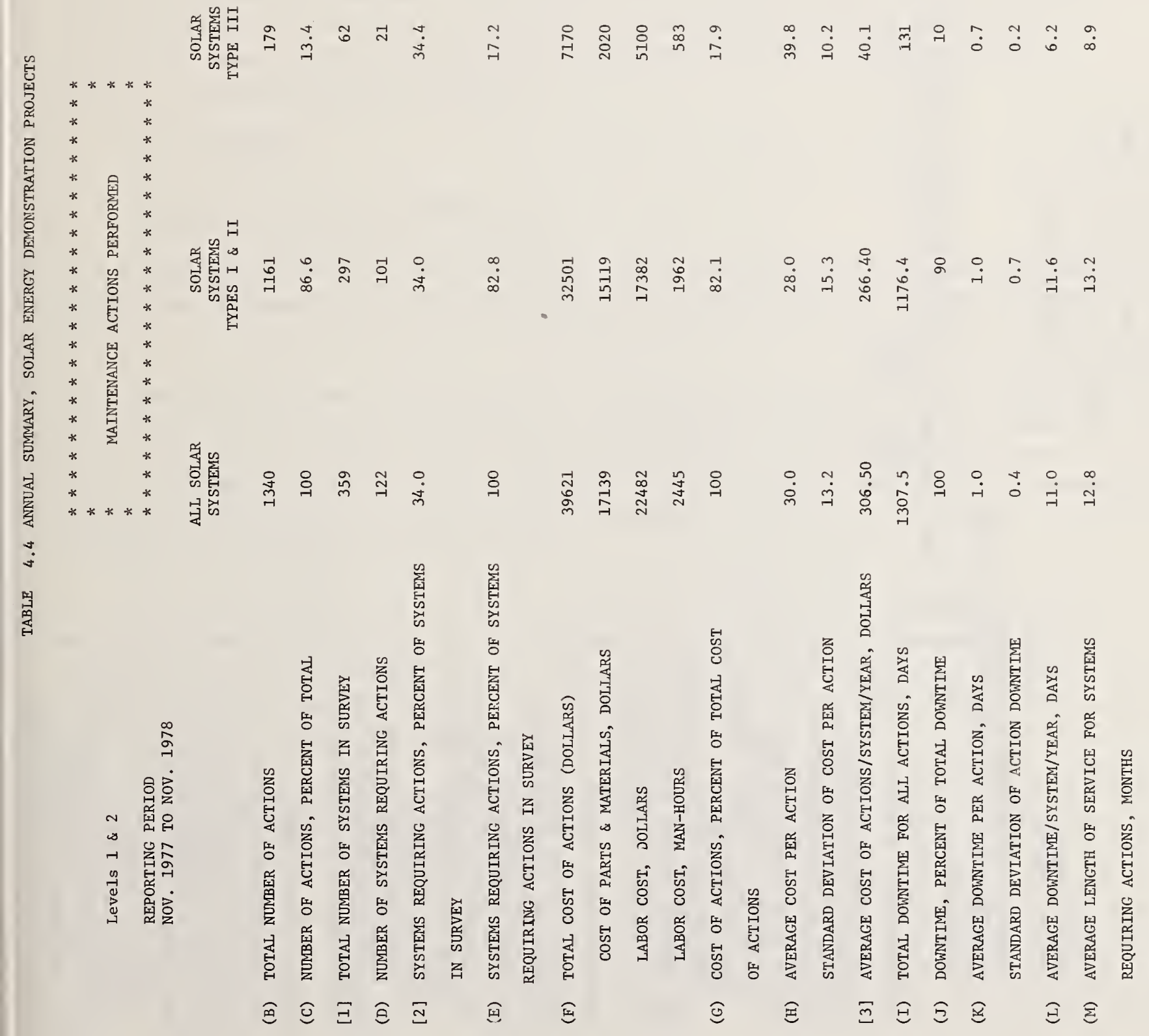



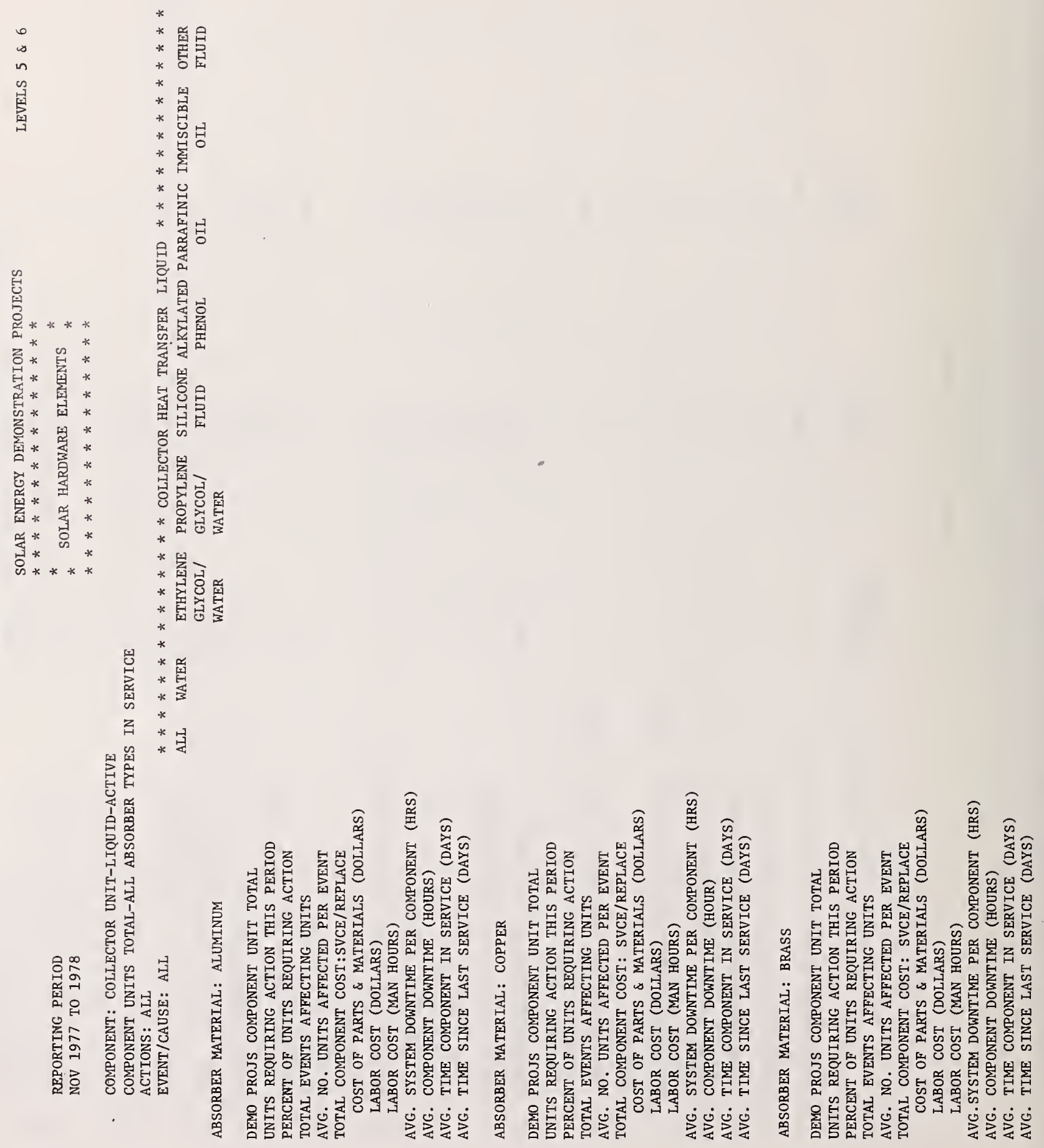


\section{SUPPLEMENTARY DATA}

1.0 INTRODUCT ION

Parts Two and Three of this plan are concerned with data intended to characterize building/site/solar hardware system. parameters and to associate these parameters with operational problems. The types of correlations that will be performed with these data are discussed in Part Four. These correlations will be performed by means of a computerized system being developed at NBS.

Part Five is concerned with the identification of additional data intended to: (1) characterize design, construction and operation problems, (2) determine the causes of significant failures when such causes cannot be determined from maintenance reports, (3) monitor the deterioration of key system components prior to their actual failure and (4) quantify the environmental conditions to which collectors are exposed at various demonstration program sites.

\subsection{DATA REQUIREMENTS}

\subsection{Design and Construction Data Requirements}

It is recommended that a detailed narrative report be prepared by the residential and commercial demonstration program management contractors for each major design problem encountered, describing the hardware involved, the causes of the problem, design changes made, cost effects and design schedule impact.

At the present time, NBS does not recommend that the information on these reports be computerized. The reason for this is that a catalog of design events, to be definitive, would have to be as comprehensive as the one developed for operational events. This in our judgement is not warranted, at the present time, for the design data. However, this recommendation should be reexamined at a future date to determine whether or not the amount of design problem data generated during the demonstration program warrants a computerized data retrieval and analysis system.

For the same reasons as those enumerated for the design data requirements, it is recommended that a detailed narrative report be written by the contractor for construction events encountered, describing the hardware involved, the causes of the event, the action taken, cost effects, and design schedule impact. Construction events are related to problem areas which have resulted in an increase in the scheduled construction time or an increase in the cost of construction.

Again, as for the design data, the reports will be reviewed by cognizant NBS staff, and based on a consideration of the amount of data amassed, a decision will be made at a future date as to whether or not to computerize the data to facilitate analysis. 
It is expected that the data required for the preparation of design and construction event reports will emanate from three primary sources: architect/engineers, builders and building officials, as discussed in Section 3.2 of Part one of this plan. The following information should be provided in reporting design and construction events:

(1) Responsible Architect/Engineer or Contractor

- Firm Name

- Firm Address

- Telephone Number

- Name of individual in charge of design or construction

(2) General Identification

Provide the following identification data:

- Unit Solar Hardware System (USHS) Identification Number

- Building Identification Number

- Site Identification Number

(3) System Hardware Identification

The following information should be provided:

- Type of System - See Part Two for a detailed list of types of systems

- Subsystem, Component, or Part:

- Name of subsystem, component, or part where the event occurred

- Manufacturer's name

- Model number or model name

(4) Causes of the Event. Describe the causes of the event in detail.

(5) Remedial Action Taken. What action was taken to correct the event? (Describe in detail)

(6) Discipline Relationship. To what discipline is the event primarily related?

- Functional (Thermal)

- Mechanical

- Structural

- Safety

- Durability/Reliability

- Maintainability

- Visual Characteristics

(7) Code or Standard Relationship to the Event, If Any

Identify as many codes and standards, and appropriate sections which relate to the event:

- Interim Performance Criteria for Solar Heating and Combined Heating/Cooling Systems and Dwellings, Section

- Interim Performance Criteria for Solar Heating and Cooling Systems in Commercial Buildings, Section

- Name of state code

- Name of local code , Section

Uniform Building Code (ICBO), Section

- Standard Building Code (Southern Conference), Section

- Basic Building Code (BOCA), Section

- National Building Code (AIA), Section

- Minimum Property Standards (HUD), Section

- Not associated with code or standard requirements

(8) Legal Problem Areas

Describe in detail any legal problems encountered during design or construction.

(9) Cost and Scheduling

- The event caused a cost overrun of $\$$ , which represents $\%$ of the contract $\cos t$

- The event caused weeks delay in completing the project 
Because of the nature of the program it is expected that a number of significant operational problems will occur during the demonstration program. In many cases the primary causes of these problems will not be capable of being determined by means of field maintenance reports. When warranted, by the magnitude of such problems, it is expected that laboratory failure analysis studies will be conducted to determine the actual causes of such problems. Such studies could be conducted either by manufacturers, as discussed.in Section 3.2.1 of Part One, by commercial testing laboratories or by government laboratories such as those at NBS and NASA. It is important that such failures be characterized so that subsequent criteria and standards can be revised to prevent further occurrence.

Problems such as those discussed above can be identified by reviewing the reports discussed in Part Four of this plan. These reports serve to identify both the frequency and the significance of reported failures, in addition to characterizing the causes of such failures as well as is possible on the basis of field maintenance reports. By reviewing these reports, NBS staff will be able to identify failures that have not been fully characterized in the field. It will then be possible to select and retrieve materials or components for failure analysis on a systematic basis. The results of such failure analyses represent a continuation of the event/cause chain discussed in Part Three and the data obtained will be entered into the NBS computer data base as a supplement to the information transcribed from maintenance reports.

Leakage in an absorber plate is an example of the type of problem that may require failure analysis to determine its actual cause. A few of the many potential causes of such a problem are: ( 1 ) fluid pH too high, (2) fluid $\mathrm{pH}$ too low, (3) contact between dissimilar metals, (4) erosion-corrosion (fluid flow rate too high), (5) inclusions in the metal and (6) grain growth induced by welding. It is obvious that the characterization of such a problem is beyond the ability of most maintenance personnel and will usually require some laboratory analysis of fluids and/or absorber materials.

\subsection{Operational Deterioration Studies}

At the present time, very little is known about the long term durability of many of the materials and components used in solar heating and cooling systems. This is especially true with regard to the long term performance of collectors and the corrosion of metal systems containing liquid heat transfer media. The two studies which follow are intended to provide information about in-service deterioration under operational conditions in actual demonstration program systems. The data obtained from such studies will be compared with the results of accelerated aging tests and the results of such comparisons used to obtain meaningful accelerated procedures for predicting long term durability. Such procedures are critical for the evolution of the current interim residential and commercial performance criteria into more definitive documents. It is believed that the two studies which follow can be performed with negligible disruption of the demonstration program.

\subsubsection{Heat Transfer Fluid Composition}

Not enough information is available to judge whether or not certain commonly used metal-heat transfer liquid combinations are capable of providing satisfactory long term performance. For example, figures quoted for the expected life of aluminum absorber panels used in combination with treated ethylene 
glycol solutions range from an unsatisfactory figure of a few years up to an acceptable figure of many years. Similar questions exist about the suitability of other metal-liquid combinations. The problem is compounded by the likelihood that the solar heating and cooling systems will be built from components containing dissimilar metals (e.g. aluminum absorber panels with brass valves and iron piping). Even though these materials are dielectrically isolated, and may be provided with getters to trap undesired ions, these protective measures may not be adequate in closed systems which continuously recirculate a heat transfer fluid. Additional questions exist about the chemical stability of certain heat transfer liquids when exposed to the collector "no flow" temperatures that will very likely occur at some point in a system's iifespan. The decomposition products of some of these fluids can be corrosive to some metals. Although it is likely that proper fluid treatment (i.e., buffering) will neutralize these decomposition products, the required frequency of such treatment is not known and it has yet to be determined whether or not it is realistic to expect that the fluid quality will be properly maintained under "real world" (operational, not laboratory) conditions. The answers to these questions can only be determined on "real world" systems.

For these reasons, it is recommended that routine determinations be made of heat transfer fluid composition; preferably on all demonstration program systems. At a minimum, such analyses should be performed on all instrumented systems. It is already planned to routinely take heat transfer fluid samples from these systems so that specific heat measurements can be made, and it would take very little additional effort to chemically analyze the liquids concurrently. Such analyses can be performed at relatively low cost by commercial testing laboratories that possess the requisite automated analytical equipment.

Data that should be obtained are:

- $\mathrm{pH}$ (for aqueous solutions)

- reserve alkalinity (per ASTM D 1121 for aqueous solutions)

- metal ion concentration (especially iron, aluminum and copper; for all liquids)

- infrared absorption spectra (for organic liquids)

- viscosity (for organic liquids and water-antifreeze solutions)

It is recommended that these analyses be performed routinely at times of $0,2,6,12,24$ and 48 months and possibly more frequently if a system is suspected of being contaminated. Records should be kept of changes made to the heat transfer fluid (e.g., replacement). Such records are also necessary for keeping track of the fluid specific heat.

The data identified above will be used by NBS to (1) identify potential corrosion problems, their cause and location, and (2) determine the stability of various types of fluids under in-use conditions. The data will be correlated with system parameters and operating conditions and fed back into the development of criteria and standards. It is only through the availability of data of this type that meaningful accelerated testing procedures can be developed.

\subsubsection{Collector Deterioration (In-Service)}

The design procedures currently used to model solar heating and cooling systems and simulate their operation do not take into account the possibility that collector performance may degrade significantly under in-use conditions. However, studies conducted by NASA-Lewis for the Langley Project indicated 
that six of seven collector types evaluated had significant efficiency losses ( 10 percent or more) after 3-9 weeks exposure to sunlight under "no flow" conditions [6]. It is not unreasonable to expect that similar "no flow" exposure will occur during the operation of most demonstration program systems. In addition, very little is known about the amount of deterioration that occurs during normal system operation. If such deterioration is significant, it should be taken account of in design procedures.

One way of taking into account this type of deterioration is by subjecting the collectors to accelerated aging procedures before conducting the collector efficiency measurements that will be used in the design calculations. However, the development of meaningful accelerated aging procedures is dependent on being able to correlate their effects with those of "real time" operation.

It is recommended that the following course of action be pursued in conjunction with the demonstration program:

(1) Monthly instrumentation data summary reports be reviewed to identify systems having significant deterioration in collector array efficiency

(2) Individual collectors should be removed from these systems and efficiency measurements made by NBS, or its subcontractors, in accordance with ASHRAE Standard 93-77. In addition, similar measurements should be made on "zero time" collectors of the same type in order to establish a baseline for comparison.

(3) Materials property measurements should be conducted by NBS, or its subcontractors in order to identify the causes of the collector performance deterioration.

Note: It is recognized that because of program constraints it may only be possible to obtain this type of information from government owned installations.

The results from this study will make it possible (1) to determine to what extent long term collector deterioration affects system thermal performance, (2) to develop procedures by means of which such deterioration can be quantified and (3) to obtain "real time" materials deterioration data that can be correlated with the results of accelerated tests and be factored into system performance predictions and maintenance requirements.

The accelerated tests that have been proposed for use in evaluating collector aging involve exposure under "no flow" conditions. However, correlations between collector damages under "no flow" and "real time" exposure have not been developed. Thus, it is impossible to interpret the results of "no flow" exposure in terms of "real time." Since accelerated collector tests are necessary if long term performance data are to be obtained in a reasonable period of time, it is recommended that a laboratory based testing program be initiated. The program would consist of exposing collectors of different types under "no flow" conditions at several outdoor test sites. Weather factors such as temperature and solar radiation would be measured and measurement of thermal efficiency and materials properties would be conducted at fixed time periods, e.g. after 0, 2, 6, 12, 24, and 48 months of exposure. The results of these tests would be correlated with observations and results of "real time" exposure of collectors on the demonstration programs. The results of this study will make it possible to better interpret the results of "no flow" accelerated tests in terms of "real time" exposure. 
Two basic types of environmental conditions can affect the deterioration of solar hardware elements. The first of these is concerned with outside (weather) exposure and the second with the operating conditions (e.g. temperatures) that arise inside the system. It is important that both of these conditions be characterized so that they can be correlated with materials deterioration.

Because of cost considerations, it will not be possible to make actual measurements of key environmental parameters at the various demonstration program sites. Sections 2.4.1 and 2.4.2 which follow, identify the key types of data required and make recommendations as to how they should be obtained.

\subsubsection{Outside Exposure Data}

Data including: (1) air temperature, (2) relative humidity, (3) rainfall, (4) snow cover, (5) wind velocity and direction, (6) ultraviolet and total solar radiation, (7) hail incidence, (8) solid particulate concentrations and (9) pollutant levels (including $\mathrm{O}_{3}, \mathrm{SO}_{2}$ and $\mathrm{NO}_{2}$ ) should ideally be obtained for the various demonstration program sites. An attempt will be made to utilize data from the nearest weather stations for those parameters that will not be measured on-site. However, in special cases, e.g., where exposure conditions are thought to be the cause of serious problems, it will be desirable to set up temporary on-site monitoring stations.

\subsubsection{Collector Temperatures}

Many of the problems that have arisen to date in solar installations are related to the improper use of materials. A major cause of these problems can be attributed to a lack of knowledge about the operating conditions to which materials will be exposed in solar installations. This lack of knowledge has become especially obvious in the case of solar collectors where an alarming number of materials failures have occurred.

Although information of this type is essential for the proper selection of materials by collector manufacturers, attempts by NBS to obtain such information from several collector manufacturers have failed resulting in the conclusion that they lack this information.

Although it would be desirable to measure collector material temperatures by carefully instrumenting the collectors used on demonstration program sites, the costs of such a program would be excessive. For this reason it is recommended that a laboratory based program be undertaken to measure the temperatures to which materials are exposed in several different types of collectors under both "flow" and "no flow" conditions. This study would be conducted in several different geographic locations and could be carried out in conjunction with the laboratory based collector deterioration study discussed at the end of section 2.3.2.

The results of this study will be incorporated into revisions of criteria and collector materials draft standards currently under development by NBS in cooperation with ASTM. 
1. "Interim Performance Criteria for Solar Heating and Combined Heating/Cooling Systems and Dwellings," January 1, 1975, prepared for HUD by NBS. Available from GPO, order by SD Catalog No. C13.6/2:504, price $\$ 1.90$.

2. "Interim Performance Criteria for Commercial Solar Heating and Combined Heating/Cooling Systems and Facilities," February 28, 1975, prepared for ERDA by NASA, Document No. 98M 10001, Revision Basic, NASA-TM-X-64958. Available from ERDA Technical Information Center, P.0. Box 62, Oak Ridge, Tennessee 37830 .

3. Waksman, D. et al, "Interim Performance Criteria for Solar Heating and Cooling Systems in Commercial Buildings," prepared for ERDA by NBS, NBS Report NBSIR 76-1187, November 1976. Available from NTIS, Order No. PB 262114 , price $\$ 5.50$.

4. "National Program for Solar Heating and Cooling of Buildings," ERDA 76-6, November 1976. Available from the Superintendent of Documents, U.S. Government Printing 0ffice, Washington, D.C. 20402, Stock No. 052-003-00043-3, price \$1.55.

5. Streed, E. R., et al "Thermal Data Requirements and Performance Evaluation Procedures for the National Solar Heating and Cooling Demonstration Program," NBS Report NBSIR 76-1137, August 1976. Available from NTIS, Order No. PB 257770 , price $\$ 5.00$.

6. Knoll, R. H. and Johnson, S.M., "Baseline Performance of Solar Collectors for NASA Langley Solar Building Test Facility," NASA Lewis Research Center, Cleveland, Ohio, (presented at Flat-Plate Solar Collector Conference, Orlando, Florida, March 1, 1977). 
NBS-114A (REV.7-73)

\begin{tabular}{|c|c|c|}
\hline $\begin{array}{l}\text { U.S. DEPT. OF COMM. } \\
\text { BIBLIOGRAPHIC DATA } \\
\text { SHEET }\end{array}$ & 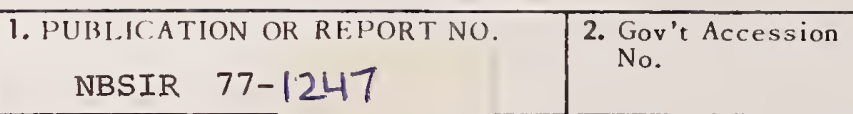 & 3. Recipient's Accession No. \\
\hline \multirow{3}{*}{\multicolumn{2}{|c|}{$\begin{array}{l}\text { 4. TITLE AND SUBTITLE: } \\
\text { Proposed Technica1 Data Requirements for the National } \\
\text { Solar Heating and Cooling Demonstration Program }\end{array}$}} & 5. Publication Date \\
\hline & & May 1977 \\
\hline & & 6. Performing Organization Code \\
\hline \multicolumn{2}{|c|}{$\begin{array}{l}\text { 7. AUTHOR(S) } \\
\text { Solar Energy Program Team, Center for Building Technology }\end{array}$} & 8. Performing Organ. Report No. \\
\hline \multirow{2}{*}{\multicolumn{2}{|c|}{$\begin{array}{l}\text { 9. PERFORMING ORGANIZATION NAME AND ADDRESS } \\
\text { NATIONAL BUREAU OF STANDARDS } \\
\text { DEPARTMENT OF COMMERCE } \\
\text { WASHINGTON, D.C. } 20234\end{array}$}} & $\begin{array}{l}\text { 10. Project/Task/Work Unit No. } \\
4656500 \text { TASK A }\end{array}$ \\
\hline & & 11. Contract/Grant No. \\
\hline \multirow{2}{*}{\multicolumn{2}{|c|}{ 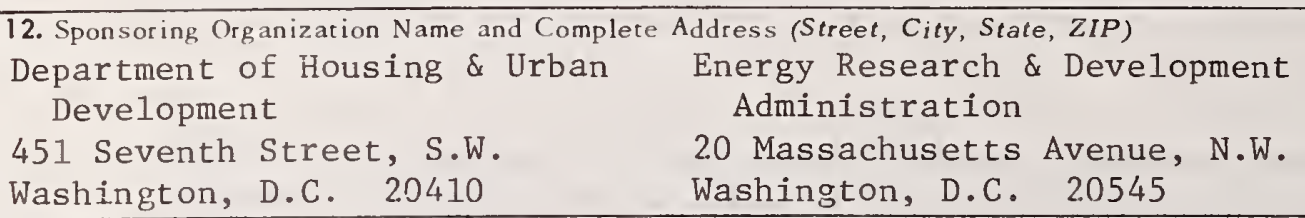 }} & $\begin{array}{l}\text { 13. Type of Report \& Period } \\
\text { Covered }\end{array}$ \\
\hline & & 14. Sponsoring Agency Code \\
\hline
\end{tabular}
15. SUPPLEMENTARY NOTES

16. ABSTRACT (A 200-word or less factual summary of most significant information. If document includes a significant bibliography or literature survey, mention it here.)

Public Law 93-409, the "Solar Heating and Cooling Demonstration Act of 1974 " calls for the development of interim performance criteria for solar heating and cooling systems and the buildings in which they will be used. Section 8 of the law provides for the use of data from the demonstration program to develop definitive performance criteria, as well as testing procedures whereby manufacturers can certify that their products conform to definitive performance criteria. Responsibility for the development of these definitive performance criteria has been assigned by the Energy Research and Development Administration and the Department of Housing and Urban Development to the National Bureau of Standards (NBS).

The plan presented in this document was prepared in order to define the technical noninstrumentation (TNI) data required by NBS in order to effectively monitor the residential and commercial demonstration programs, mandated by PL 93-409, for feedback. These data either cannot be collected electronically or can be gathered more effectivel by other means.

This plan is intended to be a companion document to a similar plan published by NBS in August 1976 which identified the instrumentation data required by NBS to monitor and evaluate the "thermal effectiveness" and reliability of solar heating, cooling and hot water systems.

17. KEY WORDS (six to twelve entries; alphabetical order; capitalize only the first letter of the first key word unless a proper name; separated by semicolons)

Data requirements; non-instrumented data; solar buildings; solar energy; solar. heating and cooling; solar hot water

18. AVAILABILITY Unlimited

X For Official Distribution. Do Not Release to NTIS

Order From Sup. of Doc., U.S. Government Printing Office Washington, D.C. 20402, SD Cat. No.C13

Order From National Technical Information Service (NTIS) Springfield, Virginia 22151
19. SECURITY CLASS

(THIS REPURT)

UNCL ASSIF IED

20. SECURITY CLASS

( THIS PAGE)

UNCLASSIFIED
21. NO. OF PAGES

22. Price 